Prepared in cooperation with the U.S. Agency for International Development

\title{
Monitoring Live Vegetation in Semiarid and Arid Rangeland Environments with Satellite Remote Sensing in Northern Kenya
}

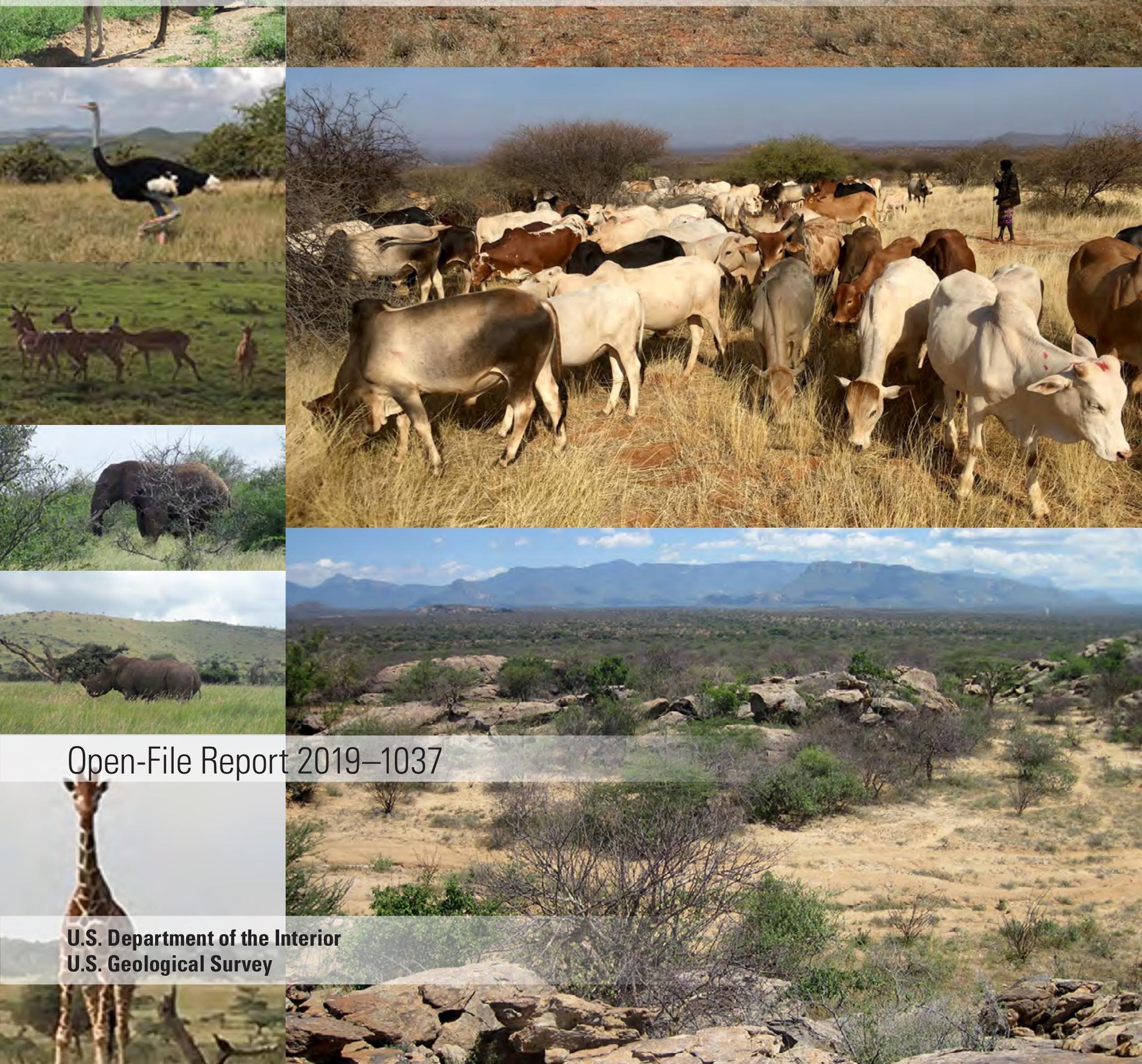


Cover. The cover portrays the balance managed by Northern Rangelands Trust (NRT) Conservancies to protect iconic species (such as elephants, rhinos, giraffes, Grevy's zebras, gazelles, and ostriches) while sustaining grazing for livestock (such as cattle and camels) within the semiarid and arid landscapes of northern Kenya. 


\section{Monitoring Live Vegetation in Semiarid and Arid Rangeland Environments with Satellite Remote Sensing in Northern Kenya}

By Amina Rangoonwala and Elijah W. Ramsey III

Prepared in cooperation with the

U.S. Agency for International Development

Open-File Report 2019-1037 


\title{
U.S. Department of the Interior \\ DAVID BERNHARDT, Secretary
}

\author{
U.S. Geological Survey \\ James F. Reilly II, Director
}

U.S. Geological Survey, Reston, Virginia: 2019

For more information on the USGS - the Federal source for science about the Earth, its natural and living resources, natural hazards, and the environment-visit https://www.usgs.gov or call 1-888-ASK-USGS.

For an overview of USGS information products, including maps, imagery, and publications,

visit https://store.usgs.gov.

Any use of trade, firm, or product names is for descriptive purposes only and does not imply endorsement by the U.S. Government.

Although this information product, for the most part, is in the public domain, it also may contain copyrighted materials as noted in the text. Permission to reproduce copyrighted items must be secured from the copyright owner.

Suggested citation:

Rangoonwala, Amina, and Ramsey, E.W., III, 2019, Monitoring live vegetation in semiarid and arid rangeland environments with satellite remote sensing in northern Kenya: U.S. Geological Survey Open-File Report 2019-1037, 83 p., https://doi.org/10.3133/ofr20191037.

ISSN 2331-1258 (online) 


\section{Acknowledgments}

We would like to acknowledge the following people who made this project possible:

- Stephanie Romañach, Research Ecologist with the U.S. Geological Survey and East Africa Program Manager with the U.S. Department of the Interior International Technical Assistance Program (DOI-ITAP), for providing us the opportunity to conduct this work.

- Kieran Avery, Rangeland Director of the Northern Rangelands Trust (NRT), for his invaluable support in field data collections and guidance in preparation of this report, and Samson Kuraru, NRT GIS Analyst, and Kiptoor, NRT vehicle driver, for their help in field data collections.

- Julius Lopeyok, Nasuulu rangelands coordinator, and Benson Lelukai, Kalama rangelands coordinator, for locating suitable field collection sites within their conservancies and for helping with data collections.

- Bryan Leavitt, Research Systems Analyst for the Center for Advanced Land Management Information Technologies, University of Nebraska at Lincoln, Nebraska, for his unwavering support of the radiometer-webcam system used to collect field data for calibration of the satellite data.

- Mark Ritchie, Professor, Biology Department, Syracuse University, for taking time and offering insightful advice on carrying out our field work.

- U.S. Agency for International Development (USAID), Kenya and East Africa, for funding the development of the rangeland mapping technology, and the Deputy Directors for Kenya, Environment Office, Brad Arsenault and Beatrice Wamalwa, and their team, Brian Friedman, Executive Officer, Enoch Kananga, Executive Officer, and Mikala Lauridsen, Senior Counter Wildlife Trafficking/Conservation Advisor, for their interest and help in carrying out the project.

- DOI-ITAP for funding the travel, and Colleen Castle, DOI-ITAP Africa \& Middle East Team Lead, James llako, East Africa Regional Coordinator, and Olivia Anton, Assistant Program Manager, for guiding us through the myriad of documents and logistics needed for international travel. 


\section{Contents}

Acknowledgments .........................................................................................................................ii

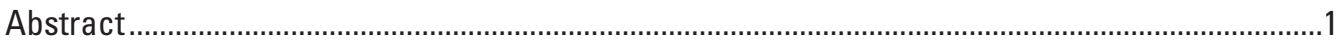

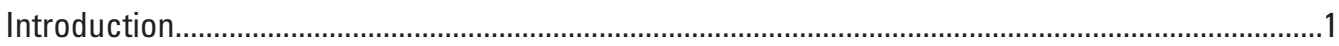

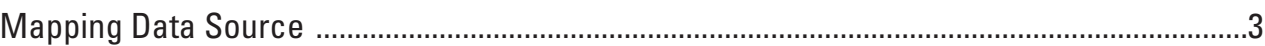

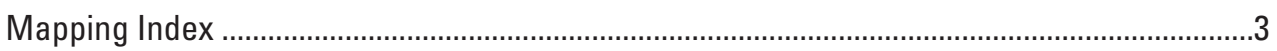

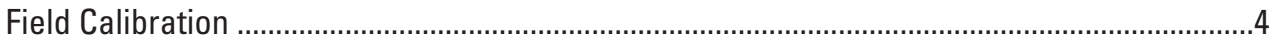

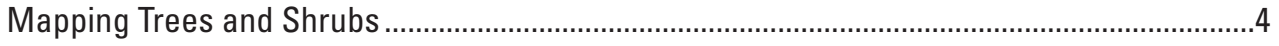

Methods

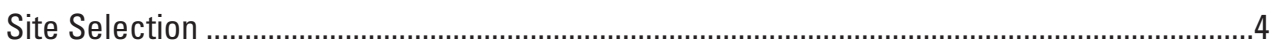

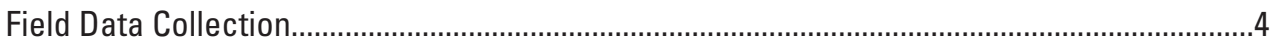

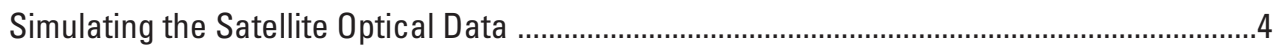

Ground Cover Classification ...................................................................................................

Field Vegetation Classes Connected to the Field Reflectance.................................................

Sentinel-2 Optical Image Data Calibration ..........................................................................

Sentinel-1 SAR Image Data Calibration .............................................................................

Gravimetric Weight Analyses ..............................................................................................

Tree Mask.....................................................................................................................

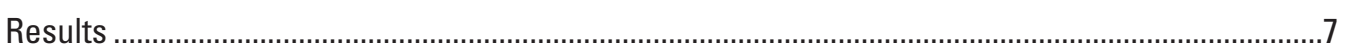

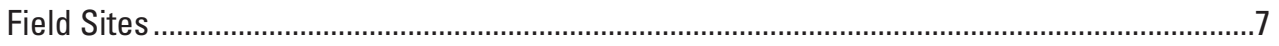

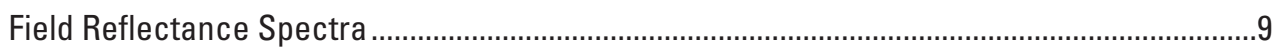

Gravimetric Weight Relationship to Webcam Classes.......................................................

Ground Cover Classification ........................................................................................11

Field-MSAVI2 Calibrated to the Vegetation Classific ation....................................................16

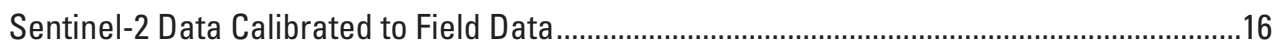

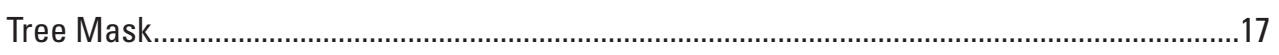

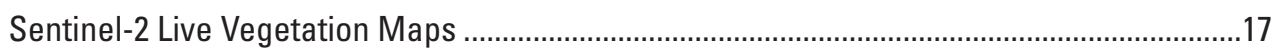

June 2018 Live Vegetation Map......................................................................................18

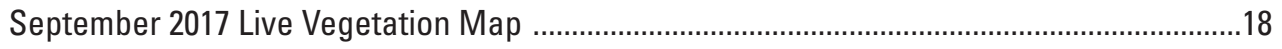

June 2017 Live Vegetation Map ...................................................................................19

June 2017 to June 2018 Live Vegetation Change Map ......................................................19

September 2017 to June 2018 Live Vegetation Change Map ..................................................19

June 2017 to September 2017 Live Vegetation Change Map ..................................................19

Site-Specific Comparisons of the Live Vegetation Maps .......................................................32

Nakuprat-Gotu Conservancy and Buffalo Springs National Reserve..............................32

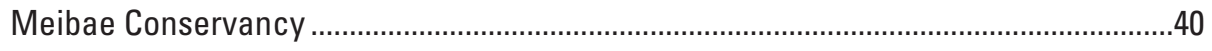

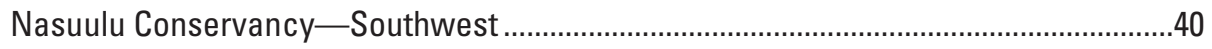

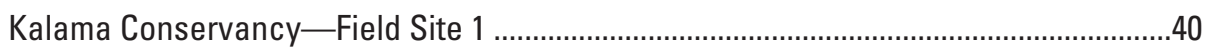

Nasuulu Conservancy—Field Sites 1, 2, 3, and 12 .....................................................59

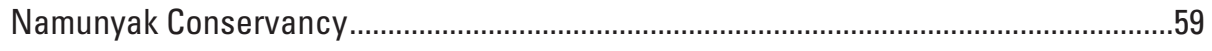

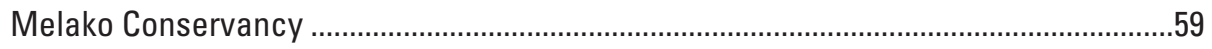

Extending Live Vegetation Mapping into the Past.................................................................

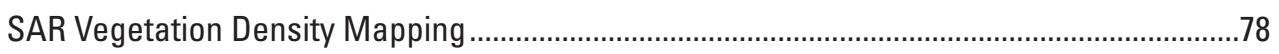

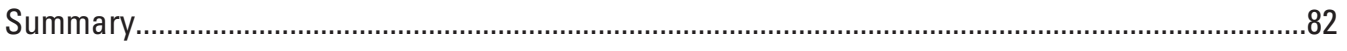

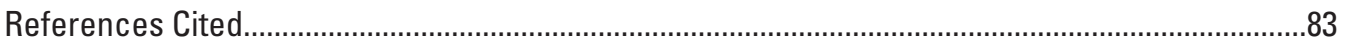




\section{Figures}

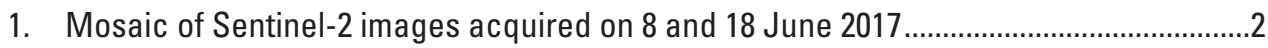

2. Individual Sentinel-2 images needed to cover the core-NRT .........................................3

3. Photograph showing field collection of surface reflectance spectra and webcam images.

4. Graph showing canopy reflectance spectra obtained from field measurements collected by the radiometer system shown in figure 3

5. A webcam photograph showing one of four locations at site 4 in the Kalama Conservancy taken coincidently with the radiometer recordings.

6. Photograph showing light attenuation measurements being collected along one of four transects at site 1 in the Lewa Conservancy .........................................................

7. Photograph showing collection of ground grass plus weed clippings at site 7 in the Lewa Conservancy.

8. Graphs showing site-averaged canopy reflectance spectra at the Kalama, Nasuulu, and Lewa Conservancies.

9. Graph showing the relation between the clip live/total biomass weight ratio and the webcam-predicted live/total vegetation cover proportions.

10. Kalama Conservancy natural color and classified webcam images................................12

11. Nasuulu Conservancy natural color and classified webcam images .............................14

12. Graph showing the correlation between the field-MSAVI2 calculated from field reflectance data and webcam classifications

13. Graph showing the correlation between the MSAVI2 calculated from site-averaged field reflectance data and from site-averaged Sentinel-2 satellite reflectance data.....17

14. Graph showing the correlation between the Sentinel-2 site-averaged proportion of live vegetation and the predicted site-averaged proportion of field live vegetation based on equation 3

15. June 2018 live vegetation map. June 2018 live vegetation map with tree mask overlay......

16. September 2017 live vegetation map. September 2017 live vegetation map with tree mask overlay...

17. June 2017 live vegetation cover proportion map. June 2017 live vegetation cover map with tree mask overlay.

18. June 2017 to June 2018 live vegetation cover proportion change map. Live cover map with tree mask overlay

19. September 2017 to June 2018 live vegetation cover proportion change map. Live cover maps with tree mask overlay

20. June 2017 to September 2017 live vegetation cover proportion change map. Live vegetation change map with tree mask overlay

21. Nakuprat-Gotu Conservancy and Buffalo Springs National Reserve, June 2018 live vegetation cover proportion and Google Earth image showing the same features on 6 June 2016 .

22. Nakuprat-Gotu Conservancy and Buffalo Springs National Reserve, June 2018 live vegetation cover proportion classification with the September 2017 tree mask overlain

23. Nakuprat-Gotu Conservancy and Buffalo Springs National Reserve, September 2017 live vegetation cover proportion classification and September 2017 tree overlay 
24. Nakuprat-Gotu Conservancy and Buffalo Springs National Reserve, June 2017 live vegetation cover proportion classification and September 2017 tree overlay .........36

25. Nakuprat-Gotu Conservancy and Buffalo Springs National Reserve, change in live vegetation cover proportion between September 2017 and June 2018 and September 2017 and June 2018 with September 2017 tree overlay..

26. Nakuprat-Gotu Conservancy and Buffalo Springs National Reserve, change in live vegetation cover proportion between June 2017 and September 2017 and June 2017 and September 2017 with September 2017 tree overlay.

27. Nakuprat-Gotu Conservancy and Buffalo Springs National Reserve, change in live vegetation cover proportion between June 2017 and June 2018 and June 2017 and June 2018 with September 2017 tree mask overlay.

28. Meibae Conservancy, live vegetation cover proportion classification and September 2017 tree mask overlay, June 2018, September 2017, and June 2017 41

29. Meibae Conservancy, live vegetation cover proportion change and September 2017 tree mask overlay, September 2017 and June 2018, June 2017 and September 2017, and June 2017 and June 2018

30. Nasuulu Conservancy, live vegetation cover proportion and September 2017 tree mask overlay, June 2018, September 2017, and June 2017.

31. Nasuulu Conservancy, live vegetation cover proportion change and September 2017 tree mask overlay, September 2017 and June 2018, June 2017 and September 2017, and June 2017 and June 2018.

32. Kalama Conservancy site 1 , live vegetation cover proportion and September 2017 tree mask overlay, June 2018, September 2017, and June 2017

33. Kalama Conservancy site 1 , live vegetation cover proportion change and September 2017 tree mask overlay, September 2017 and June 2018, June 2017 and September 2017, and June 2017 and June 2018 56

34. Nasuulu Conservancy, live vegetation cover proportion and September 2017 tree mask overlay, June 2018, September 2017, and June 2017.

35. Nasuulu Conservancy, live vegetation cover proportion change and September 2017 tree mask overlay, September 2017 and June 2018, June 2017 and September 2017, and June 2017 and June 2018

36. Namunyak Conservancy, live vegetation cover proportion and September 2017 tree mask overlay, June 2018, September 2017, and June 2017.

37. Namunyak Conservancy, live vegetation cover proportion change and September 2017 tree mask overlay, September 2017 and June 2018, June 2017 and September 2017, and June 2017 and June 2018 69

38. Melako Conservancy live vegetation cover proportion and September 2017 tree mask overlay, June 2018, September 2017, and June 2017.

39. Melako Conservancy, live vegetation cover proportion change and September 2017 tree overlay, September 2017 and June 2018, June 2017 and September 2017, and June 2017 and June 2018

40. Landsat-8 map showing live vegetation cover proportion for the core-Kenyan Northern Rangelands Trust conservancies in June 2017 and June 2018

41. A red-green-blue color composite of June 2018 synthetic aperture radar vertical send and vertical receive and vertical send and horizontal receive images

42. Graph showing field leaf area index data and Sentinel-1 synthetic aperture radar image data 


\section{Table}

1. Conservancies and reserves in the Northern Rangelands Trust study area......................1

\section{Conversion Factors}

International System of Units to U.S. customary units

\begin{tabular}{lcl}
\hline \multicolumn{1}{c}{ Multiply } & \multicolumn{1}{c}{ By } & \multicolumn{1}{c}{ To obtain } \\
\hline centimeter $(\mathrm{cm})$ & Length & \\
millimeter $(\mathrm{mm})$ & 0.3937 & inch (in.) \\
meter $(\mathrm{m})$ & 0.03937 & inch (in.) \\
kilometer $(\mathrm{km})$ & 3.281 & foot $(\mathrm{ft})$ \\
kilometer $(\mathrm{km})$ & 0.6214 & mile $(\mathrm{mi})$ \\
meter $(\mathrm{m})$ & 0.5400 & mile, nautical $(\mathrm{nmi})$ \\
\hline & 1.094 & yard (yd) \\
\hline square meter $\left(\mathrm{m}^{2}\right)$ & Area & acre \\
square meter $\left(\mathrm{m}^{2}\right)$ & 0.0002471 & square foot $\left(\mathrm{ft}^{2}\right)$ \\
square kilometer $\left(\mathrm{km}^{2}\right)$ & 10.76 & square mile $\left(\mathrm{mi}^{2}\right)$ \\
\hline
\end{tabular}

\section{Datum}

Horizontal coordinate information is referenced to the World Geodetic System of 1984 (WGS84).

\section{Abbreviations}

GE

Google Earth

GIS geographic information system

GPS Global Positioning System

GSA ground surface area

LAI leaf area index

MSAVI2 modified soil-adjusted VI2

NDVI normalized difference VI

NIR near-infrared

NRT Northern Rangelands Trust

SAR synthetic aperture radar

VI vegetation index

VIS visible

VH vertical send and horizontal receive

VV vertical send and vertical receive 



\title{
Monitoring Live Vegetation in Semiarid and Arid Rangeland Environments with Satellite Remote Sensing in Northern Kenya
}

\author{
By Amina Rangoonwala ${ }^{1}$ and Elijah W. Ramsey III ${ }^{2}$
}

\section{Abstract}

As part of the U.S. Department of the Interior's (DOI) commitment to provide technical assistance to the Kenyan Northern Rangelands Trust (NRT), the U.S. Geological Survey, in collaboration with the DOI International Technical Assistance Program and the U.S. Agency for International Development's regional mission in East Africa, created a high spatial and time-sensitive live vegetation monitoring system for NRT. The system built with advanced field and sensor technologies produced directly calibrated and highly accurate satellite mapping that is extendable both forward and backward in time. The maps are produced in a simple $0-100$-percent representation of live vegetation status and change over time. The backbone of the mapping is the Sentinel satellite remote sensing systems with 5-day collection frequencies and ground spatial resolutions of 10 meters. The European Space Agency (ESA) offers free Sentinel satellite image data through conveniently accessed websites and free user-friendly image processing software downloadable directly onto a personal workstation. ESA provides free online software support. The mapping capability was extended from the forward mapping of Sentinel back in time with the Landsat satellite remote sensing system that has an available and free data archive back to 1983. Although Landsat has coarser spatial resolution, the Landsat to Sentinel live vegetation mapping comparison supports the use of Landsat to provide NRT the historical recreation of prominent live vegetation changes.

\section{Introduction}

In the arid and semiarid landscape stretching across northern Kenya, the Northern Rangelands Trust (NRT) works to protect iconic species such as elephants, rhinos, and cheetahs while supporting a pastoral population dependent on access to grazing areas for livestock. In 2016, the U.S. Department of the Interior's U.S. Geological Survey committed to support NRT's need to improve responsive management through development of a timely monitoring system that captures the spatial complexity of the rangeland vegetation by creating a high spatial resolution mapping technology for NRT. The development encompassed 17 NRT conservancies, 1 affiliated conservancy, and 3 national reserves (table 1). The spatially contiguous conservancies and reserves are referred to here as the core-NRT (fig. 1).

${ }^{1}$ Contractor to the U.S. Geological Survey.

${ }^{2}$ U.S. Geological Survey.

Table 1. Conservancies and reserves in the Northern Rangelands Trust (NRT) study area.

\begin{tabular}{|c|c|c|c|c|c|c|}
\hline \multicolumn{5}{|c|}{ Core-NRT conservancies } & \multirow{2}{*}{$\begin{array}{c}\begin{array}{c}\text { Affiliated } \\
\text { conservancy }\end{array} \\
\text { Lewa }\end{array}$} & \multirow{2}{*}{$\begin{array}{l}\text { National reserves } \\
\text { Buffalo Springs }\end{array}$} \\
\hline Biliqo Bulesa & Leparua & Nakuprat-Gotu & Songa & Mpus Kutu & & \\
\hline Kalama & Melako & Nasuulu & Shurr & & & Samburu \\
\hline Lekurruki & Naibunga & Il Ngwesi & West $\mathrm{C}$ & & & \\
\hline
\end{tabular}




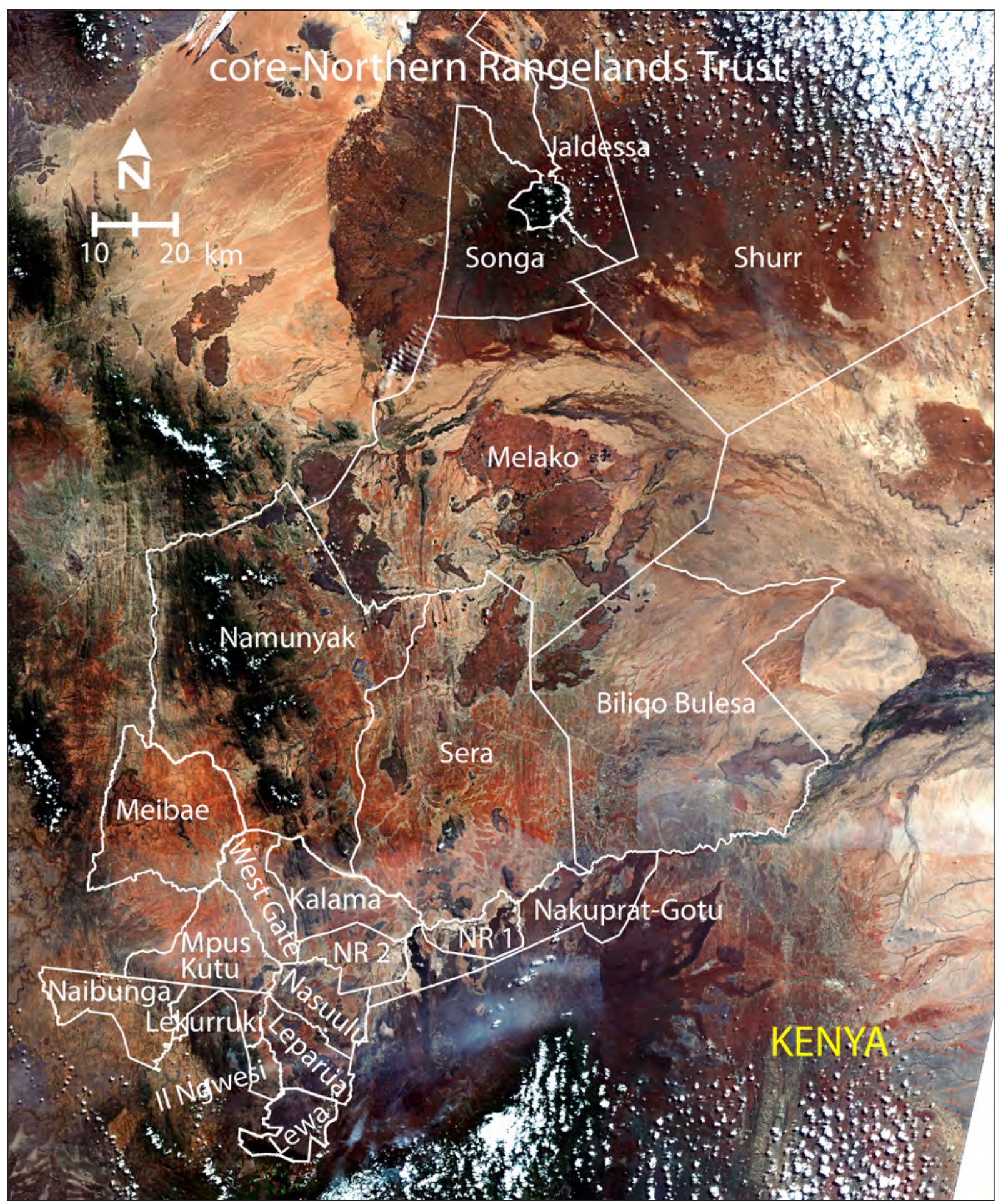

Figure 1. Mosaic of Sentinel-2 images acquired on 8 and 18 June 2017. The natural color composite covers the coreNorthern Rangelands Trust conservancies listed in table 1. NR 1 locates Samburu and NR 2 locates Buffalo Springs and Shaba National Reserves. 


\section{Mapping Data Source}

The creation of the high spatial resolution rangeland mapping technology began with identifying the proper data sources. In monitoring the core-NRT, the data source criteria were that collections (1) cover the core-NRT in a short period of time in order to preserve mapping continuity, (2) are at an appropriate spatial resolution to represent the rangeland complexity with respect to the mapping objective, and (3) support the map production frequency needed for responsive management. To maximize the potential for technology transfer, the developed mapping technology needed to be (1) operational and repeatable, requiring minimal labor hours and (2) based on available free image data and processing capabilities whether cloud-based or implemented on a local workstation. With these criteria addressed, the foremost criterion is that the data provide a suitable metric for assessment of the mapping objective.

Because the primary purpose of this rangeland mapping is support of grazing animals, monitoring of rangeland condition is focused on the live vegetation cover proportion (native grasses, grass-like plants, forbs, and shrubs [approximately $<2$ meters (m) in height]) that represents the primary food source of grazers. Considering all criteria, optical and synthetic aperture radar (SAR) satellite remote sensing systems offer the best data sources. Of these systems, those carrying optical sensors are optimal. Data from optical sensors provide the proportion of live vegetation per ground surface area (GSA), thus gaining a measure of live vegetation abundance. SAR data can provide a measure of vegetation density useful in mapping the total dead plus live vegetation per ground area.

Two current optical satellite systems fit the foremost required criteria: Landsat and Sentinel-2. Both satellite systems outperform the 250-m MODIS GSA mapping; the 30-m Landsat GSA outperforms the MODIS GSA mapping by 69 times, and the 10-m Sentinel-2 GSA outperforms the MODIS GSA mapping by 625 times. Because of Sentinel-2's

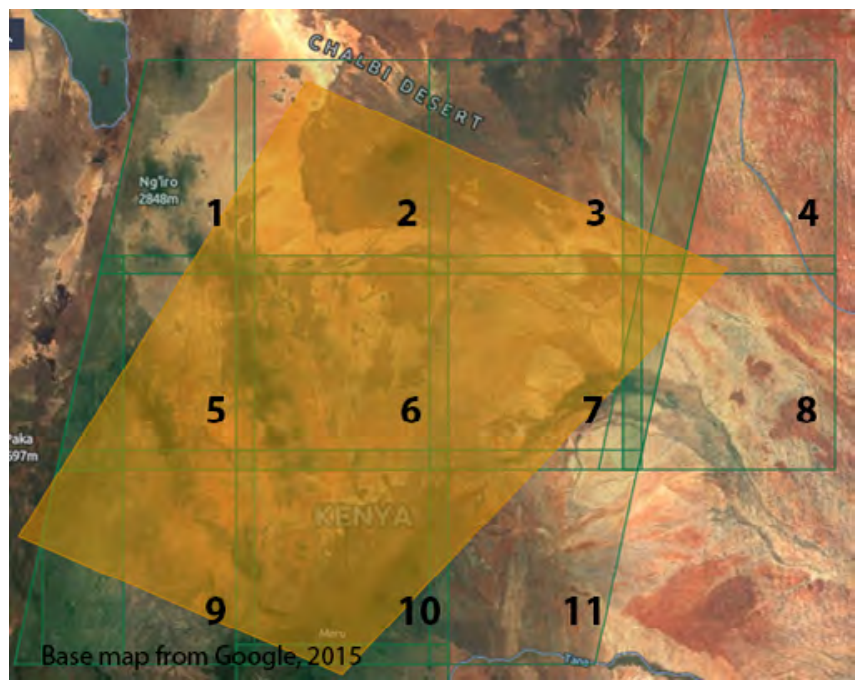

Figure 2. Individual Sentinel-2 images needed to cover the core-NRT. The background is a Google Earth representation of the region. higher spatial resolution ( 9 times higher) and collection frequency (5 days compared to Landsat's 16 days), Sentinel-2 was chosen as the optical data source. Eleven mosaiced Sentinel-2 images were needed to cover the core-NRT (fig. 2).

NRT also needed to be able to compare current rangeland conditions to those of the past; however, Sentinel-2's availability only extends back to 2016 . The solution relied on the spectral similarity of Sentinel-2 and Landsat, which provides the mechanism to transfer the created Sentinel-2 mapping technology to Landsat; also, Landsat has an extensive historical archive. Although Landsat's coarser spatial resolution means a more generalized map product, recent to historical comparisons can supply a long-term performance assessment of policy and management actions.

Another aspect of Sentinel-2 live vegetation mapping is the proven ability to combine higher spatial resolution optical data with 250-m MODIS data to increase the spatial information detail of the MODIS high temporal (daily) mapping performance (Ramsey and others, 2011). The MODIS mapping is used to detect time-sensitive changes ("hot spots") in the landscape and Sentinel mapping to more directly assess the cause of these changes. Lilian Wangui and her colleagues at the Regional Centre for Mapping of Resources for Development in Kenya suggested combining the Sentinel and MODIS mapping products for this reason (oral commun., 2018).

\section{Mapping Index}

Optical satellite mapping of live vegetation proportion is well established. Since Tucker (1979) proved a simple optical ratio or vegetation index (VI) can be directly related to ground-observed live vegetation, numerous VI adaptations have evolved. These various adaptations correct for differences in the landscape, atmosphere, vegetation, satellite sensor, and other factors. The most commonly used variation of Tucker's VI is the normalized difference VI (NDVI) (Guo and others, 2005). NDVI's primary advantage is to minimize the influence of atmospheric variability in the VI mapping. In the highly variable NRT vegetation landscape, the soil and the atmosphere are most often the overwhelming contributors to the recorded satellite data. These contributions result in variable and nonaccountable error in the live vegetation mapping.

We implemented the atmospheric removal process as an operational component within the mapping. The atmospheric removal transforms the Sentinel-2 (and Landsat) image data to ground reflectance, a direct reflection of the properties (such as live vegetation proportion) on the ground at the time of image collection. The atmosphere is simply removed at the onset of image processing. With the automated atmospheric removal, the satellite ground reflectance data now directly reflects the ground condition. The two dominant competing influences on the ground reflectance then become the live vegetation and soil. We then chose a VI most appropriate for removal of soil influences. The advanced modified soil-adjusted VI2 (MSAVI2) (Qi and others, 1994) was selected because of its proven capability to minimize soil influences in remote sensing data and its ease of implementation into an operational mapping system (Liu and others, 2007). 


\section{Field Calibration}

Near in time to the satellite data collections, field data were also collected. Field data included measurements simulating the optical satellite image reflectance data and measurements of the live (and dead) vegetation and exposed soil proportion per site. The field reflectance data were used to calculate the field-based MSAVI2. Simultaneously, separate field data were collected to provide live, dead, and soil vegetation proportions. The two field measurements were then related forming the field-MSAVI2 and live proportion calibration equation. The coincident field measurements ensured conformity in the spatial coverage and time.

The final calibration equation was obtained from the calculated relation between the satellite and field reflectancebased MSAVI2 values. The combination of the field-MSAVI2 to field live vegetation and field-MSAVI2 to satellite-MSAVI2 connects the live vegetation proportion to the satellite image data.

\section{Mapping Trees and Shrubs}

Ubiquitous trees were scattered throughout the core-NRT. Unless accounted for at least at a generalized level, the scattered and occasional dense stands of green-leafed trees and possibly larger shrubs ( $>2 \mathrm{~m}$ in height) hampered the production of maps reliably representing live vegetation needed by most grazers. In general, trees are the brightest (highest reflectance) vegetation perceived by the optical sensor. Partial inclusion of trees in the satellite sensor GSA will increase the ground reflectance to some indeterminable amount, thus confusing the interpretation of the live vegetation proportions. The satellite GSA element (or picture element, pixel) will therefore be misclassified and the level of classification error unknown. To minimize influence on the rangeland ground cover condition maps, an evergreen tree occurrence map was added to the project products. The produced occurrence maps were overlain on the produced live vegetation maps to diminish the influence of trees in the interpretation of live cover.

\section{Methods}

\section{Site Selection}

The primary goal of the field activities was to document key vegetation features that broadly encompass the highly varied NRT vegetation landscape. Field activities at each site were grouped into observational and instrument data collections. Observational data included field notes, Global Positioning System (GPS) locations, and photographic documentation. Instrument data included radiometers for simulating the satellite data, webcam photography for site classification, light recorders for capture of vegetation density for SAR calibration, and clip plots for gravimetric weight analyses.

\section{Field Data Collection}

Advanced instruments were used, and new methods were implemented to ensure that collected field data provided good calibration equations to link ground measurements to the Sentinel-2 image data. These instruments and methods produced critical information sources that well represented the complex vegetation landscape and were easily relatable to calibration of remote sensing data.

\section{Simulating the Satellite Optical Data}

The field radiometer system was used to simulate the optical satellite image data (fig. 3). The dual radiometer system measured reflected sunlight from an approximate 3.5-m-diameter GSA while simultaneously recording the sunlight illuminating the same ground area (Rundquist and others, 2014). The large GSA presents a truer representation of the vegetation canopy reflectance than the commonly used systems with diameters less than $1 \mathrm{~m}$. A 3.5-m-diameter GSA covers more than 12 times the area of a 1-m-diameter GSA. That larger ground sample substantially improves the link between the field and satellite measured reflectance as well as to the simultaneously recorded webcam photography.

The simultaneous measurements of the illuminating and reflecting sunlight allowed quality data to be collected under extreme cloud cover variability. The crucial importance of that operational freedom was substantiated by quality data collected during the highly variable cloud conditions dominating the 10-day intense field collections throughout the core-NRT. Those conditions would have prevented quality data collections by the commonly used radiometer systems.

The fully controlled field surface reflectance measurements provide the highest level of calibration and validation of the satellite ground reflectance mapping. In mapping the live vegetation within the core-NRT, the most critical component of the satellite mapping is how well the satellite-MSAVI2 calculated from the satellite reflectance represents the fieldMSAVI2 calculated from ground reflectance. Given that fact, the best indicator of the satellite mapping performance is the integrity ("goodness of fit") of the satellite-MSAVI2 and fieldMSAVI2. To that end, spectral bands mimicking the Sentinel-2 spectral bands (blue, green, red, and near-infrared) were extracted from the field-collected reflectance spectra (fig. 4) and used to calculate the field-MSAVI2s. This method not only provides the highest level of satellite data calibration and validation, but it also optimizes the representation of satellite surface reflectance to the live vegetation fractional-cover. 


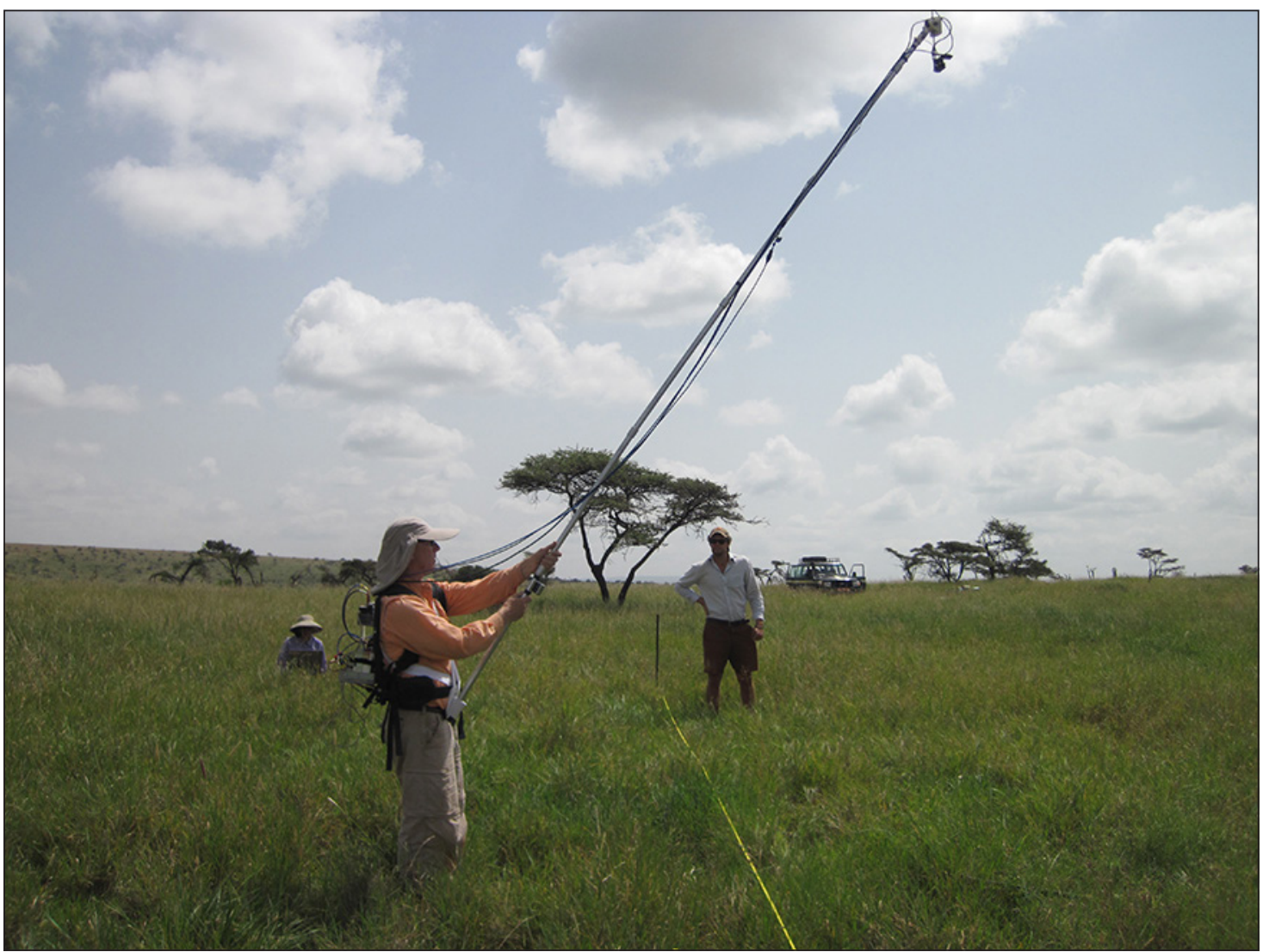

Figure 3. Field collection of surface reflectance spectra and webcam images. The two radiometers and webcam mounted at the end of the pole are positioned vertical to the surface. The radiometer facing upward collects the sunlight, and the radiometer facing downward collects the sunlight reflected from the surface. The webcam faces downward. All three measurements are sent simultaneously to the computer operator.

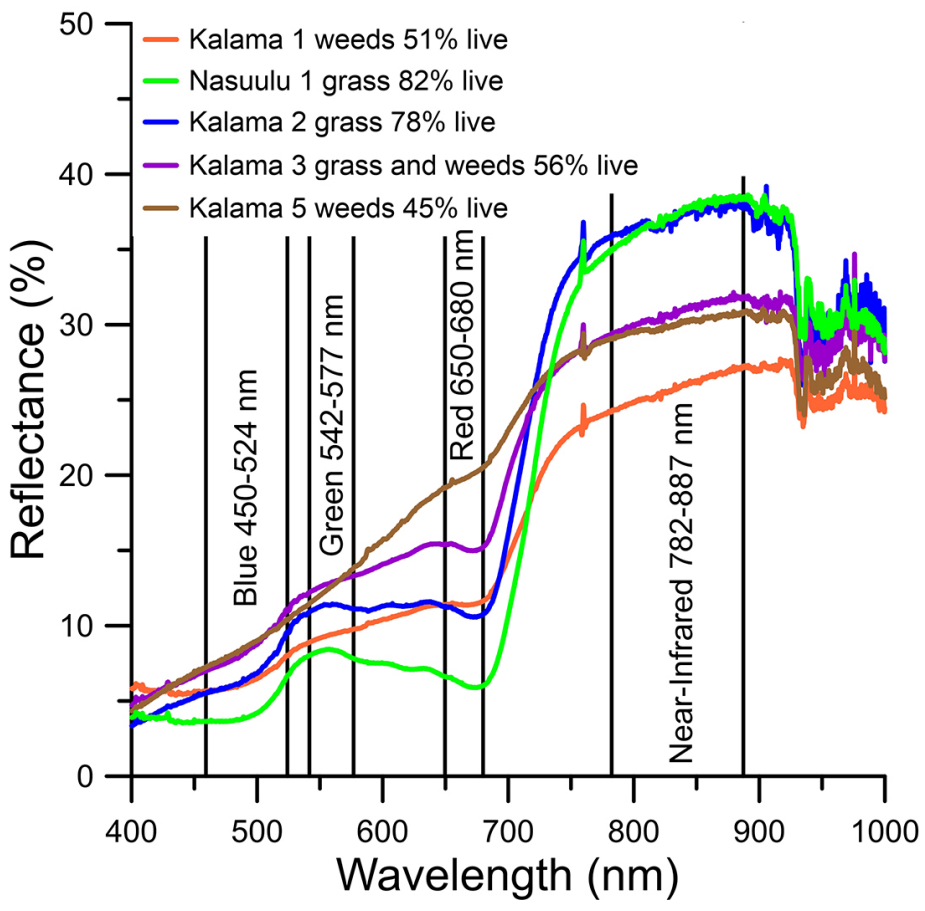

Figure 4. Canopy reflectance spectra obtained from field measurements collected by the radiometer system shown in figure 3. Overlain on the near-continuous resolution reflectance spectra are the Sentinel-2A bandwidths used in this mapping. The average reflectance for each Sentinel-2 bandwidth was used to calibrate and validate the field live vegetation mapping to the Sentinel-2 MSAVI2 mapping. See figure 1 for locations of the Kalama and Nasuulu Conservancies. [\%, percent; $\mathrm{nm}$, nanometer] 


\section{Ground Cover Classification}

The webcam photography was vital in documenting the vegetation types, spatial distribution, canopy density, and soil exposure, and central to this project, the cover fraction of live vegetation. The webcam system mounted above the surface at the same point as the radiometer obtained an approximately 4-m by 6-m high spatial resolution red-green-blue picture of the ground area coincident with the radiometer measurement. The common point of view allowed the radiometer GSA to be in the webcam photography frame affording near exact overlap of the two systems (fig. 5).

Thresholds were used to classify the red, green, and blue webcam photographic band data. Trial and error were used to determine the lower and upper red/green photographic band ratio thresholds that performed best in classifying the live, dead, and bare ground fractions in the photographic image at two sites; one site with gray soil background and another site with red soil background. Basing the red/green ratio calculation on the red and green photographic image bands provided a simple way to standardize the ratio to each of the webcam photos. First, dependent on the target photograph soil appearance, a "gray" or "red" reference threshold was chosen. Second, the average red/green ratio of the target photographic image was calculated and used to normalize the lower and upper reference thresholds. Third, those normalized thresholds were used to classify the webcam photograph. This classification procedure suited the photograph spectral quality, substantially simplified the classification, and unified the processing while accommodating the high spectral variability reflecting the high composition variability captured by the webcam photographs.

\section{Field Vegetation Classes Connected to the Field Reflectance}

Creating the calibration equation was based on the field-MSAVI2 data and vegetation classes. The field-MSAVI2 was related to the photographic classified live vegetation proportion by using a simple (single dependent and independent variables) regression procedure. Statistics associated with the regression quantified the overall goodness-of-fit ( $\mathrm{R}^{2}$, confidence in the prediction) of the regression equation to the field-MSAVI2 and photographic classification data points. An $\mathrm{R}^{2}$ of 100 percent denotes a perfect prediction

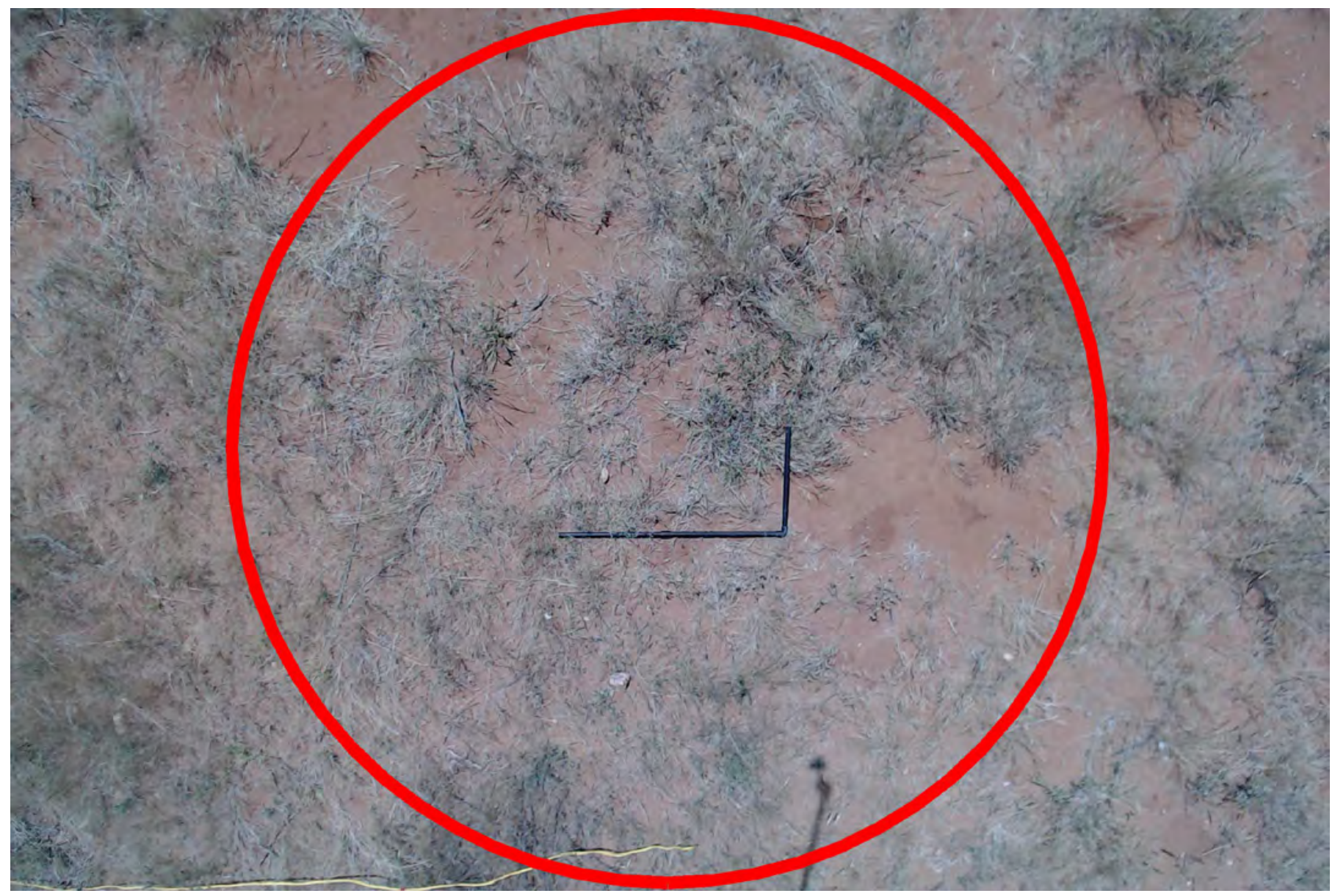

Figure 5. One of four locations at site 4 in the Kalama Conservancy taken coincidently with the radiometer recordings. The black elbow is 0.5 meter $(\mathrm{m})$ in height and $1 \mathrm{~m}$ in length. The red circle represents the approximately $3.5-\mathrm{m}$ field of view of the downward-looking radiometer (see fig. 3). Canopy reflectance spectra as shown in figure 4 are calculated from radiometer measurements (approximately 175 per location) within the red circle, whereas the webcam photography documents the exact ground cover. 
correlation. Coefficients calculated by the regression allowed calibration of the field-MSAVI2 based on field reflectance data to the live vegetation proportion obtained from webcam photographic data.

\section{Sentinel-2 Optical Image Data Calibration}

Up to 11 atmospherically corrected Sentinel-2 reflectance images were mosaiced to create a continuous cover of the core-NRT extent (fig. 2). The Sentinel-2 optical data used to calculate the satellite-MSAVI2 were extracted from the core-NRT mosaiced image by using the central GPS coordinates obtained at each field site. Six Sentinel-2 10-m by $10-\mathrm{m}$ pixel elements were obtained that best represented the spatial distribution of ground measurements at whole sites ( $30-\mathrm{m}$ by $30-\mathrm{m}$ transects). Likewise, three pixels were obtained from the image at half-sites (two 15-m transects), and a single pixel was obtained at single observation sites. The obtained satellite data were used to calculate the site-averaged satellite-MSAVI2.

Site-averaged satellite-MSAVI2 data were calibrated to site-averaged field-MSAVI2 data by using a simple regression procedure. Regression statistics quantified the $\mathrm{R}^{2}$ prediction confidence of the field-MSAVI2 and satellite-MSAVI2 regression calibration. Coefficients calculated by the regression were used to calibrate the satellite-MSAVI2 to field-MSAVI2.

\section{Sentinel-1 SAR Image Data Calibration}

The light probe was used to measure sunlight at the top and at the bottom of the vegetation canopy (fig. 6). These measurements were limited to sites containing a substantial vegetation cover. The sunlight measurements were processed to obtain the site average leaf area per square meter of surface area, or the leaf area index (LAI) (Ramsey and others, 2015). LAI is a quantifiable metric that is independent of bulk weight, increasing its comparability across diverse vegetations and use in a variety of biophysical models. LAI is used to estimate vegetation density (LAI per volume) to calibrate the Sentinel-1 SAR image data.

\section{Gravimetric Weight Analyses}

Vegetation clip plots were obtained at most instrument field sites (fig. 7). Clip plots are a classic means to characterize vegetation bulk properties as the vegetation weight per surface area. To provide relevant information concerning the vegetation ground cover, the clip plots must adequately represent the cover types and mixtures, spatial distribution, and densities of the study site. Because ground vegetation dominantly exhibited extreme heterogeneity within the NRT conservancies (excluding Lewa and a few Nasuulu and Kalama Conservancy sites), clip plot samples were most often inadequate in representing the vegetation proportion. Outside of the inadequate spatial representation of cover proportion, there was uncertainty in the determination of live and dead vegetation. Assignment of live during the live-dead separation depends on whether a green tint is visually apparent on the plant stem or leaf. At a few grassland sites in the Lewa and Nasuulu Conservancies, live or dead assignment was straightforward; however, at most grassland sites, the decision was tenuous, based on a barely discernable green tint. In general, weeds were more easily assigned to live-dead classes than grass. At several sites, however, weeds contained woody material or flowers, further confusing the assignment.

\section{Tree Mask}

Trees, including possibly large shrubs with heights greater than $2 \mathrm{~m}$, were identified by using the 2017 Sentinel-2 satellite-MSAVI2 image data. September was chosen because it provided the highest contrast between the trees and shrubs and the senesced ground cover. MSAVI2 was applied to enhance the contrast of trees to the senescent ground cover.

Single and small stands of trees were mapped with a spatial filter constructed as part of this mapping to detect large changes in MSAVI2 within a small area. The spatial filter was moved through the satellite-MSAVI2 image until every pixel was assigned a "uniqueness" value. If the pixel's uniqueness was higher than a set threshold, the pixel was identified as an evergreen tree or shrub. When the stand extent and density became too high, the uniqueness filter was replaced by a simple satellite-MSAVI2 threshold value. Threshold values used in both detection methods were selected by trial and error.

The tree mapping capability was limited by the image spatial resolution. The 10-m GSA mapping was larger than the estimated 2-m- to 5-m-diameter tree crowns. By using these estimated crown diameters, even if the crown was wholly enclosed within in a single pixel, the crown area was found to occupy only 12-75 percent of the pixel. Partial crown inclusion in the pixel further decreases that percentage. MSAVI2 enhanced even the lowest contrast; however, decreasing the threshold too low increased false detections to unacceptable levels.

\section{Results}

\section{Field Sites}

Observation data were collected at 105 field locations, and instrument data were collected at 60 of those field locations. Sites located solely for observation data collection were scattered within Lewa, Kalama, and Nasuulu Conservancies and along the A2 highway stretching from Lewa to the Namunyak Conservancies (fig. 1). Instrument sites were located throughout Lewa, Kalama, and Nasuulu Conservancies (fig. 1), and at most instrument sites, data were collected at multiple locations. 


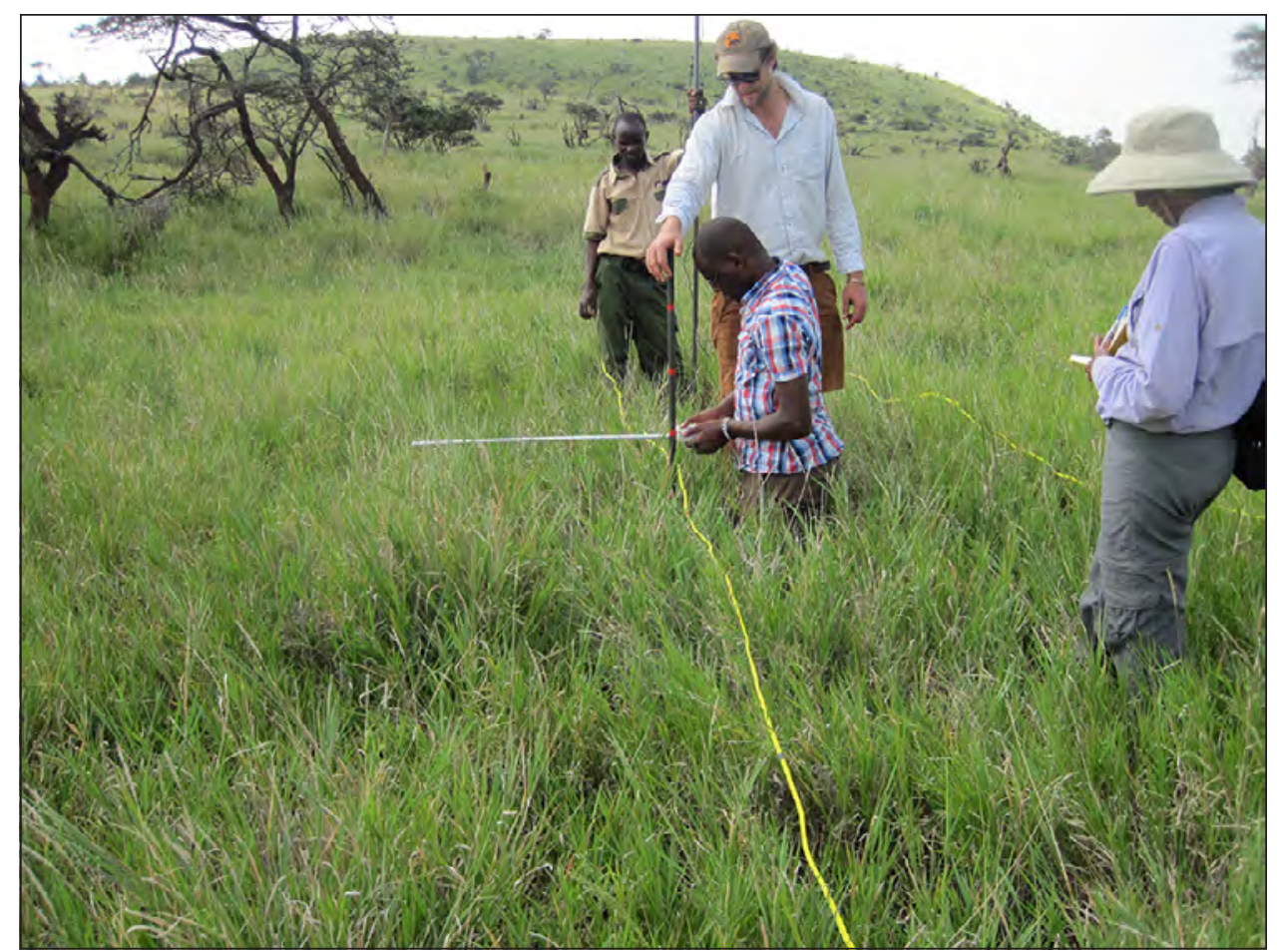

Figure 6. Light attenuation measurements being collected along one of four transects at site 1 in the Lewa Conservancy. The horizontal light probe measures sunlight at different heights in the grass canopy while the light sensor mounted on the vertical pole simultaneously records sunlight at the top of canopy.

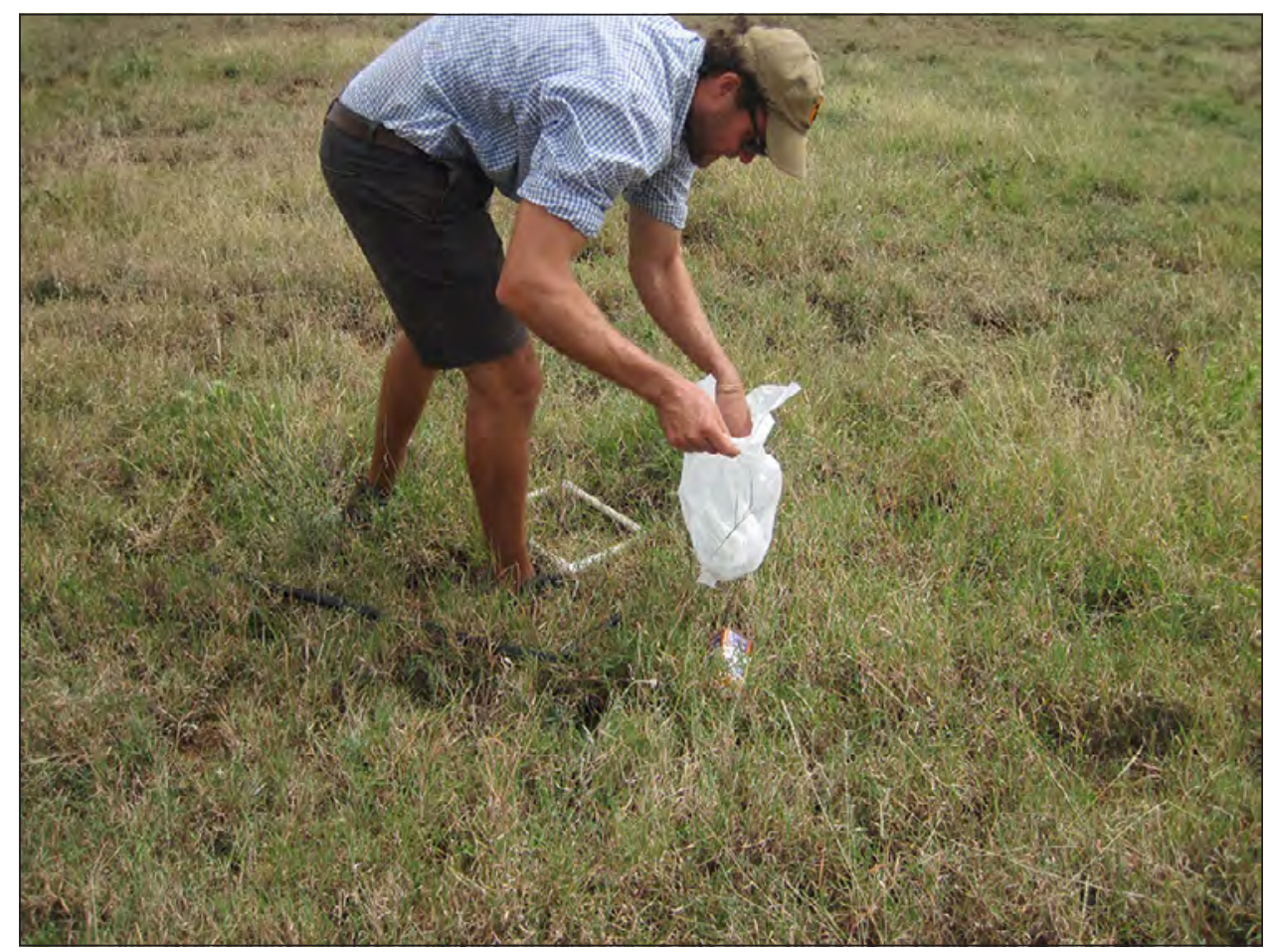

Figure 7. Collection of ground grass plus weed clippings at site 7 in the Lewa Conservancy. One to four clip samples were taken at each field site. The biomass clips include all plant material above the ground within a 25 -centimeter $(\mathrm{cm})$ by $25-\mathrm{cm}$ square (lying on the ground in the picture), or a 0.0625 -square-meter area. The clip samples were weighed and air dried (for 1 to 3 days), and then the live and dead portions were weighed separately. These biomass samples support the light attenuation measurements used to calibrate the radar image data. 


\section{Field Reflectance Spectra}

Reflectance spectra were obtained at 60 locations within 27 instrument sites. At sites containing multiple locations, spectra collected at each location were processed to create an average spectrum per site. The site spectra exhibit high variance in magnitude and form. The high variance reflects the sensitivity of reflectance to composition variability between sites. Although variable, patterns in the spectral data help demonstrate how reflectance data represent the varying mixtures of vegetation and soil.

Spectra presented in figure 4 depict changes in reflectance with varying amounts of live cover and vegetation type. For instance, as grass changes from lush green and dense at Nasuulu Conservancy site 1 to light green and moderate density at Kalama Conservancy site 2, the spectra amplitude increases; however, the spectra shapes, or features, largely remain constant. Within the visible (VIS) wavelengths (400 to 700 nanometers [nm]), a low amplitude plateau defines the blue region (centered at $450 \mathrm{~nm}$ ), a peak distinguishes the green region (centered at $550 \mathrm{~nm}$ ), and a slight trough delineates the red region (centered at $660 \mathrm{~nm}$ ). At the visible and near-infrared (NIR) (700 to $1,000 \mathrm{~nm}$ ) boundary, the reflectance sharply rises to the NIR high plateau that extends to about $940 \mathrm{~nm}$ where sunlight absorbance by water vapor diminishes the reflectance. Each of these spectral features represents healthy live vegetation. Broadly and specific to the live proportion, as the distinctness of these features diminish, the "greenness" (pigment concentration), density (amount per volume), cover (as opposed to bare soil), or a mixture of these factors tends to decrease. The pattern of diminishing distinctness of features is noticeable in the spectra progression of figure 4 . Figure $8 A$ illustrates the association between spectra of a soil background and sparse vegetated cover of those soils. Figure $8 B$ provides reflectance representations of lower density grass in Kalama Conservancy sites 4 and 8 similar to Kalama Conservancy site 2 in figure 4 . The Nasuulu Conservancy site 12 spectrum in figure $8 B$ represents some of the lowest cover densities sampled. Figure $8 C$ portrays how reflectance represents the live vegetation proportion changes in sites containing the same cover type.

\section{Gravimetric Weight Relationship to Webcam Classes}

Although the clip samples are a very tenuous measure of grass and weed composition at all field sites, especially where high spatial variability of cover existed, some level of correlation should exist between the live and dead percentages obtained from the clip weights and webcam photographic classifications.

The comparison of the two measures was obtained by application of multiple regression analysis. In contrast to the more straightforward simple regressions applied in all other analyses in this project, the multiple regression considers the addition of more than two explanatory variables. In this case, the three vegetation variables (live, middle or mixed, and dead) calculated from the webcam classification were used to explain the variability of the clip weights as represented by one variable, either total, live, or dead weight or the ratio of two of these (fig. 9).

The complementary live/total and dead/total multiple regressions resulted in similar, significant $(\mathrm{p}<0.001)$ relationships but low $\mathrm{R}^{2}$ values of 52 percent that were caused by scatter about the mean trend. Equation 1 and figure 9 show the live/total clip weight relation to the multiple webcam classes representing live/total information.

$$
\begin{aligned}
& \text { clip } \frac{\text { live }}{\text { total }}=-0.0203 \times \text { webcam_mix }+0.160 \times \\
& \text { webcam_mix / bare }-0.1404 \times \text { webcam_live / } \\
& \text { bare }+1.520,26 \text { observations }
\end{aligned}
$$

The multiple regression results confirm the significant correlation between the clip biomass weights and webcam classification. Although significant, the correlation is highly scattered as expected from field site observations and webcam photography. In contrast, the webcam-classified photography provides a more complete representation of the varied vegetation cover within the core-NRT and provides reproducible vegetation greenness (live) that is directly relatable to optical remote sensing. 

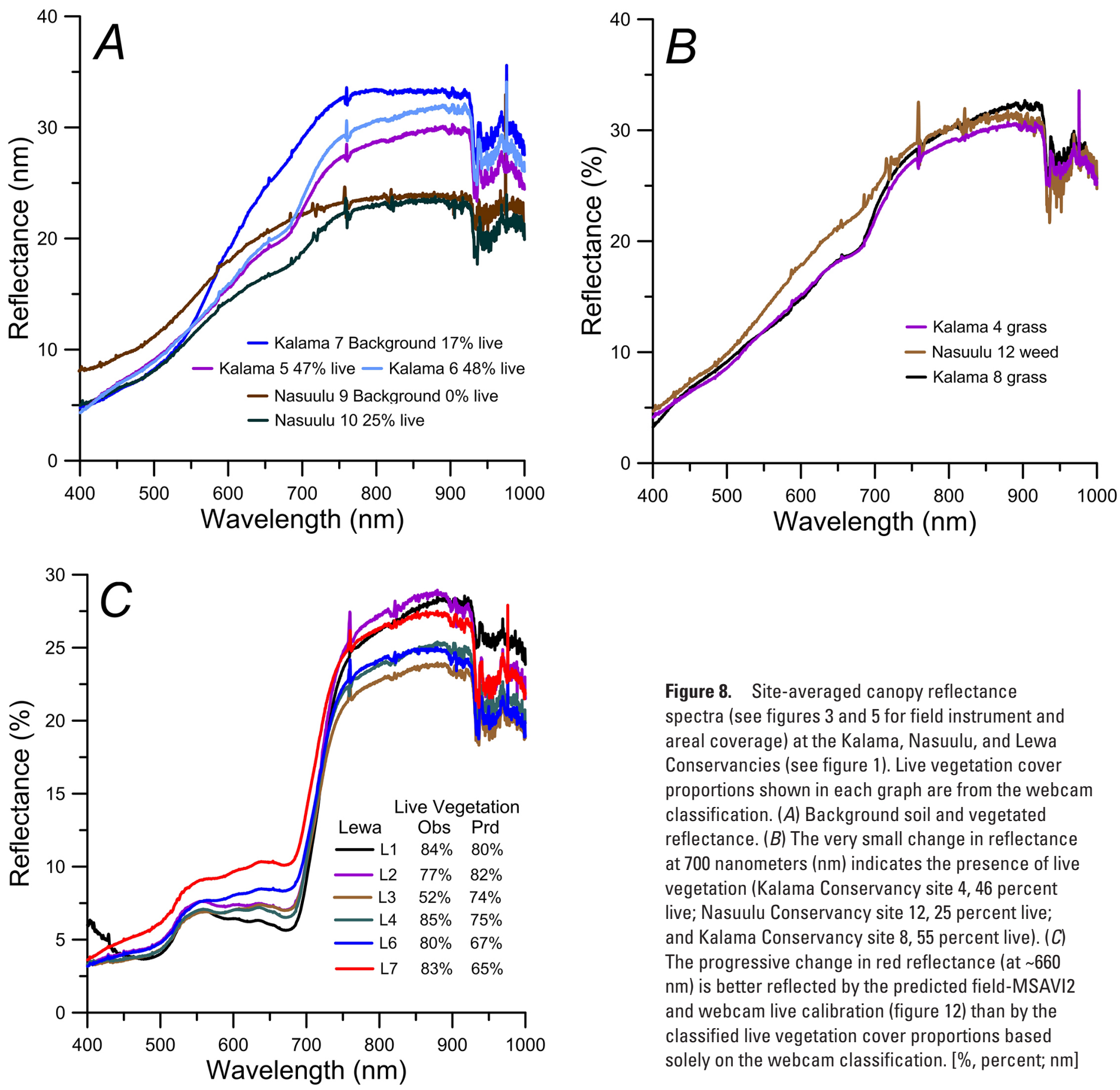

Figure 8. Site-averaged canopy reflectance spectra (see figures 3 and 5 for field instrument and areal coverage) at the Kalama, Nasuulu, and Lewa Conservancies (see figure 1). Live vegetation cover proportions shown in each graph are from the webcam classification. (A) Background soil and vegetated reflectance. $(B)$ The very small change in reflectance at 700 nanometers $(\mathrm{nm})$ indicates the presence of live vegetation (Kalama Conservancy site 4, 46 percent live; Nasuulu Conservancy site 12, 25 percent live; and Kalama Conservancy site 8, 55 percent live). (C) The progressive change in red reflectance (at $\sim 660$ $\mathrm{nm}$ ) is better reflected by the predicted field-MSAVI2 and webcam live calibration (figure 12) than by the classified live vegetation cover proportions based solely on the webcam classification. [\%, percent; nm] 


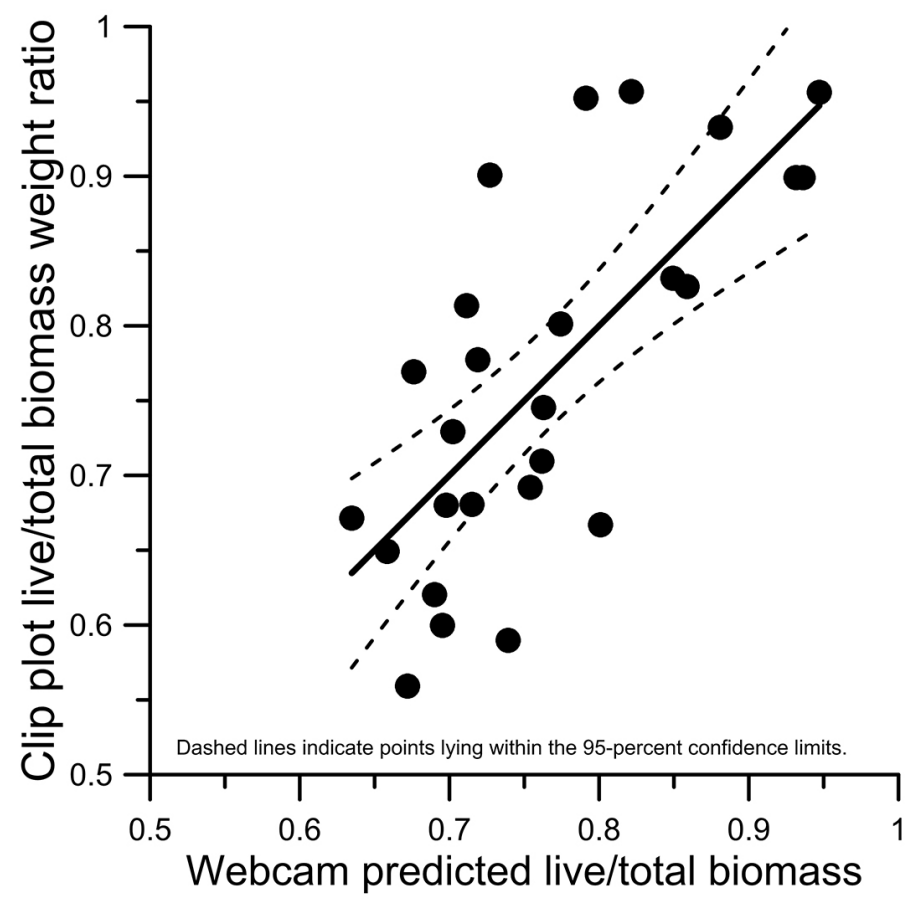

Figure 9. The relation between the clip live/total biomass weight ratio and the webcam-predicted live/total vegetation cover proportions. The regression analysis is limited to those locations where clip plots were obtained.

\section{Ground Cover Classification}

Classification of the ground cover was performed at each location where webcam photography was collected. Simple threshold processing was used to perform the classifications; however, a slightly modified approach was needed at Nasuulu Conservancy site 5 . Nasuulu Conservancy site 5 is a small site $(<10$-m diameter) containing an unusual 90-percent live patch of grass and weeds.

The webcam classification thresholds resulted in three classes: (low) live vegetation below the low threshold, (high) soil plus dead vegetation above the high threshold, and (middle or mixed) in between the low and high thresholds. In a few cases where soil was more than 75 percent of the cover proportion, there was no middle class. In all other cases, the middle class was associated with grass and weeds (figs. 10 and
11). In nearly every one of those cases, the webcam photography exhibited a slight green tint scattered within the middleclass vegetation. We applied the method used in separating live and dead vegetation in clip samples to assign the middle vegetation class to live or dead. That separation criterion designates a stem or leaf as live if any part exhibits a green color. Based on that criterion, the middle vegetation class was combined into the live class. The assignment strategy kept the webcam photographic classifications simple and unbiased, and thereby, repeatable and extendable.

Although combining the middle vegetation class into live vegetation provided a good visual representation of ground cover, the optical satellite representation and visual perception can differ. An optical sensor perceives the full areal cover and vertical depth component of green vegetation by its modification of the sunlight reflectance. As the cover proportion and greenness (purity of green color) increase, the modification of the reflectance spectrum increases (for example, fig. 4). Given the varying cover proportions and greenness of the middle classes, combining the entire middle vegetation classes into the live class is likely the highest source of error in the fieldMSAVI2 live vegetation cover prediction.

The comparison of the webcam photography with its classification demonstrates the correlation of ground cover composition with the three classes. Figures $10 A$ and $B$ show a forb-dominated area and the site sampled with the most pure gray soil background. Typical of sites with dominant forbcover proportions, the soil background dominates the cover proportion and the middle class is minimal, and in some cases nonexistent. Figures $10 C$ and $D$ show a grass-dominated site with a sizeable portion of taller weeds. The green weeds make up the live class, and the very light green grass makes up the middle class. The grass has a very thin stalk with a flowering top. In contrast, figures $11 A$ and $B$ represent a much greener and wider leafed grass site containing few weeds and minimal gaps exposing soil. Reflectance spectra at this Nasuulu Conservancy site exhibited the highest "greenness" of all grass sites sampled.

Figures $11 C$ and $D$ exemplify a less grazed grass cover in the Lewa Conservancy. Overall, the grass cover proportion is high with few gaps. The grass leaves are relatively broad, and the dead grass composition is the highest of all sites sampled except for two sites in the Nasuulu Conservancy. 

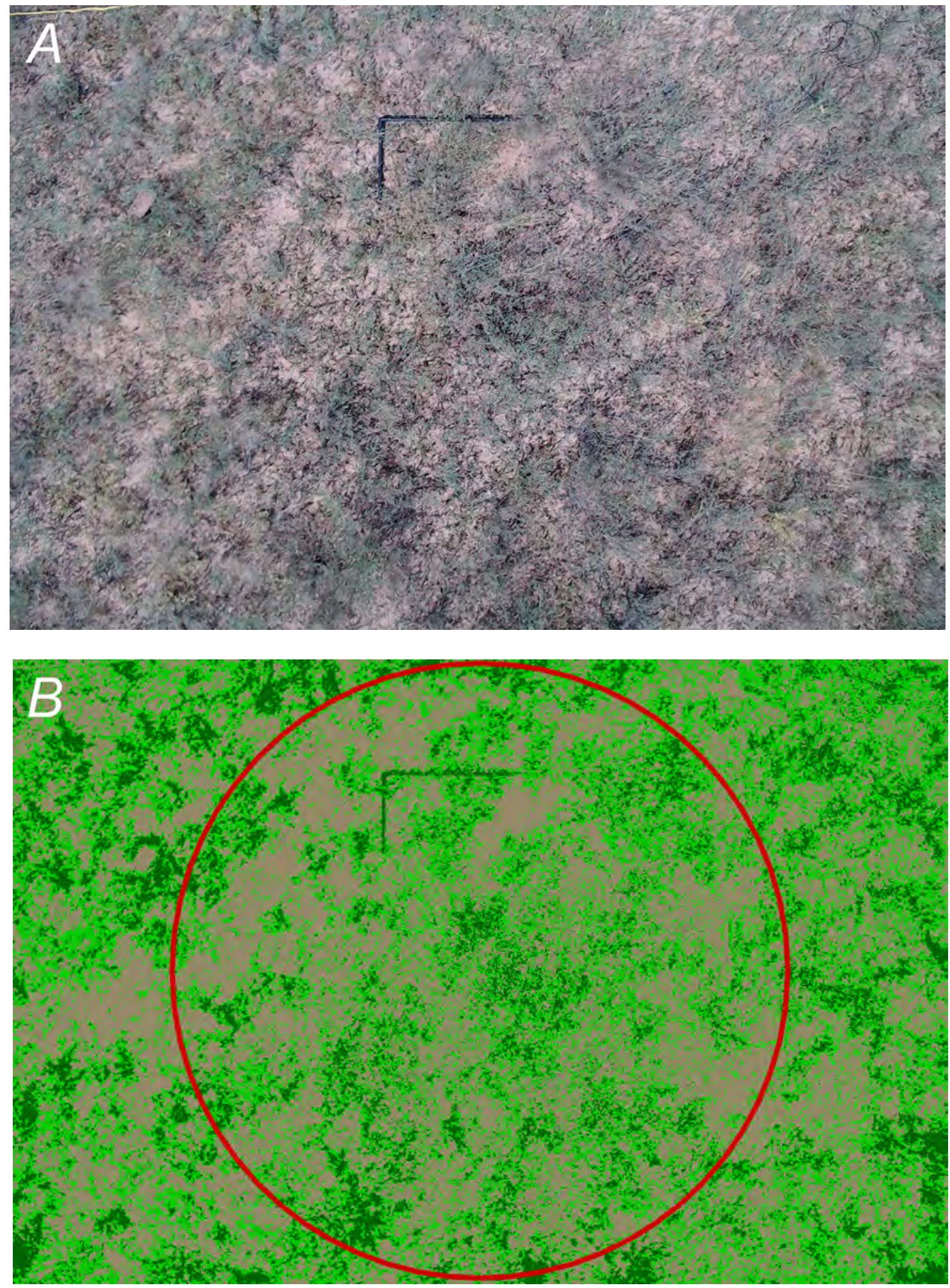

Figure 10. Kalama Conservancy natural color and classified webcam images. Site K1NE $(A)$ natural color webcam and $(B)$ classified webcam; Kalama Conservancy site K2-320 (C) natural color webcam and $(D)$ classified webcam. Low class—dark green, live vegetation; middle class—light green, live vegetation; and high class—brown, soil and dead vegetation. 

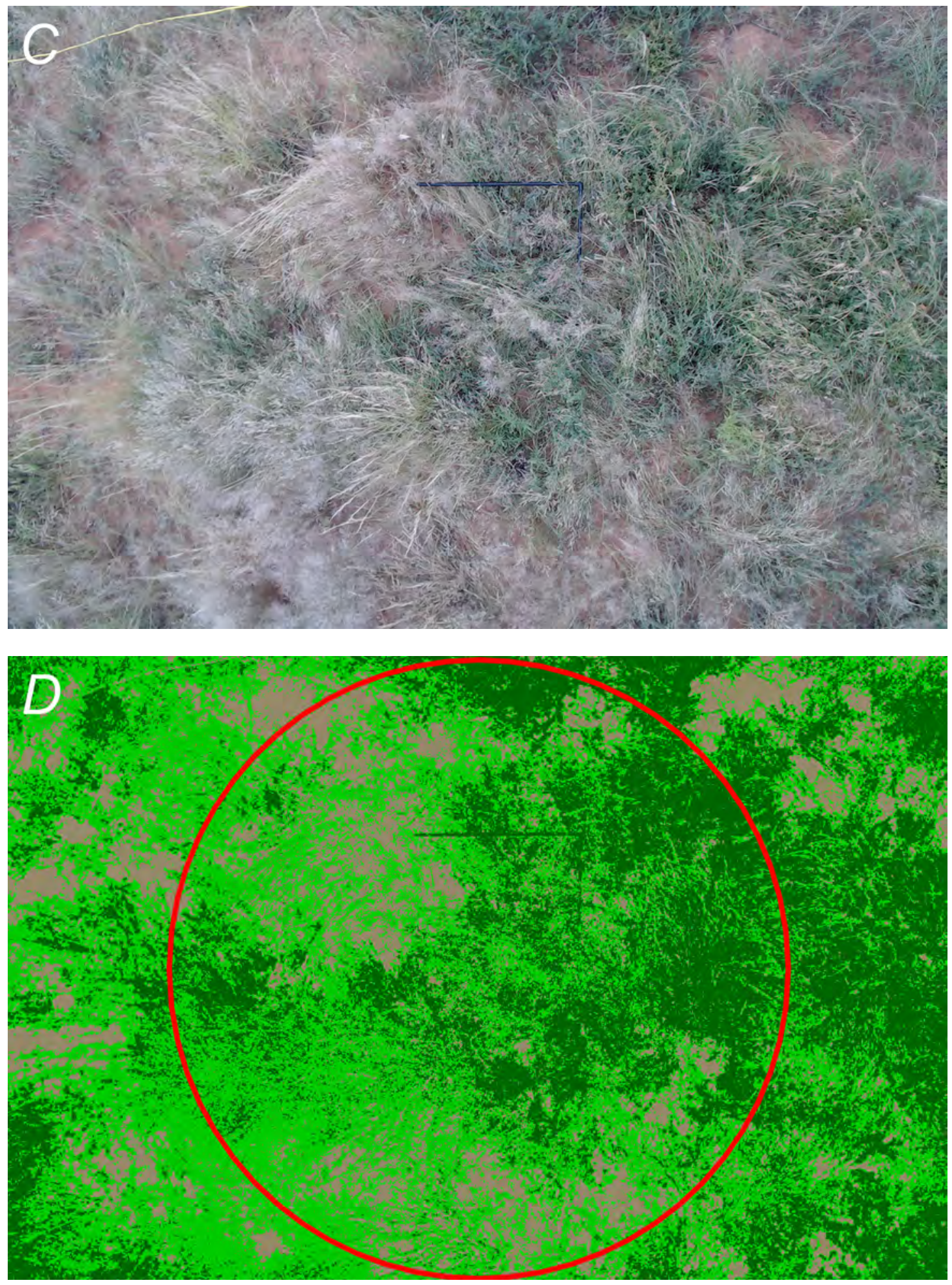

Figure 10. Kalama Conservancy natural color and classified webcam images. Site K1NE $(A)$ natural color webcam and $(B)$ classified webcam; Kalama Conservancy site K2-320 $(C)$ natural color webcam and $(D)$ classified webcam. Low class_-dark green, live vegetation; middle class_-light green, live vegetation; and high class—brown, soil and dead vegetation.-Continued 

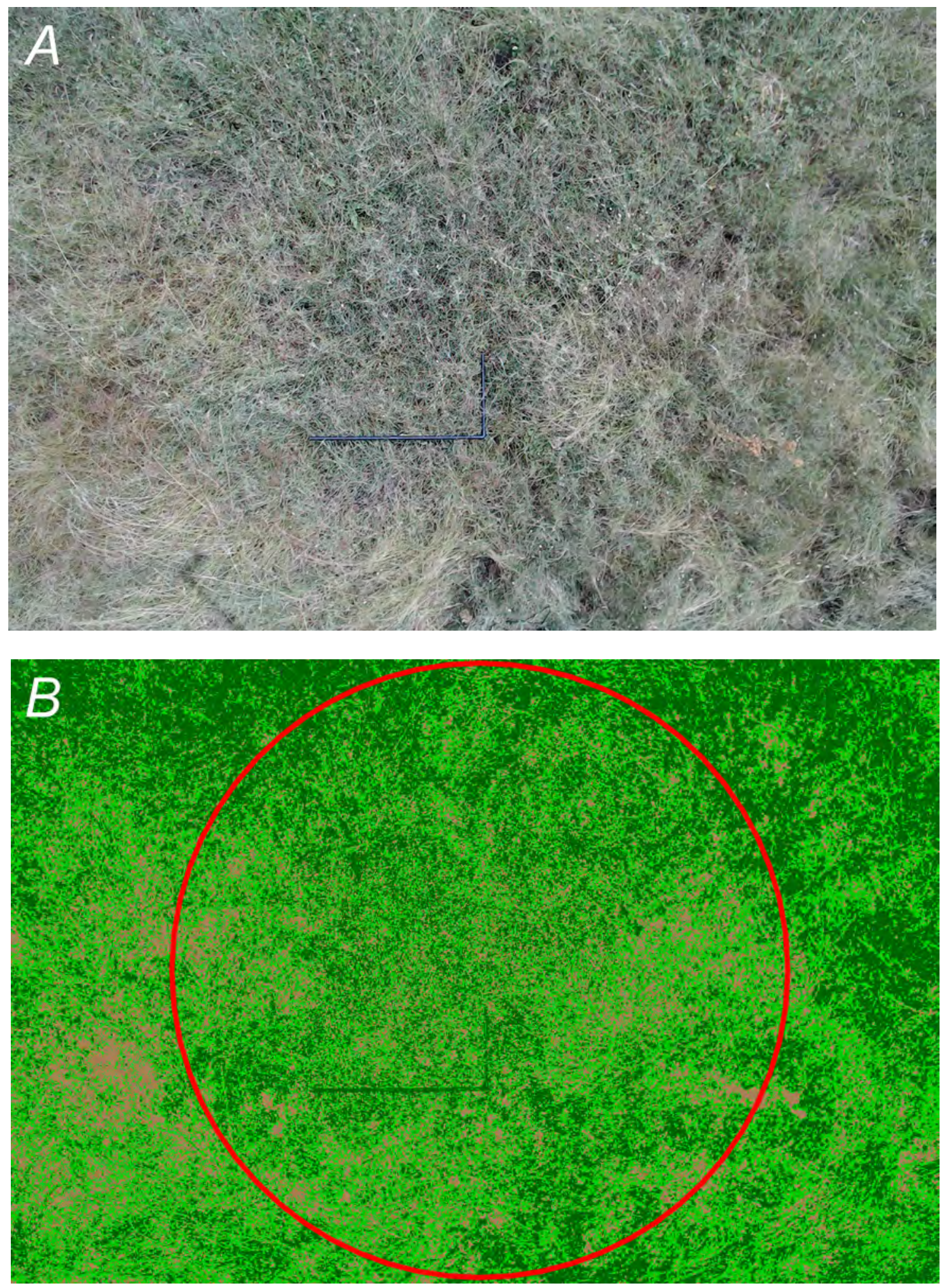

Figure 11. Nasuulu Conservancy natural color and classified webcam images. Site N1N $(A)$ natural color webcam and $(B)$ classified webcam; Lewa Conservancy site $1 \mathrm{~W}(C)$ natural color webcam and $(D)$ classified webcam. Low class—dark green, live vegetation; middle class—light green, live vegetation; and high classbrown, soil and dead vegetation. 

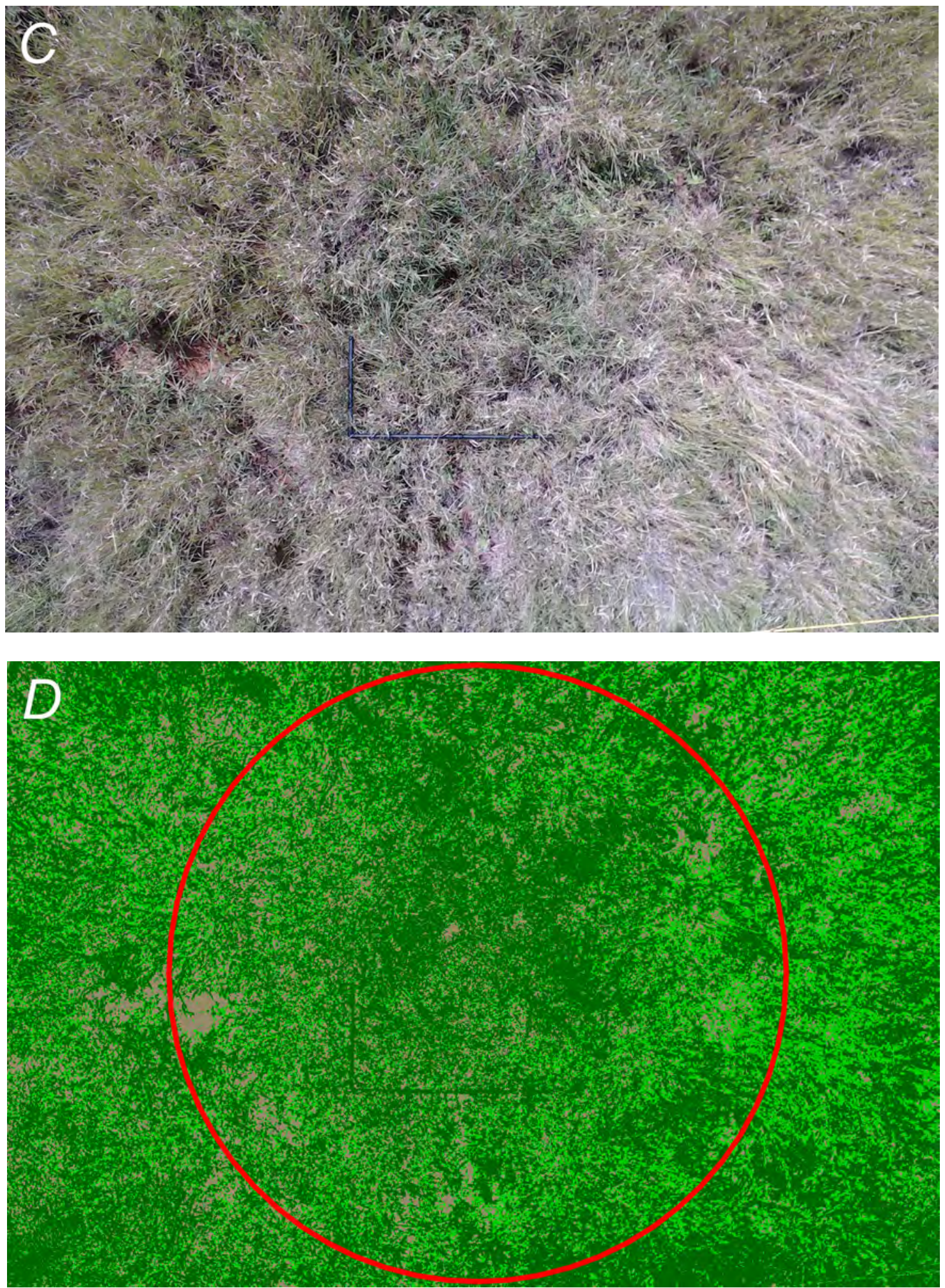

Figure 11. Nasuulu Conservancy natural color and classified webcam images. Site N1N $(A)$ natural color webcam and $(B)$ classified webcam; Lewa Conservancy site $1 \mathrm{~W}(C)$ natural color webcam and $(D)$ classified webcam. Low class — dark green, live vegetation; middle class — light green, live vegetation; and high classbrown, soil and dead vegetation.-Continued 


\section{Field-MSAVI2 Calibrated to the Vegetation Classification}

The field-MSAVI2 and the webcam photography live class correlation was high (fig. 12). The best-fit regression explained 80 percent $\left(\mathrm{R}^{2}\right)$ of the live class variance. Although the prediction of live vegetation was high, the positive 6.07-percent intercept suggested that a zero MSAVI2 represented a positive live vegetation cover (eq. 2). In addition, Nasuulu Conservancy site 9, a bare ground site with an 11-percent field-MSAVI2 value, predicts $>17$ percent live cover by using equation 2 . That misclassification suggests that the minimum mapping threshold of field-MSAVI2 ranges from 11 percent up to about 20 percent where field sample representation is good. To better represent the low range of fieldMSAVI2 prediction of live cover, a second regression was constrained to pass through zero (eq. 3).

Best-fit: webcam photography live class $\%=$ field-MSAVI2 $\times 94.8 \%+6.07 \%, 60$ observations

Constrained-fit: webcam photography live class $\%=$ field-MSAVI2 × 103.89\%, 60 observations

The constrained regression slope explains 98 percent of the live vegetation variance with a slope of 103.89 percent and an intercept of zero (eq. 3). The $\mathrm{R}^{2}$ is inflated because of the reduction in explained variables (setting the intercept to zero). The near one-to-one slopes of both the best-fit and constrained regressions indicate the near consistency of the two regression representations of the field-MSAVI2 and live vegetation correlation. However, at field-MSAVI2 values below about 20 percent, the predicted live vegetation values based on the constrained regression are more in line with expectations and differences than the best-fit regression. The constrained regression live predictions only become slightly higher than those predicted by the best-fit regression at the highest fieldMSAVI2 values.

\section{Sentinel-2 Data Calibrated to Field Data}

Minimal cloud coverage over parts of the NRT on 28 June 2018 allowed Sentinel-2 image data to be obtained over Nasuulu and Kalama Conservancy field sites; however, clouds covered all Lewa Conservancy field sites. Variable cloud conditions over Lewa allowed image data to be obtained from sites 1, 2, and 3 on 18 June and from all Lewa sites (1, $2,3,4,6$, and 7) on 18 July 2018. Initial regression analyses showed satellite-MSAVI2 data from Lewa sites 4, 6, and 7 were low compared to the regression trend. Comparison of satellite-MSAVI2 data from Lewa Conservancy sites 1, 2, and
3 based on 18 June and 18 July image data indicated about a 25-percent decrease in satellite-MSAVI2 over the month lag between collection dates. Based on that difference and the expected live vegetation cover proportion decrease from June to July, we applied a correction to the satellite-MSAVI2 data calculated from 18 July image data to compensate for the estimated 25-percent decrease. In addition, Nasuulu Conservancy site N5 was removed from the regression analysis because its small extent $(<10 \mathrm{~m})$ was inappropriate for the calibration of the satellite data.

The regression calibration obtained a high confidence $\mathrm{R}^{2}$ of 93 percent and produced a slope of 0.877 and an intercept of -0.0018 (eq. 4 ; fig. 13). As in the vegetation cover calibration, the high confidence, near one-to-one linearity, and near zero intercept signify the correctness of the field methods and choice of satellite vegetation mapping index.

$$
\begin{gathered}
\text { satellite-MSAVI2 }=\text { field-MSAVI2 } \times 0.877-0.0018, \\
26 \text { observations }
\end{gathered}
$$

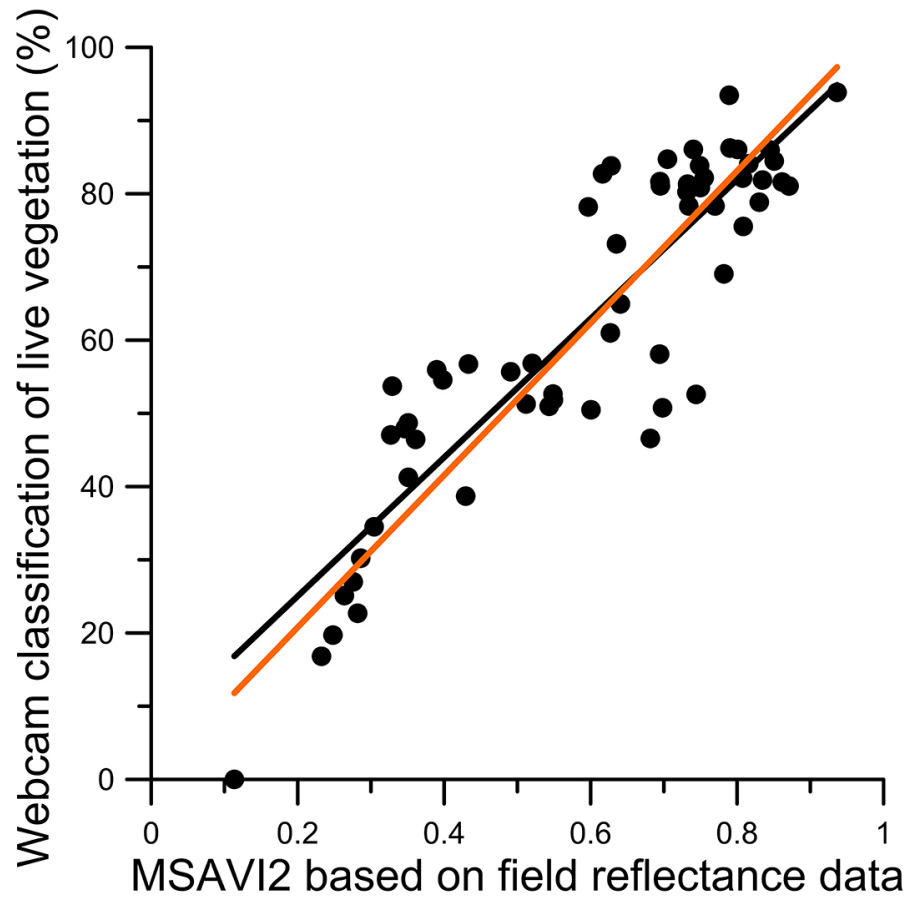

Figure 12. Correlation between the field-MSAVI2 calculated from field reflectance data (figs. 3 and 4) and webcam classifications (figs. 10 and 11). The best-fit regression model results (eq. 2) are represented by the black line, and the constrained-fit results (eq. 3 ) are represented by the orange line through the 60 plotted points. The constrained-fit results were used to calibrate the imageMSAVI2 data. The predicted live vegetation cover proportions shown in figure $8 C$ are based on equation 3. [\%, percent] 


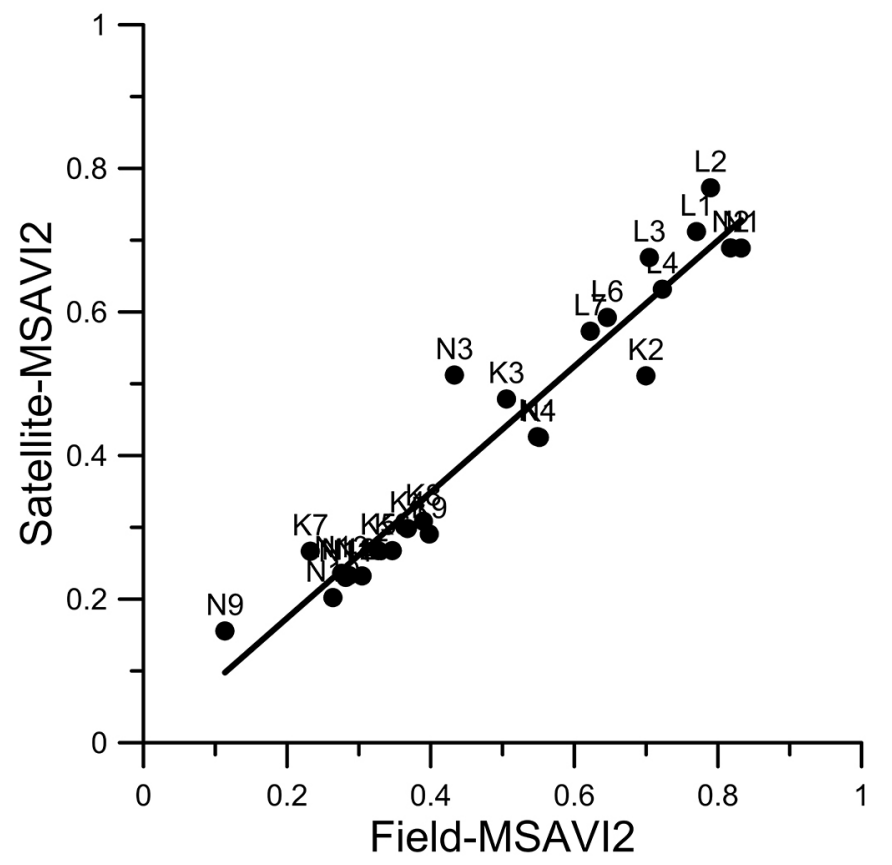

Figure 13. Correlation between the MSAVI2 calculated from siteaveraged field reflectance data (figs. 3 and 4 ) and from site-averaged Sentinel-2 satellite reflectance data. The satellite-MSAVI2 was then calibrated to the field-MSAVI2, allowing the calibrated satelliteMSAVI2 values to replace the field-MSAVI2 values in equation 3. With that replacement, the satellite-MSAVI2 image was directly linked to the live vegetation cover proportion via equation 3.

\section{Tree Mask}

Given the spatial resolution constraints, the tree mapping produced exceptional results. Although false detections occur, visual comparison with Google Earth (GE) images suggested that the largest mapping error was omission, or nondetection, of trees that were present. Even with the indicated high omission, the September 2017 mapped tree coverage reproduced tree patterns and densities that were aligned with those visible on GE. The one-to-one tree occurrence mapping precision was not assessed as part of this project.

The good reproduction of the highly variable patterns and changing densities within the core-NRT provides the guidance needed to aid interpretation of the live vegetation maps. Mapped trees prevent misinterpretation of live vegetation as solely associated with ground cover. In addition, relatively moderate to higher concentrations of trees suggest caution in direct interpretation of the live ground cover lying in gaps between mapped trees. That caution is based on the fact that some of the trees, and larger shrubs, were not captured by the tree mapping. Those missed trees and shrubs could heighten the live vegetation base level over that purely due to grass and weeds.

In addition, the patterns and density of tree occurrences give context to the live ground cover mapping. For instance, spatial patterns of tree occurrence and live ground cover may reveal vegetation associations as cohesive units repeated throughout the NRT. Response at the association level to changes in grazing intensity or to invasive establishment could offer a more unified management approach to mitigate and reverse detrimental change. Lastly, changes in tree extents from wetter to drier periods (such as June to September) may help separate and identify different types of trees and shrubs.

\section{Sentinel-2 Live Vegetation Maps}

The field-to-satellite MSAVI2 calibration (eq. 4) converted the 28 June 2018 core-NRT satellite-MSAVI2 image to field equivalents. The field-equivalent image MSAVI2 values were substituted pixel for pixel into equation 3 to map the live vegetation cover throughout the NRT. The same procedure was used to produce live vegetation maps for June and September 2017. Because cloud cover was persistent over the Lewa Conservancy in the 28 June 2018 image, the Lewa live vegetation map creation was handled separately from the coreNRT conservancies. The 18 June and 18 July 2018 live vegetation maps were combined to provide the maximum coverage of Lewa Conservancy. Those areas relying on the 18 July image data were adjusted to the 18 June satellite-MSAVI2 data before equation 3 or 4 was applied. Cloud cover was not a problem in either of the 2017 Sentinel-2 images.

To document the mapping confidence, the strength of the relationship was calculated between the predicted live vegetation cover proportions based on equation 3 and the mapped cover proportions. The two cover proportions should conform if the mapping is reliable. First, cover proportions were extracted in units of percent from the June 2018 live vegetation map, and site averages were calculated. Second, predicted live vegetation cover proportions were calculated based on equation 3 , and these were used to produce predicted site-average live cover proportions expressed in percent. Third, a simple statistical regression relationship was used to calculate how well the mapped cover proportions replicated the predicted cover proportions. The regression produced a high confidence of 92 percent, a correlation of almost one-toone (1.024), and an intercept close to zero $(-0.074$ percent $)$ (eq. 5 ; fig. 14).

$$
\begin{gathered}
\text { predicted live percent }=\text { mapped live percent } \times \\
1.024-0.074 \%, 26 \text { observations }
\end{gathered}
$$




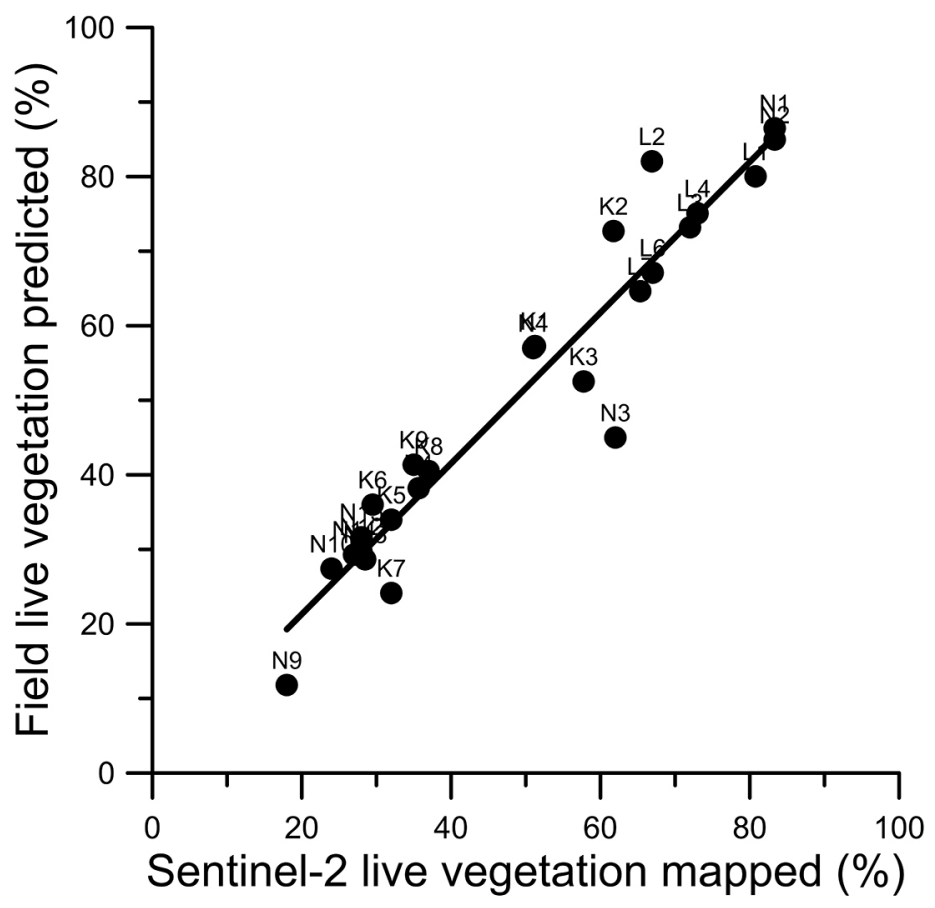

Figure 14. Correlation between the Sentinel-2 site-averaged proportion of live vegetation and the predicted site-averaged proportion of field live vegetation based on equation 3. [\%, percent]

The live vegetation cover proportion ranged from 0 percent to somewhat above 100 percent. Except for a large drainage feature in the north of core-NRT, live values higher than 100 percent were associated with dense trees that were not included in the ground vegetation calibration (eqs. 2 and 3). To stay within the bounds of the calibration while preserving the accuracy of the live vegetation ground cover mapping, values above 100 percent were truncated to 100 percent.

The mapped live vegetation cover proportion range was represented as a continuous color gradient from brown to yellow-green. In the sparsely vegetated rangeland, the continuous gradient is needed to properly represent and portray the low and subtly varying live vegetation cover. With live cover often below 30-40 percent and seldom above 50 percent (outside of Lewa Conservancy), soil most often dominates the optical satellite and visual nadir view of the ground. The drawback of the two-color gradient is the subtleness of change or lack of vividness in portraying changing spatial patterns. For example, outside of riparian, elevated topography and isolated trees, distinction between spatial changes of live cover proportion may only be the brightening of the brown, or in more diverse regions, the increased intermix of green shades. Image reproduction is also challenging. Slight differences in shades may become indistinguishable when printed or displayed with low resolution monitors. However, the continuous color ramp most truly represents the calculated live vegetation cover information, and the produced maps best convey the high information content obtained from the advanced field methods and spatial analyses. The same color representation of live vegetation cover proportion was used in June and September 2017 maps as well. Colors are directly comparable between the June 2018 and June and September 2017 live vegetation maps (figs. 15-17).

Following the live vegetation cover proportion status maps, the live vegetation cover proportion change between two dates is illustrated (figs. 18-20). The change calculation is defined so that the lower proportion of live vegetation is subtracted from the expected higher proportion of live vegetation. In that way, most change is positive. However, the database was constructed to store positive as well as negative change results, so negative changes are displayed as well in shades of greens and blues. The live vegetation change result represented in the change graphics can be calculated per pixel by hand.

Although the two-color gradient best represents the status of live vegetation cover proportion, the color rendition of mapped differences between two dates is applied to emphasize differences. A continuous color gradient was used again; however, the color ramp is more vivid. Greens bridge the live cover increase and decrease range, pinks and reds reflect the highest increases, and blues indicate the highest decreases between the two dates. The same color representation of differences in live vegetation was used to compare the live vegetation in June and September 2017 to the live vegetation in June 2018 (figs. 18-20).

\section{June 2018 Live Vegetation Map}

The core-NRT had a wide distribution of live vegetation cover proportions in June 2018 (fig. 15A). Outside of the Lewa Conservancy, scattered pockets of live cover above 80 percent exist as documented at Nasuulu Conservancy sites 1 and 2.

However, as shown by the September 2017 tree mask overlay onto the June 2018 live vegetation cover map, often the 80-100-percent live vegetation cover extends from the mask associated with evergreen high-density tree stands (fig. 15B). That association could indicate that the yellowgreen extension incorporates a varying mix of compositions: grasses and forbs and non-evergreen trees and shrubs. Darker browns reflecting live cover at less than about 25 percent are scattered throughout the core-NRT, becoming more dominant to the north.

\section{September 2017 Live Vegetation Map}

The September 2017 map exhibits the full range of live vegetation cover proportions as in June 2018; however, outside of dense trees stands, riparian areas, and high relief features, the core-NRT had less live vegetation in September 2017 than in June 2018 (fig. 16A). Even where live vegetation occurs, the highest values, indicated by bright yellow-green in figure $16 A$, are restricted to evergreen trees and larger shrubs (fig. 16B). 


\section{June 2017 Live Vegetation Map}

The June 2017 live vegetation cover proportion map exhibits an overall slight increase compared to the September 2017 live vegetation map (fig. 17A). Similar contrasts and similarities noted in September 2017 and June 2018 are also seen in the June to September 2017 comparison; however, the contrasts and similarities are more subdued. High live values (brightest yellow-greens) extended beyond the September 2017 tree mask, yet the increased extents and regions where the enlargements occurred were minor in comparison to June 2018 (fig. 17B). The increases in live vegetation cover compared to September 2017 were less than in 2018. In the lower live classes (browns), the most noticeable changes seemed to be increases in the lowest September live cover proportion areas. Areas with live vegetation covers up to 17 percent or less increased to nearly 25 percent, while live vegetation covers nearer 25 percent increased to about 50 percent. Those changes suggest small increases of live vegetation in areas nearly devoid of live vegetation and higher live vegetation increases in areas of moderately low live cover in September 2017. Overall, the June 2017 map was more aligned with the September 2017 map than the June 2018 live vegetation map.

\section{June 2017 to June 2018 Live Vegetation Change Map}

The June 2017 to June 2018 live vegetation cover proportion change map depicts the expected high increase in live vegetation due to the much wetter conditions in June 2018 than in June 2017 (fig. 18A). Even though the increase in live cover in 2018 is predominant, the high spatial variability in live cover change magnitude is also obvious. Overlaying the tree mask helps refine the comparison (fig. 18B).

As seen in figure $18 B$, most of the highest increases to the southwest are overlain by the September 2017 tree mask; however, to the east-northeast, most of the moderately high and widespread live vegetation increases remain. Some remaining high-increase areas are associated with ephemeral riparian features. A portion, however, could be linked to tree and shrub stands that were not captured in the September 2017 tree classification. Those misclassifications could be due to canopy thickening in June 2018. Outside of the broad areas of high live cover increases, the central core and smaller pockets to the north suggest a more subdued response to the wetter conditions. Higher increases are scattered in a background of low to no change in live cover.

\section{September 2017 to June 2018 Live Vegetation Change Map}

The September 2017 to June 2018 live vegetation cover proportion change map depicts the expected increase in live vegetation in the comparison of the dry to wet seasonal difference (figs. $19 A$ and $B$ ). The spatial pattern of increased live cover is like the June 2017 to 2018 increase shown in figure $18 A$; however, the magnitudes appear higher in the September 2017 to June 2018 map (fig. 19A). The reds and pinks are more extensive in figure $19 A$, and the central green-yellow region of figures $18 A$ and $B$ increases to higher magnitudes represented more dominantly as yellow-green in figures $19 \mathrm{~A}$ and $B$.

\section{June 2017 to September 2017 Live Vegetation Change Map}

The June 2017 drought period to September 2017 dry season live vegetation cover proportion change maps portray the lowest differences in live vegetation of the three comparisons (figs. $20 A$ and $B$ ). Overall, yellow-green to green-yellow colors dominate, thus signifying low change in live cover. Outside of areas covered by the tree mask and near the center of the map, a band of scattered reds within a backdrop of yellows trends to the northeast and then to the northwest of the image. This higher live vegetation band does not clearly appear in the June 2017 to June 2018 or September 2017 to June 2018 change maps. The feature appearance could indicate a different vegetation association that only became highlighted because of the vegetation conditions present at the two image dates. Although the vegetation makeup is not revealed, figure 20 demonstrates the capability of quantitative change mapping to discern patterns not necessarily available on coarser spatial and less detailed mapping. Lastly, spatial patterns of higher live cover proportion in June 2017 were enlarged in many areas beyond the September 2017 tree mask. 


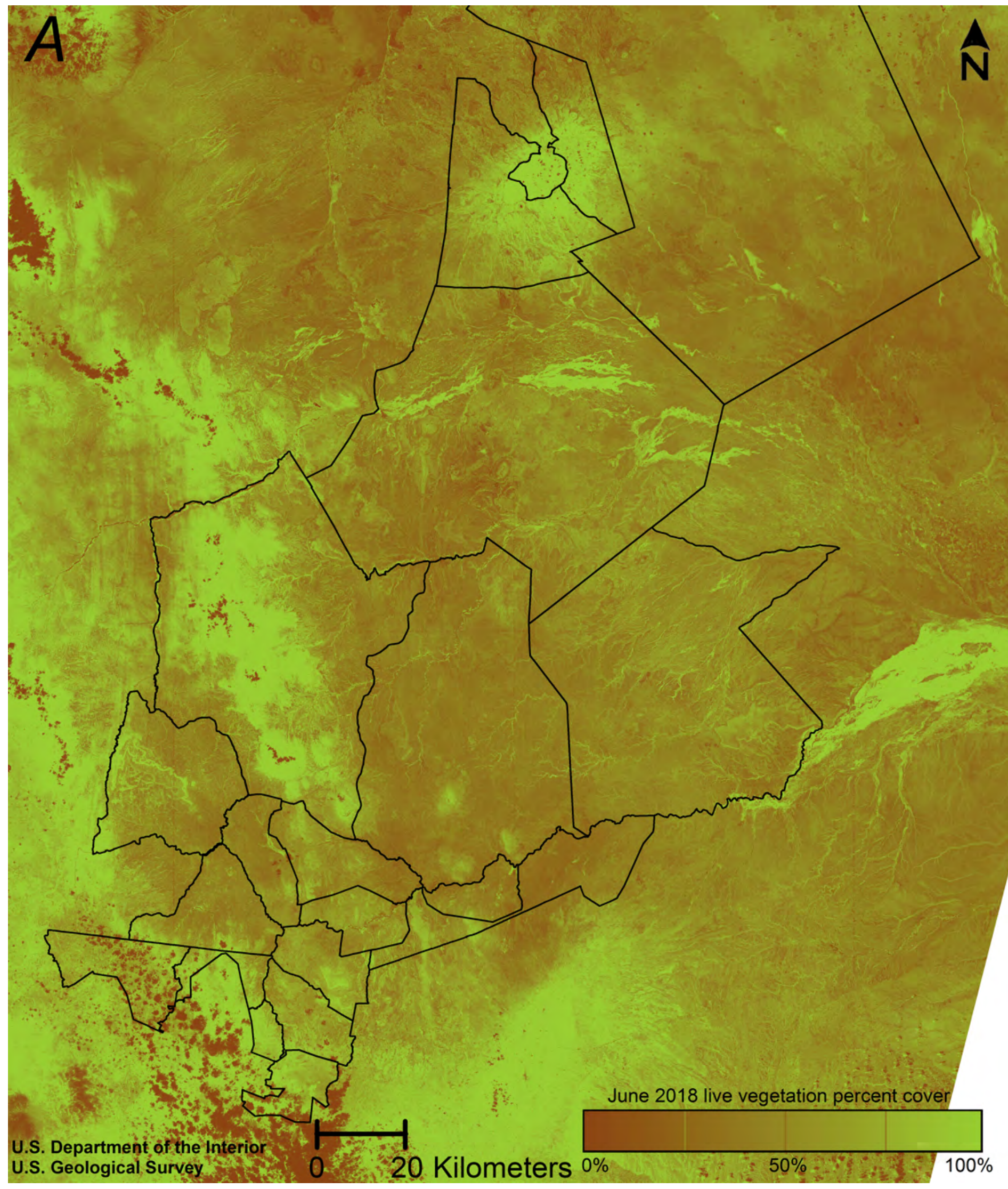

Figure 15. (A) June 2018 live vegetation map. (B) June 2018 live vegetation map with tree mask overlay (dark green). High resolution files available from https://doi.org/10.3133/ofr20191037. 


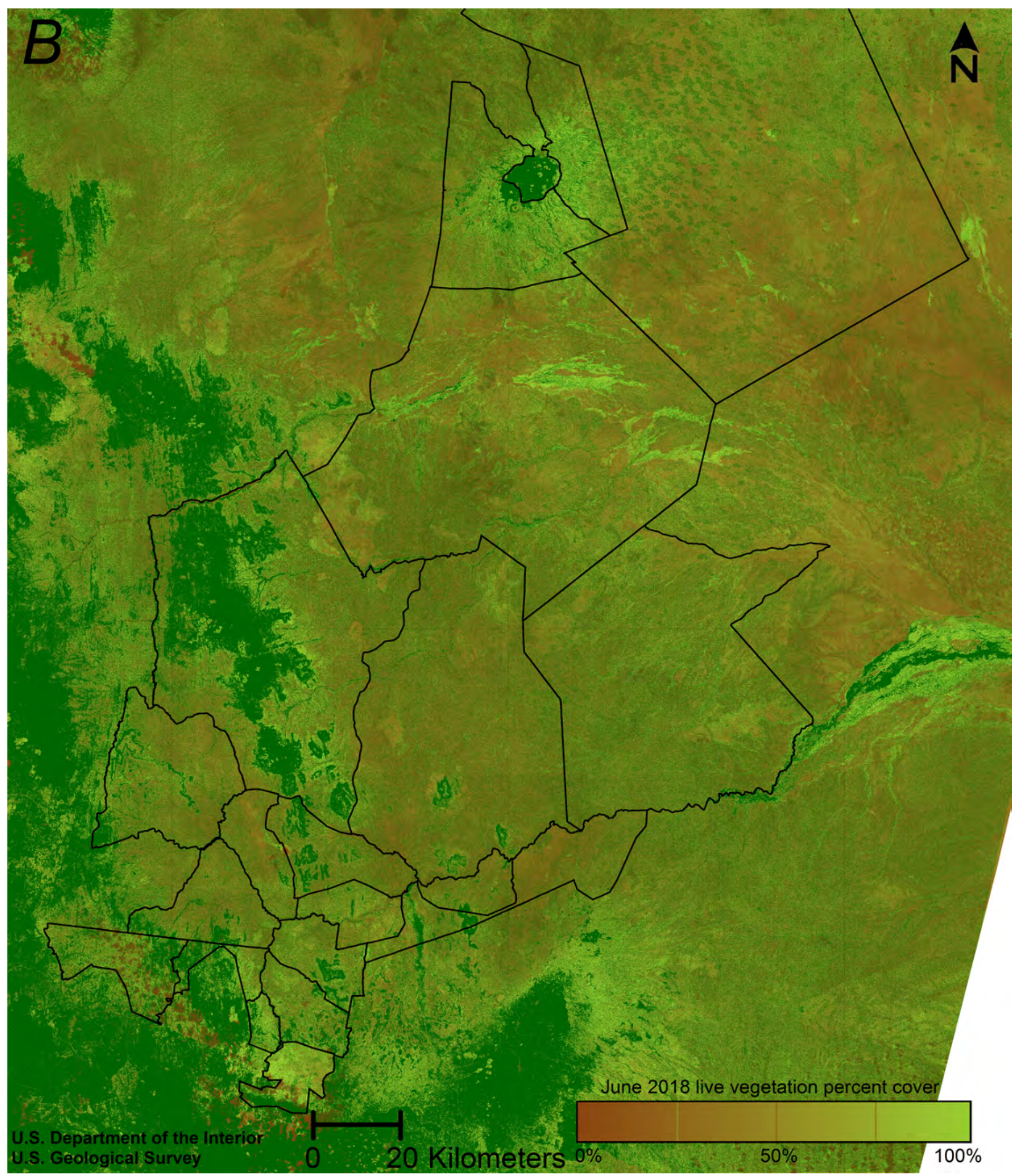

Figure 15. (A) June 2018 live vegetation map. (B) June 2018 live vegetation map with tree mask overlay (dark green). High resolution files available from https://doi.org/10.3133/ofr20191037.—Continued 


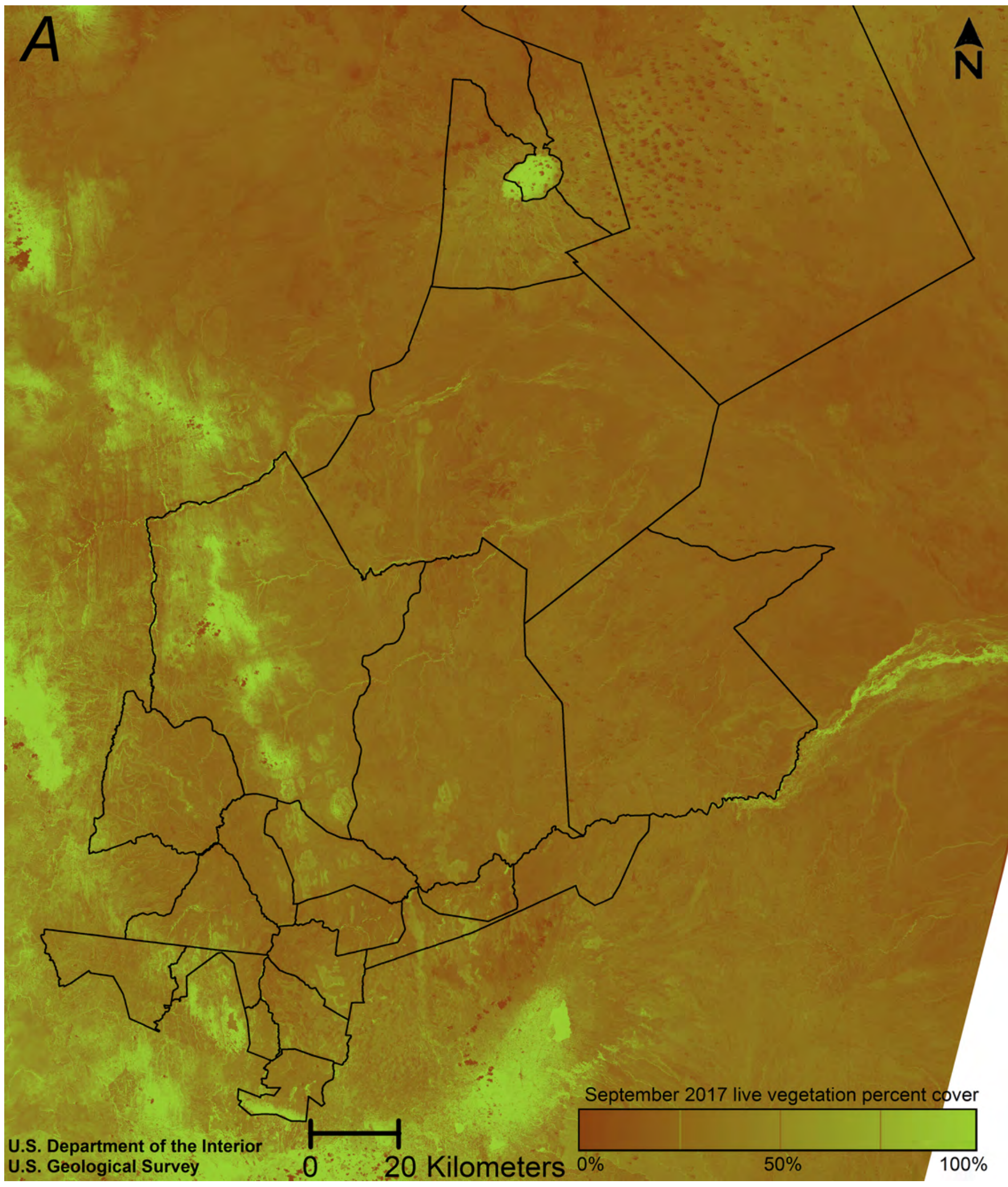

Figure 16. (A) September 2017 live vegetation map. (B) September 2017 live vegetation map with tree mask overlay (dark green). Some cloud contamination apparent in the NE. High resolution files available from https://doi.org/10.3133/ofr20191037. 


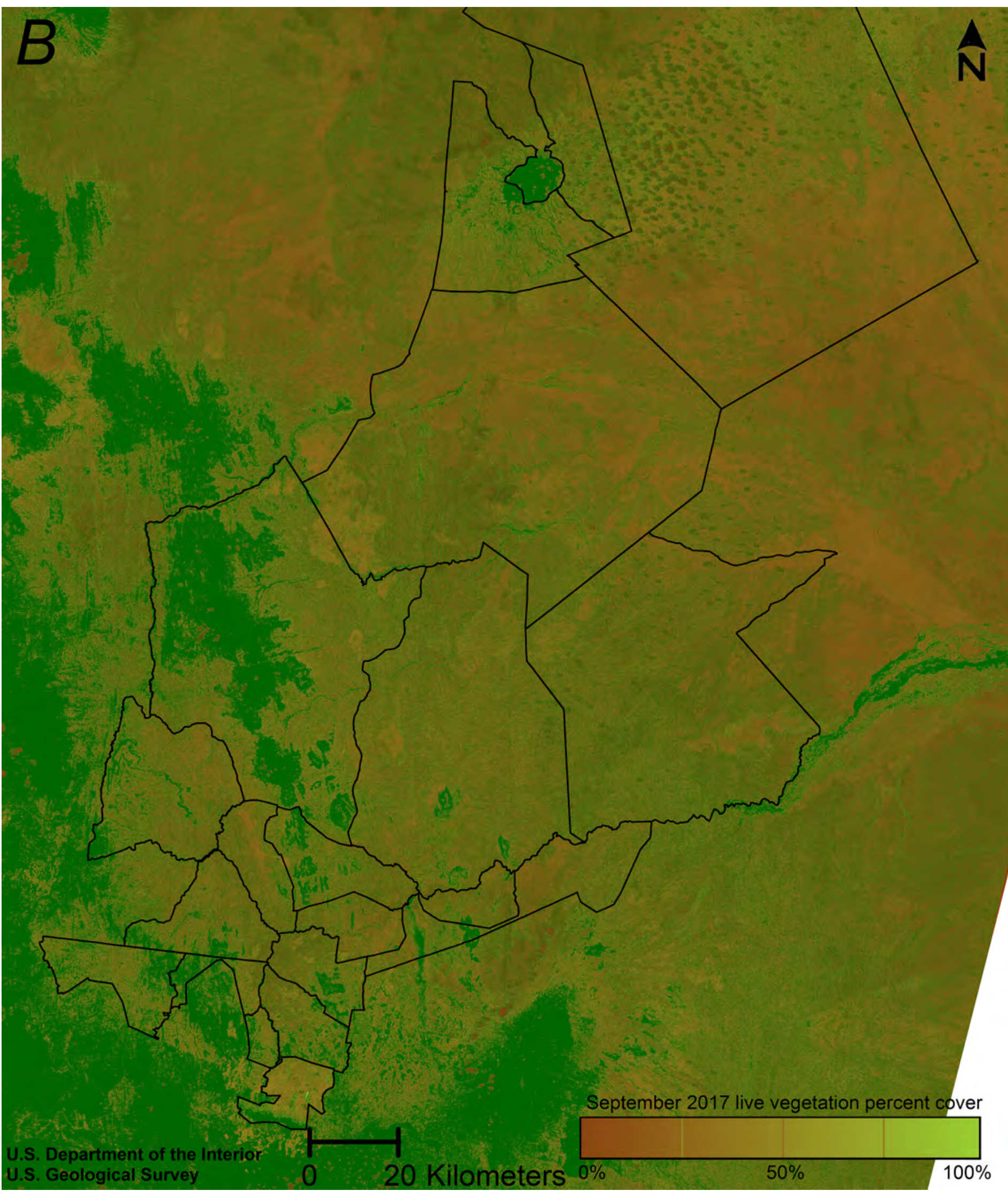

Figure 16. (A) September 2017 live vegetation map. (B) September 2017 live vegetation map with tree mask overlay (dark green). Some cloud contamination apparent in the NE. High resolution files available from https://doi.org/10.3133/ofr20191037.—Continued 


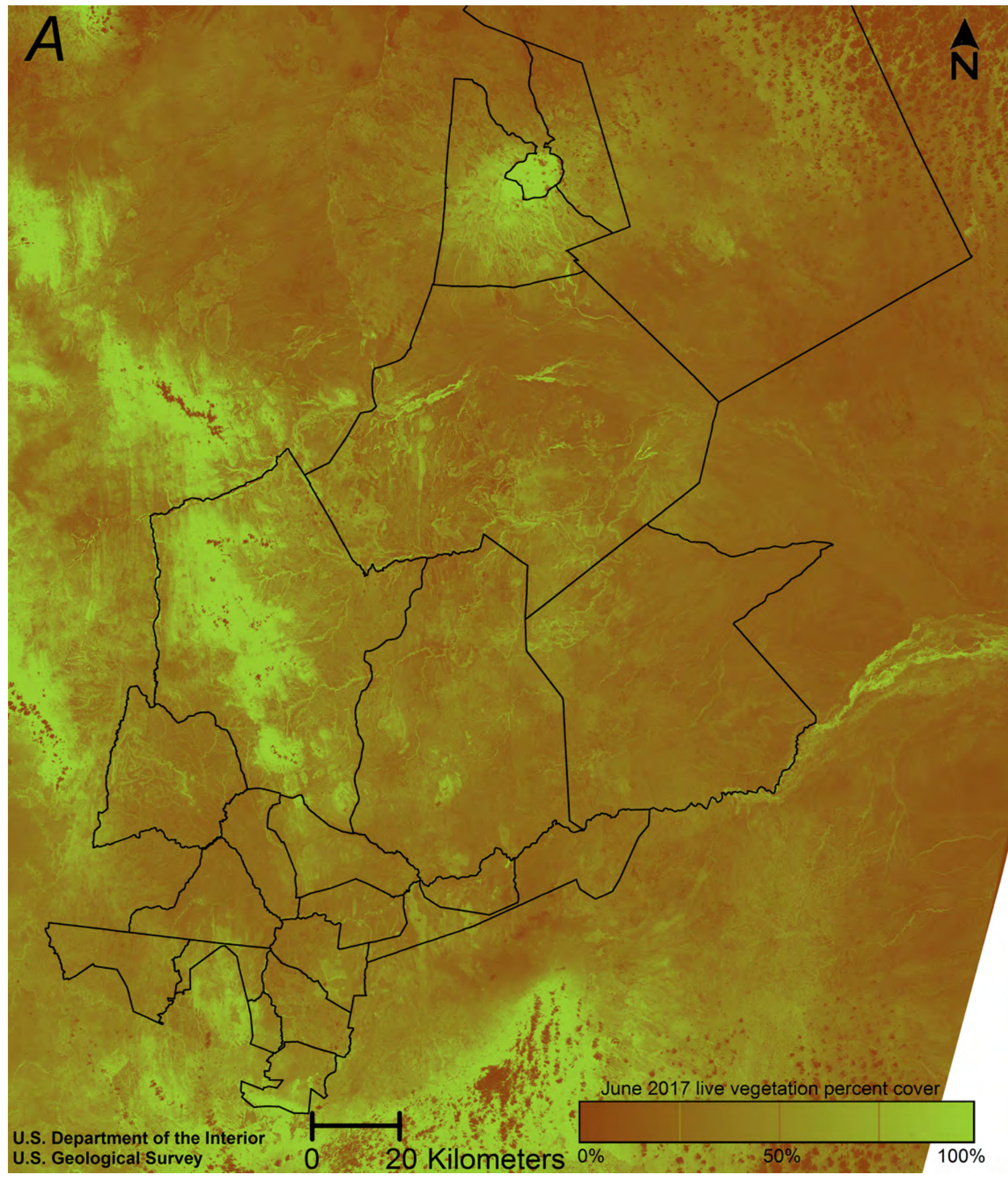

Figure 17. (A) June 2017 live vegetation cover proportion map. (B) June 2017 live vegetation cover map with tree mask overlay (dark green). Some cloud contamination apparent in the NE. High resolution files available from https://doi.org/10.3133/ofr20191037. 


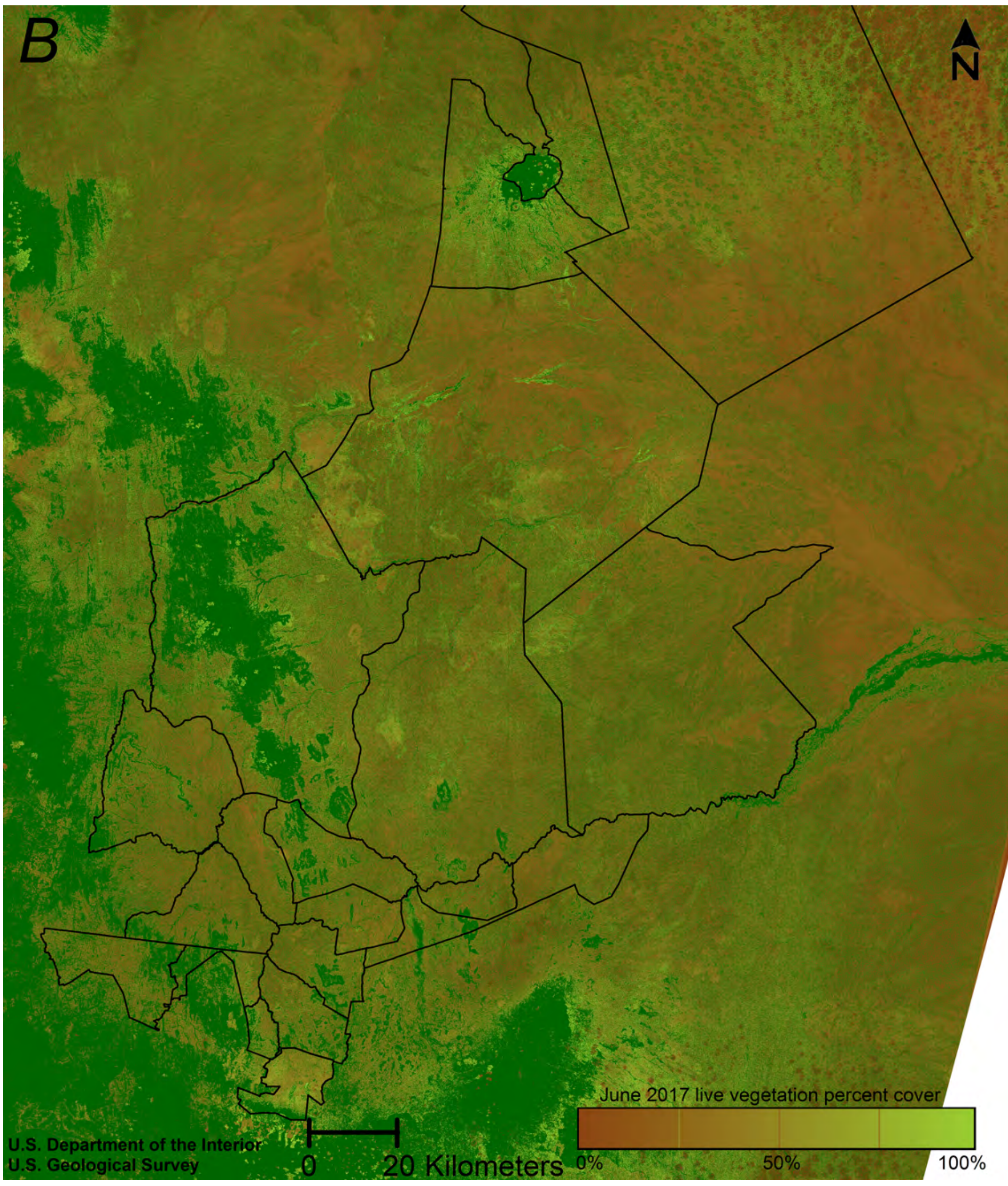

Figure 17. (A) June 2017 live vegetation cover proportion map. (B) June 2017 live vegetation cover map with tree mask overlay (dark green). Some cloud contamination apparent in the NE. High resolution files available from https://doi.org/10.3133/ofr20191037.—Continued 


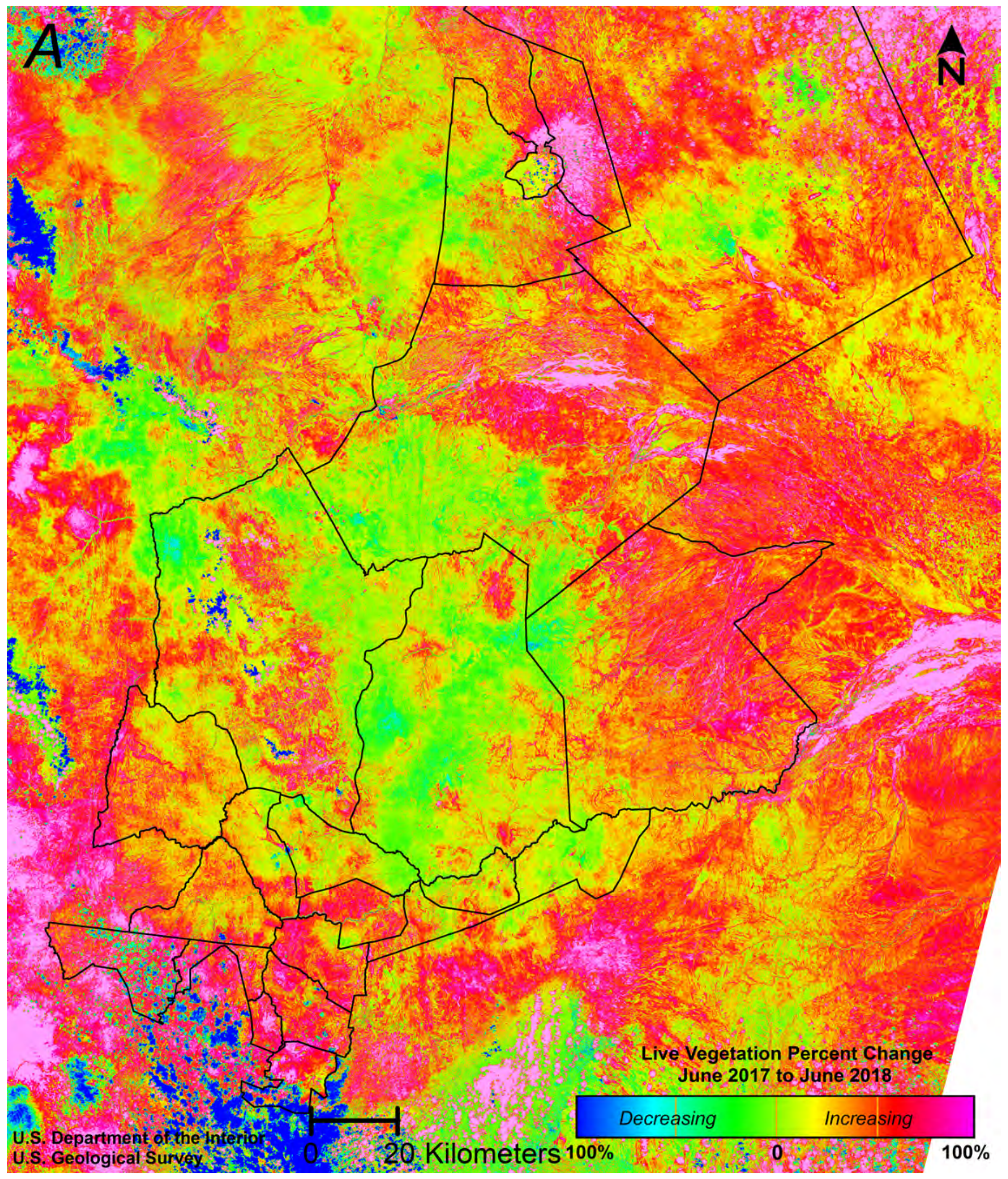

Figure 18. (A) June 2017 to June 2018 live vegetation cover proportion change map. $(B)$ Live cover map with tree mask overlay (dark green). High resolution files available from https://doi.org/10.3133/ofr20191037. 


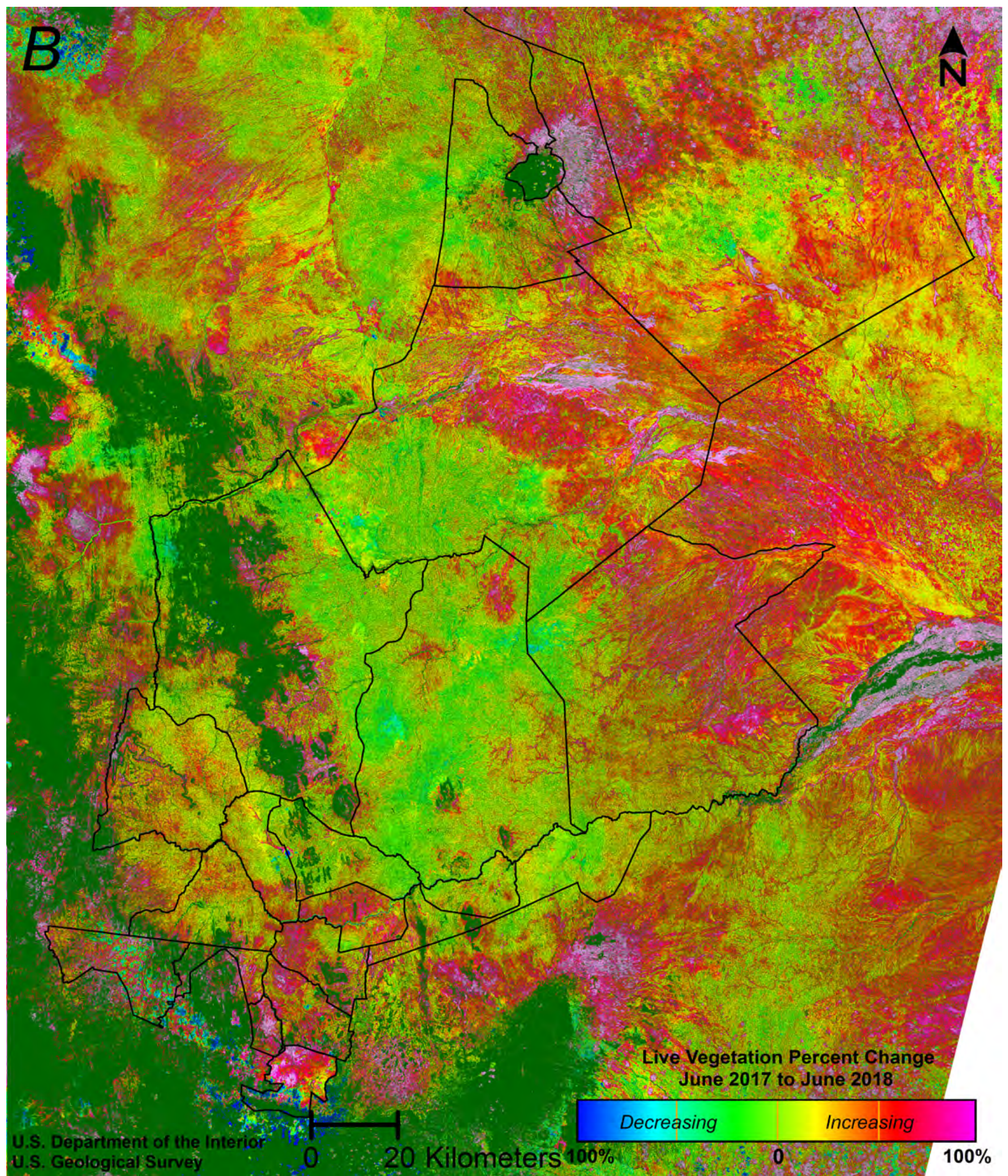

Figure 18. (A) June 2017 to June 2018 live vegetation cover proportion change map. (B) Live cover map with tree mask overlay (dark green). High resolution files available from https://doi.org/10.3133/ofr20191037.—Continued 


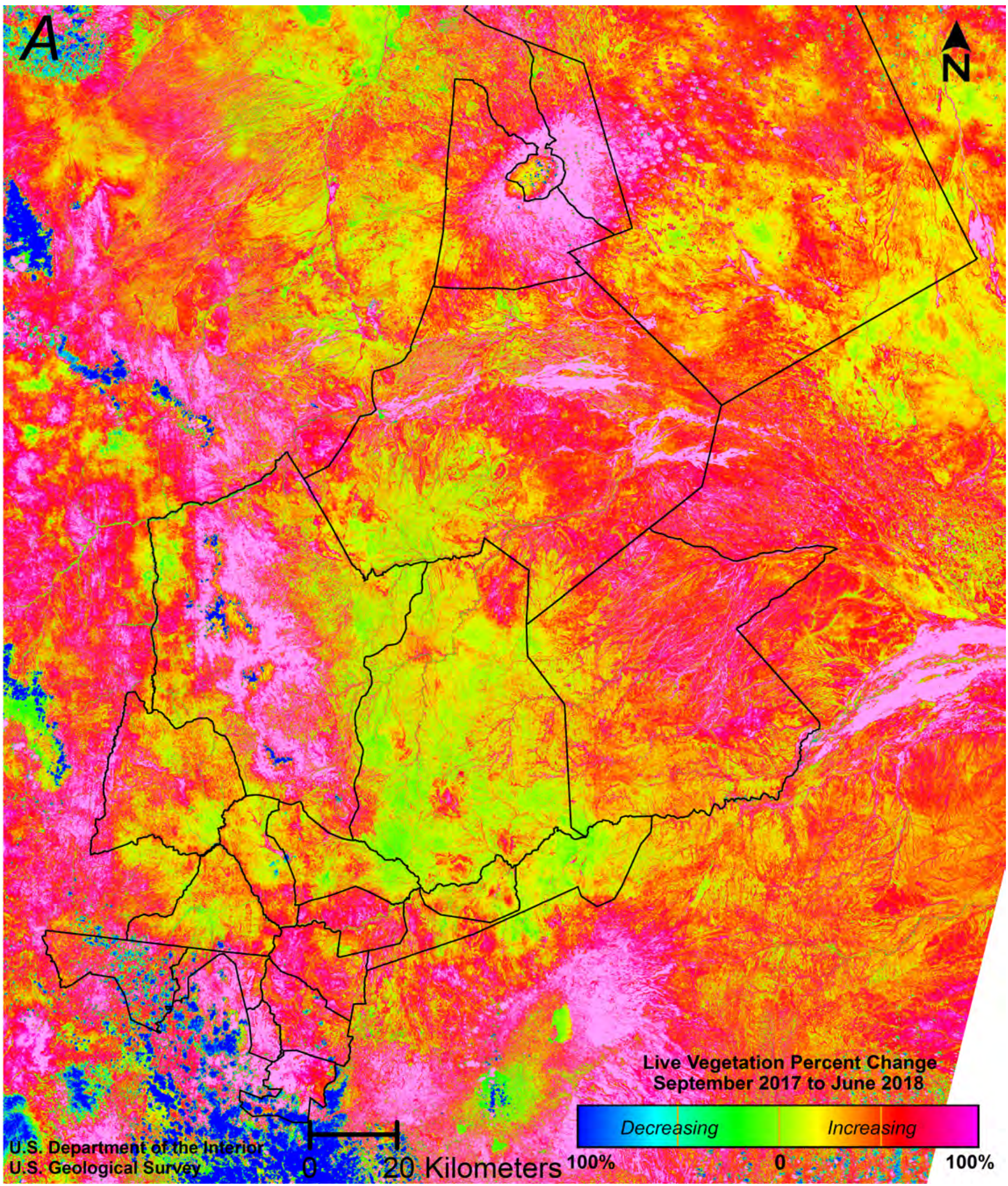

Figure 19. (A) September 2017 to June 2018 live vegetation cover proportion change map. (B) Live cover maps with tree mask overlay (dark green). High resolution files available from https://doi.org/10.3133/ofr20191037. 


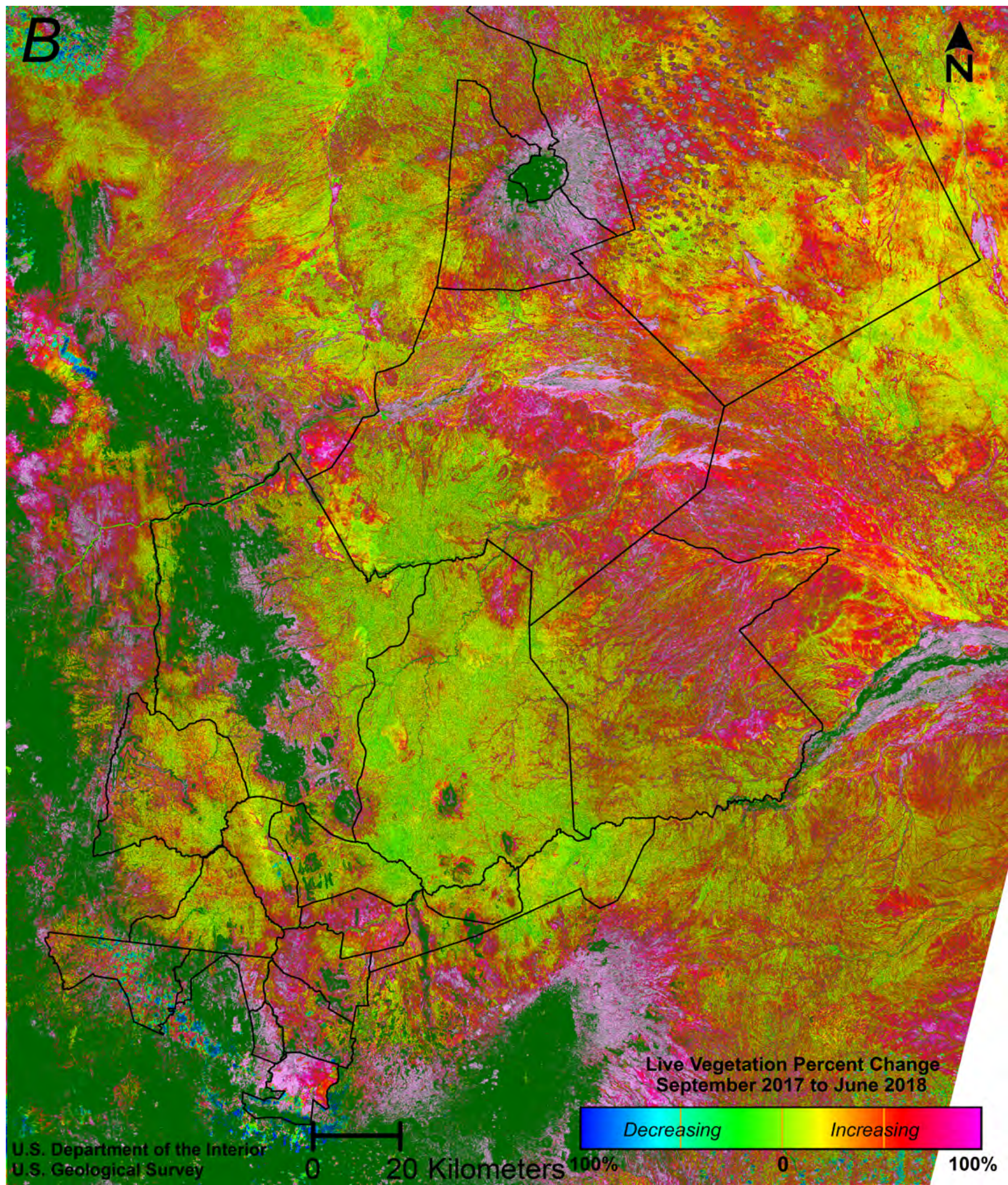

Figure 19. (A) September 2017 to June 2018 live vegetation cover proportion change map. (B) Live cover maps with tree mask overlay (dark green). High resolution files available from https://doi.org/10.3133/ofr20191037.—Continued 


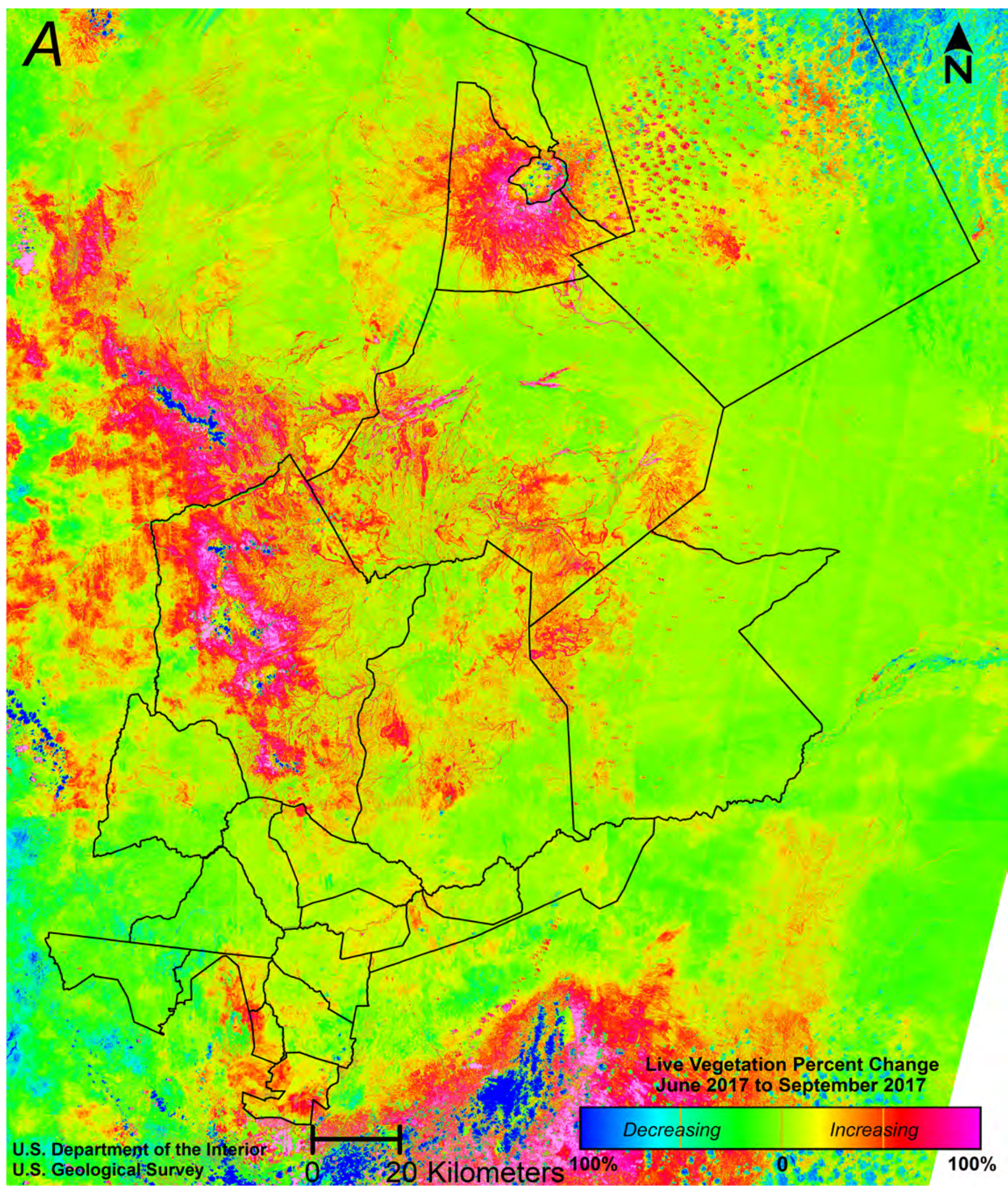

Figure 20. (A) June 2017 to September 2017 live vegetation cover proportion change map. (B) Live vegetation change map with tree mask overlay (dark green). High resolution files available from https://doi.org/10.3133/ofr20191037. 


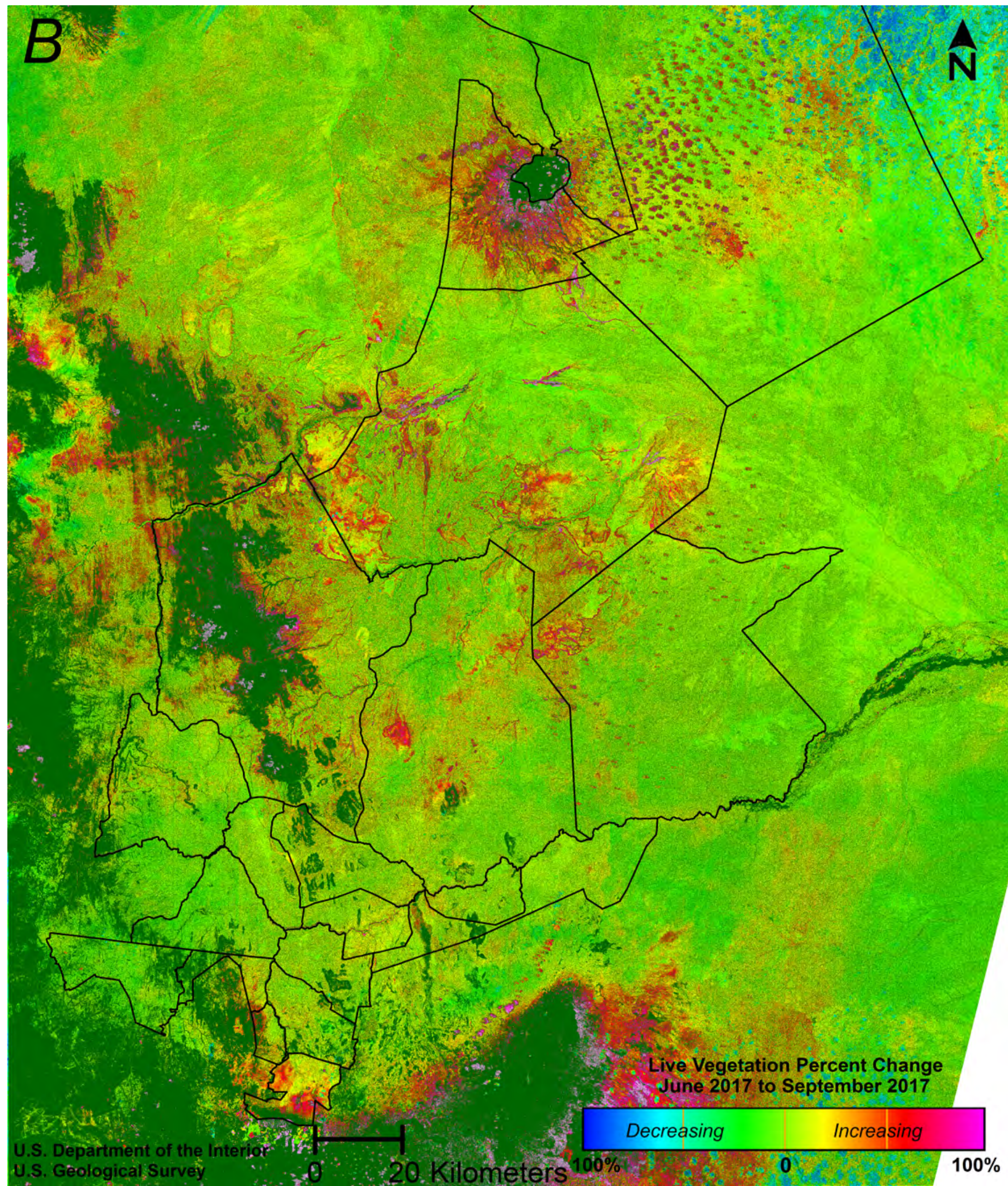

Figure 20. (A) June 2017 to September 2017 live vegetation cover proportion change map. (B) Live vegetation change map with tree mask overlay (dark green). High resolution files available from https://doi.org/10.3133/ofr20191037.—Continued 


\section{Site-Specific Comparisons of the Live Vegetation Maps}

To facilitate interpretation of the map sets, multiple examples were created covering small $(<5$-kilometer $[\mathrm{km}]$ maximum extent) to large (approximate $40-\mathrm{km}$ extent) areas to demonstrate how the live vegetation cover proportion and tree mask capture the complexity and detail of the landscape. The first example demonstrates the template used to showcase the live vegetation cover proportion status followed by the change map products.

\section{Nakuprat-Gotu Conservancy and Buffalo Springs National Reserve}

Figures 21 and 25 showcase a varied live vegetation landscape within a small area straddling the Nakuprat-Gotu Conservancy and Buffalo Springs National Reserve including observation sites along the $\mathrm{A} 2$ highway ( $2 \mathrm{~A}$ and $2 \mathrm{~B}$ and $3 \mathrm{~A}$ and 3B observation sites). Figure $21 A$ captures the June 2018 high live vegetation percent cover (yellow-green). Not only is there high live percent cover, light brown dominates the background, reflecting a low but substantial live vegetation cover.

A reasonable reference for comparison is provided from a 6 June 2016 GE map (fig. 21B). This is some of the best quality and most recent GE photography available for core-NRT.

The GE image shown in figure $21 B$ points to the cause of bright patches on figure $21 \mathrm{~A}$. Higher tree densities shown on the GE image reflect brighter as exhibited by yellow-green, whereas somewhat more scattered occurrences are associated with more diffuse yellow-green mixed with brown areas (fig. 21A). Other noticeable features are also common in the live cover and GE images. Starting at A2 highway just west of graphic reference 5 shown on figures $21 A$ and $21 B$ is a horseshoe feature shown as darker brown on the live cover image and lighter brown on the GE image that curves around references S2 and S3 ending at graphic reference 6 . The feature's color on both images indicates very low live vegetation cover. Similarly, running along the south side of the southeast-trending riparian channel appears a stretch of darker brown in the live cover and bright in the GE image. Other common distinct features are referenced in figures $21 A$ and $B$. Even though the GE image is from 2016 and reflects a much drier period than 2018, these features and many other patterns in the live vegetation cover proportion map are directly interpretable as specific features on the landscape.

Overlay of the September 2017 tree mask dramatically transforms the June 2018 live vegetation cover proportion map and enhances not only its interpretability but also its information content (fig. 22). Patterns in the map are confirmed as tree stands, and other patterns emerge that clarify associations and reveal subtle landscape features. One noticeable association is between the tree mask and high live vegetation cover proportions surrounding the evergreen stands of September 2017. The association basically enlarges and, in many cases unifies, the more scattered 2017 stands. This expansion surrounding the September 2017 tree mask suggests that the surrounding vegetation, while largely dormant in September 2017, responds rapidly and intensely to wetter conditions.
In addition to the high live cover expansion surrounding the tree mask observed in June 2018, the 2017 tree mask revealed a pattern not observed in the June 2018 live cover map (fig. 22, graphic references $7 \mathrm{a}$ and $7 \mathrm{~b}$ ): a subtle linear feature, possibly shrubs (fig. $21 B$ ). Even within the overall high June 2018 live vegetation cover, the implemented tree identifier captured subtle spatial variations of live cover, possibly revealing a minor drainage channel.

Figures 23 and 24 show the September and June 2017 live vegetation classifications and tree overlays of the same area.

Other than a few well-defined areas of dense trees, the September 2017 map (fig. 23A) is nearly devoid of yellowgreen areas and is noticeably overall a darker brown than the June 2018 live vegetation cover proportion map (fig. 21A). Overlay of the tree map from September 2017 (fig. 23B) defines the brighter yellow-green areas as trees and shrubs and helps identify some subtle changes in brown shades traceable to more vivid patterns shown on the June 2018 live vegetation map (fig. 21A). The September 2017 map exhibits little live vegetation other than trees and possibly some shrubs.

The June 2017 live vegetation cover proportion map (figs. 24A and 24B) has an overall slightly lighter brown appearance than that of September 2017. Although overall much darker than the June 2018 map, some live cover patterns on the June 2017 map mirror those clearly visible on the June 2018 map. The live cover in June 2017, while clearly much lower than in June 2018, is overall a bit higher than in September 2017 in this area.

Figures $25 \mathrm{~A}$ and $25 \mathrm{~B}$ illustrate the change in live vegetation cover proportion between September 2017 and June 2018. The increase in live cover is dramatic even when excluding the trees. The change in live cover between September 2017 and June 2018 was 50 to 75 percent over much of the study area. Other than areas of trees, areas depicting light yellow-greens form a moderately extensive secondary cover signifying little change. Notable are high live cover changes even within the trees, such as at observation sites S2 and S3. It is possible that ground cover is contributing to the live vegetation within more open tree canopies, resulting in the apparent change, or the change is related directly to the live leaf biomass of the tree stands.

The overall live vegetation cover proportion difference between June 2017 and September 2017 is relatively low (figs. 26A and 26B). Other than yellows primarily associated with trees and a notable broad north-south-trending feature in the eastern part of the map, the greens dominating the area depict a fairly neutral live vegetation landscape.

Given the small change in live vegetation cover proportion between June 2017 and September 2017 and the large change from September 2017 to June 2018, the dramatic increase from June 2017 to June 2018 was expected (figs. $27 \mathrm{~A}$ and $27 B$ ). The primary difference between the September 2017 to June 2018 and the June 2017 to June 2018 changes is the increase in yellow signifying a difference magnitude slightly less than that from September 2017 to June 2018. Even though most likely not apparent from visual ground observations, the proportion of live cover was slightly higher in June 2017 than in September 2017. 

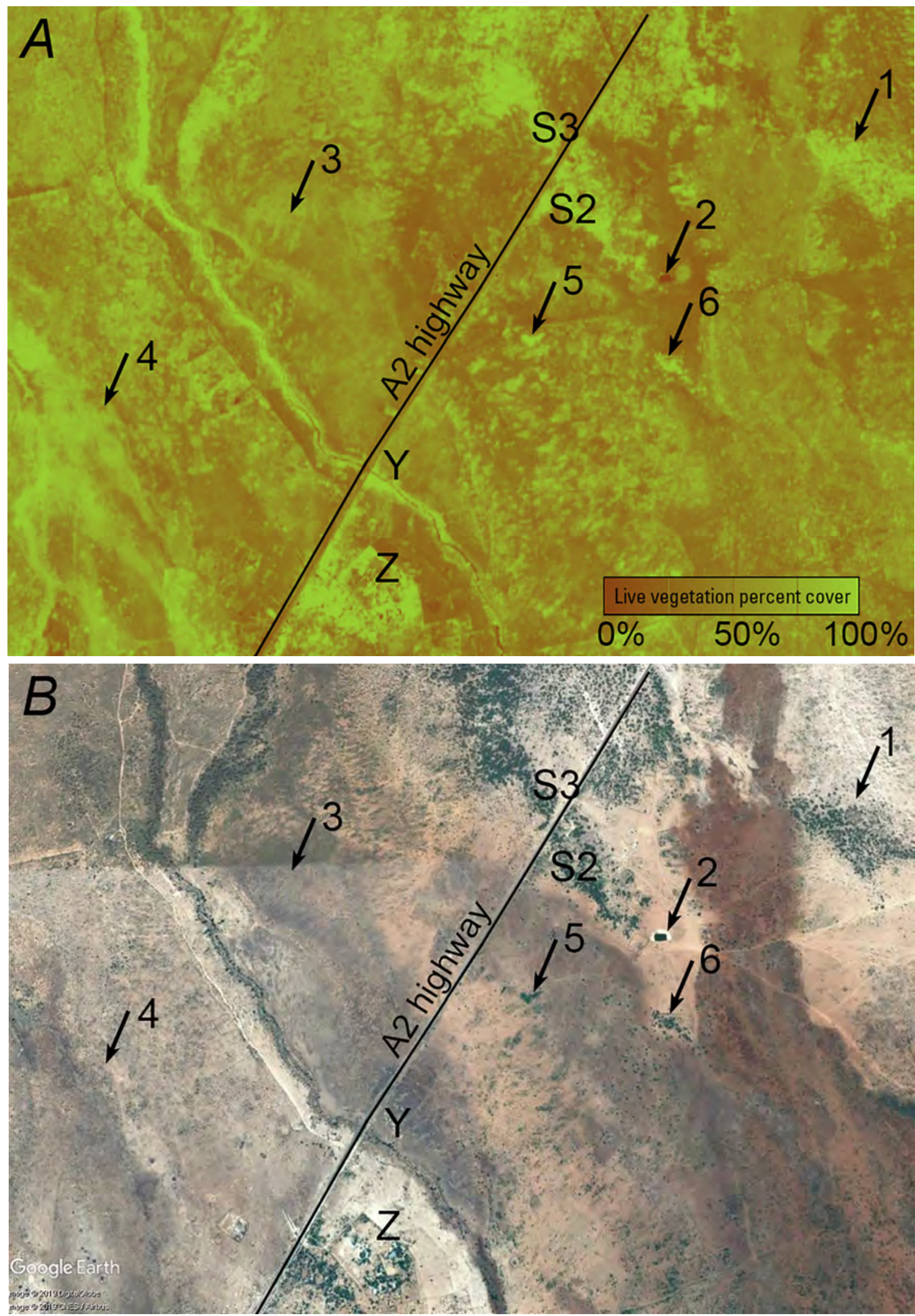

Figure 21. Nakuprat-Gotu Conservancy and Buffalo Springs National Reserve. (A) June 2018 live vegetation cover proportion [approximate frame center $37 \mathrm{~d} 39^{\prime} 12.1388^{\prime \prime} \mathrm{E}, 0 \mathrm{~d} 31^{\prime} 13.38588^{\prime \prime} \mathrm{N}$, approximately $4 \mathrm{~km} \mathrm{~N}-\mathrm{S}$ and $5.8 \mathrm{~km} \mathrm{E-W]}$. The observation sites 2 (S2) and 3 (S3) along A2 highway locating stands of trees. The drainage channel and associated riparian vegetation crossing the A2 highway to the south $(\mathrm{Y})$ and just south of that the concentration of live cover surrounding a constructed site (Z) are clearly depicted in the 2018 live vegetation cover proportion classification. Other less obvious landscape features are referenced in the graphic by numbered arrows: 1, tree stand; 2 , water trough; 3 , local drainage; 4 , high live vegetation area; 5 and 6 , concentrations of trees. $(B)$ Google Earth image showing the same features on 6 June 2016. 


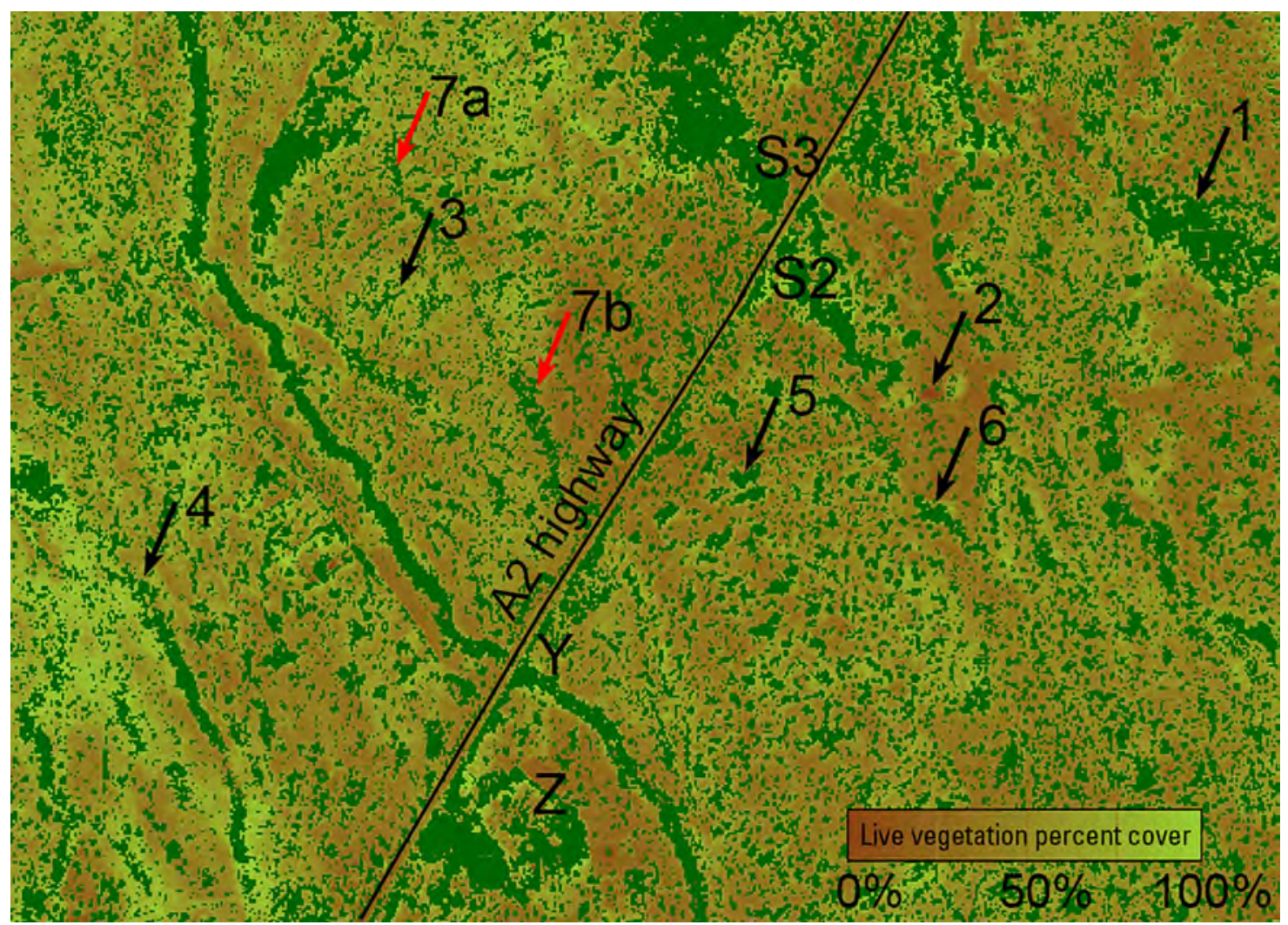

Figure 22. Nakuprat-Gotu Conservancy and Buffalo Springs National Reserve. June 2018 live vegetation cover proportion classification with the September 2017 tree mask overlain [approximate frame center $37 \mathrm{~d} 39^{\prime} 12.1388$ "E, $^{\circ} 0 \mathrm{~d} 31^{\prime} 13.3858$ "N, approximately $4 \mathrm{~km} \mathrm{~N}-\mathrm{S}$ and $5.8 \mathrm{~km} \mathrm{E-W]}$. The observation sites 2 (S2) and 3 (S3) along A2 highway locating stands of trees. The drainage channel and associated riparian vegetation crossing the $A 2$ highway to the south $(\mathrm{Y})$ and just south of that the concentration of live vegetation surrounding a constructed site (Z) are clearly depicted in the June 2018 live vegetation cover classification. Other less obvious landscape features are referenced in the graphic by numbered arrows: 1 , tree stand; 2 , water trough; 3 , local drainage; 4 , high live vegetation area; 5 and 6 , concentrations of trees and bushes. The $7 \mathrm{a}$ and $7 \mathrm{~b}$ graphic reference arrows point out a linear landscape feature derived from the September 2017 tree mask not exhibited on the June 2018 live vegetation map (fig. 21A). 

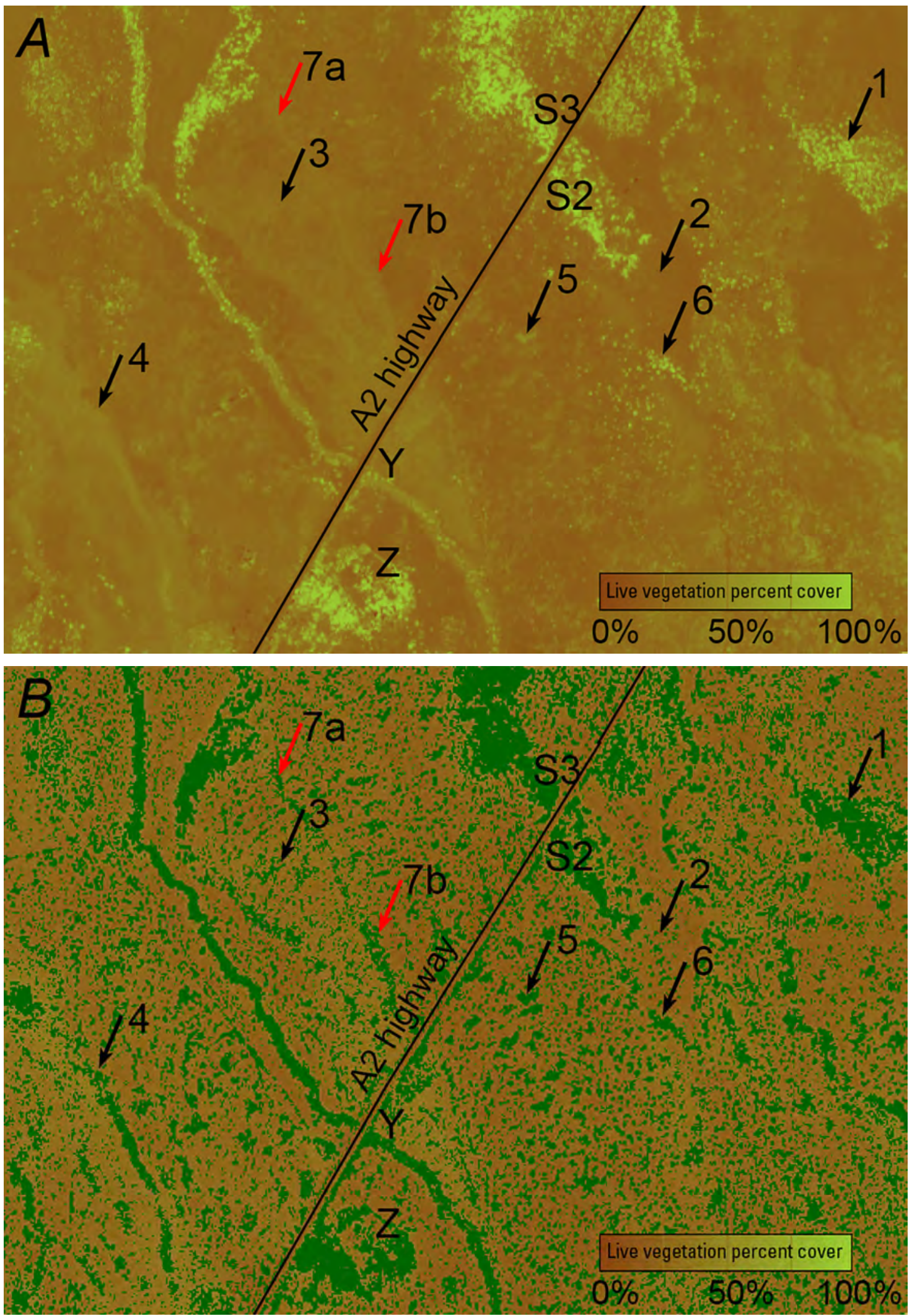

Figure 23. Nakuprat-Gotu Conservancy and Buffalo Springs National Reserve. September 2017 live vegetation cover proportion classification [approximate frame center $37 \mathrm{~d} 39^{\prime} 12.1388^{\prime \prime} \mathrm{E}, 0 \mathrm{~d} 31^{\prime} 13.3858^{\prime \prime} \mathrm{N}$, approximately $4 \mathrm{~km} \mathrm{~N}-\mathrm{S}$ and $5.8 \mathrm{~km} \mathrm{E}-\mathrm{W}$ ]. The same features noted in figure 22 associated with the $(A)$ June 2018 live cover classification and $(B)$ September 2017 tree overlay are included in these graphics. 

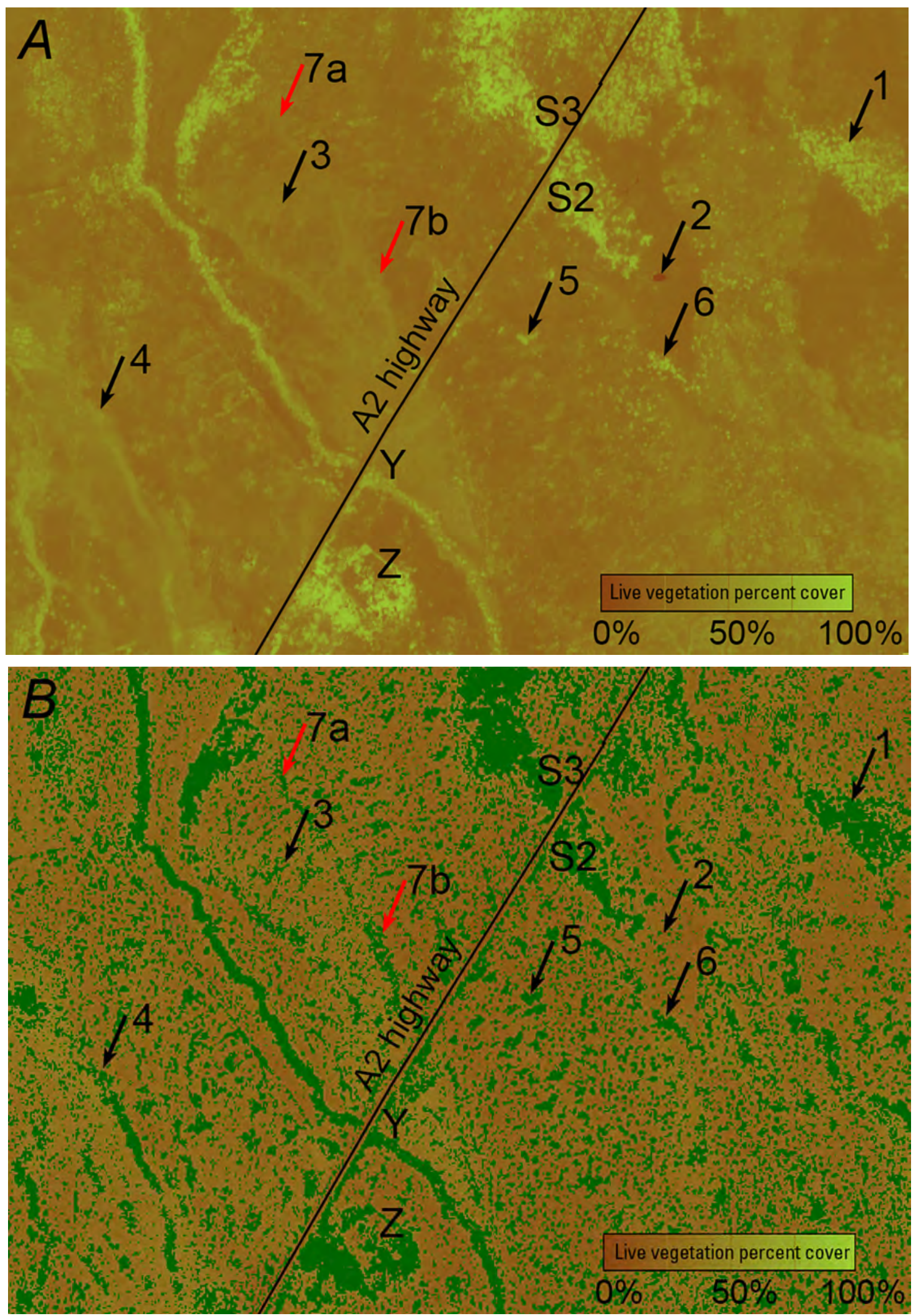

Figure 24. Nakuprat-Gotu Conservancy and Buffalo Springs National Reserve. June 2017 live vegetation cover proportion classification [approximate frame center $37 \mathrm{~d} 39^{\prime} 12.1388^{\prime \prime} \mathrm{E}, 0 \mathrm{~d} 31^{\prime} 13.3858^{\prime \prime} \mathrm{N}$, approximately $4 \mathrm{~km} \mathrm{~N}-\mathrm{S}$ and $5.8 \mathrm{~km} \mathrm{E-W]}$. The same features noted in figure 22 associated with the $(A)$ June 2018 live vegetation classification and $(B)$ September 2017 tree overlay are included in these graphics. 

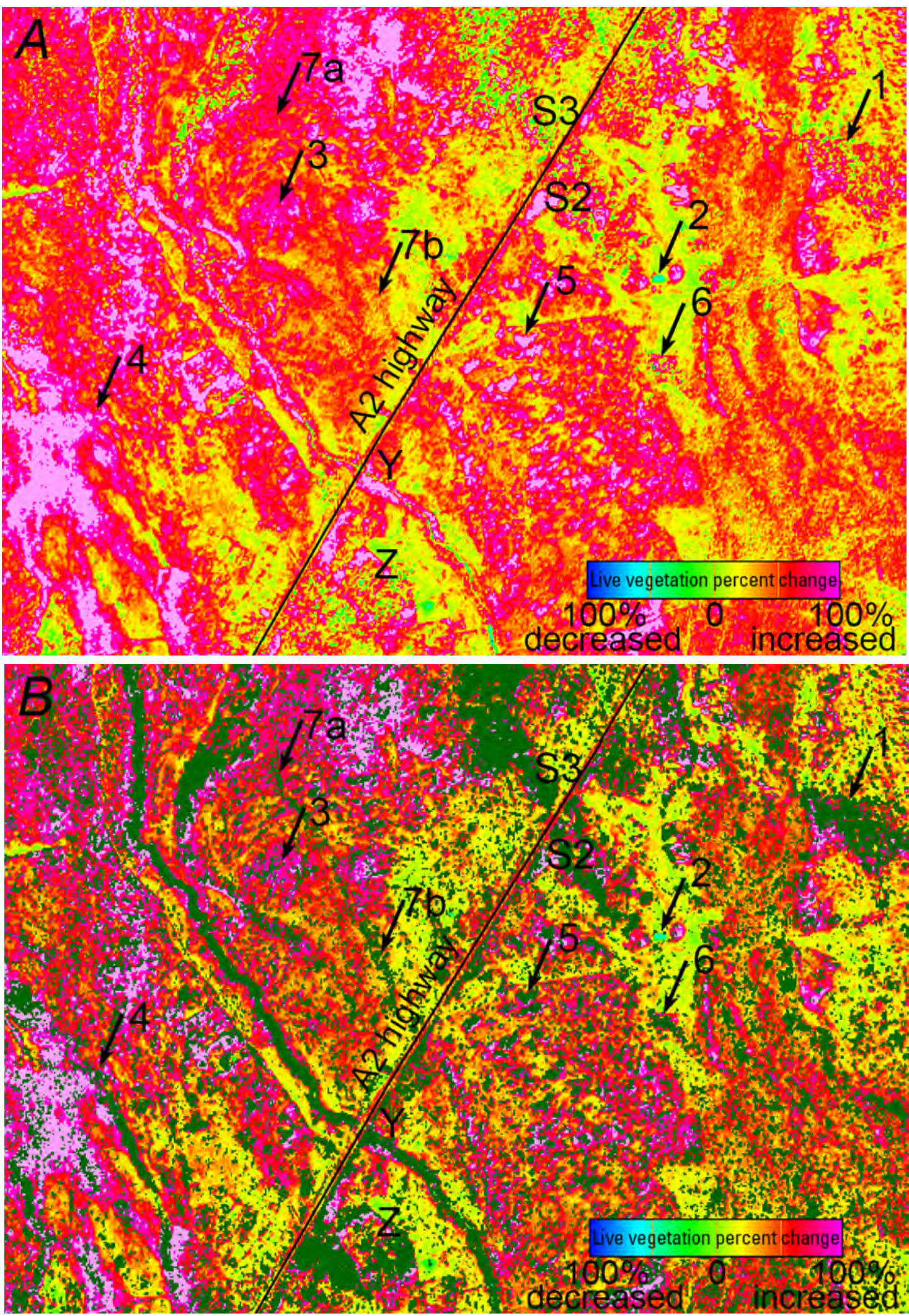

Figure 25. Nakuprat-Gotu Conservancy and Buffalo Springs National Reserve. Change in live vegetation cover proportion between $(A)$ September 2017 and June 2018 and $(B)$ September 2017 and June 2018 with September 2017 tree overlay [approximate frame center $37 \mathrm{~d} 39^{\prime} 12.1388^{\prime \prime} \mathrm{E}, 0 \mathrm{~d} 31^{\prime} 13.3858^{\prime \prime} \mathrm{N}$, approximately $4 \mathrm{~km} \mathrm{~N}-\mathrm{S}$ and $5.8 \mathrm{~km} \mathrm{E-W]}$. The annotated features are explained in figure 22. 

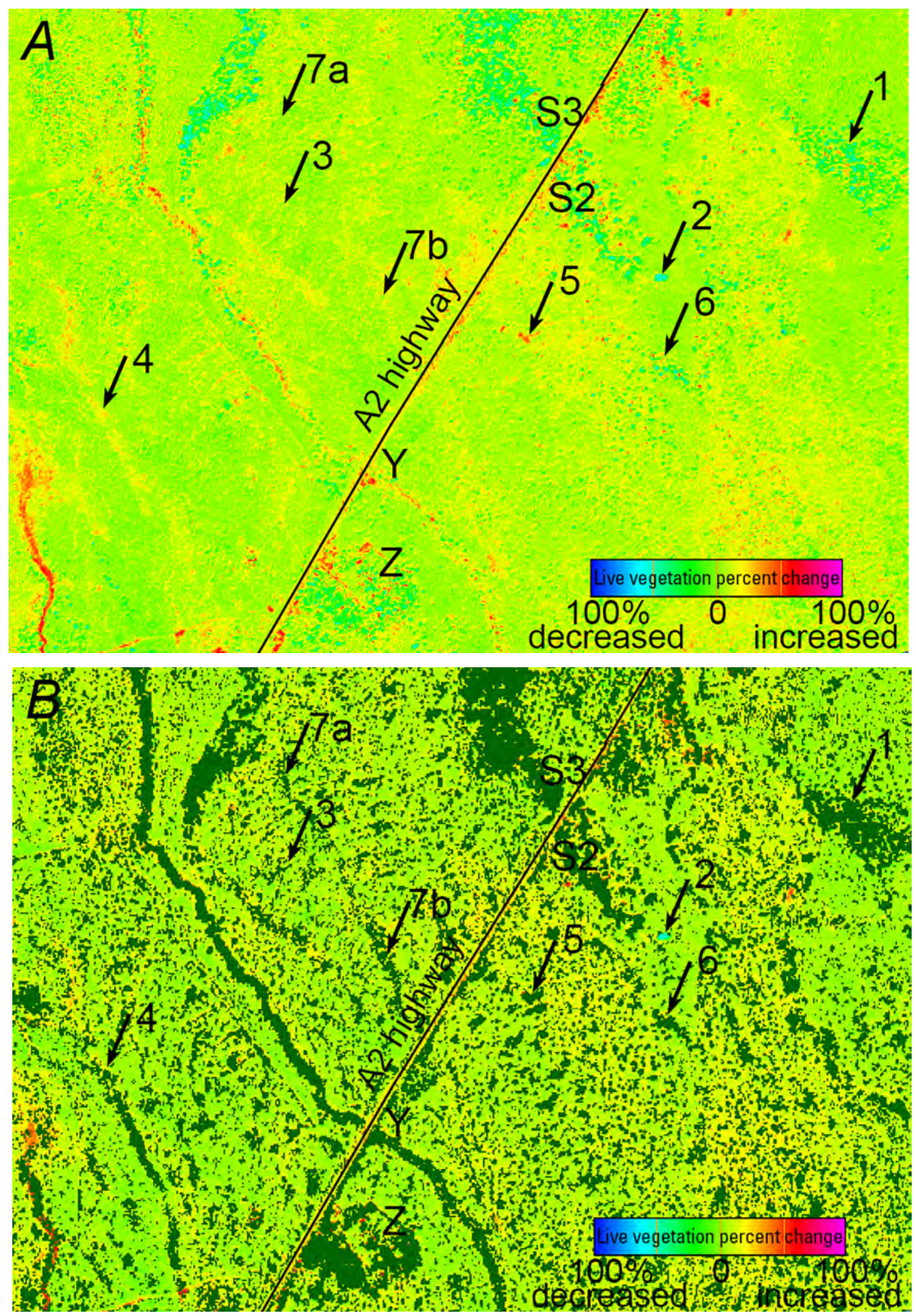

Figure 26. Nakuprat-Gotu Conservancy and Buffalo Springs National Reserve. Change in live vegetation cover proportion between $(A)$ June 2017 and September 2017 and $(B)$ June 2017 and September 2017 with September 2017 tree overlay [approximate frame center $37 \mathrm{~d} 39^{\prime} 12.1388^{\prime \prime} \mathrm{E}, 0 \mathrm{~d} 31^{\prime} 13.3858^{\prime \prime} \mathrm{N}$, approximately $4 \mathrm{~km} \mathrm{~N}-\mathrm{S}$ and $5.8 \mathrm{~km} \mathrm{E-W]}$. The annotated features are noted in figure 22. 

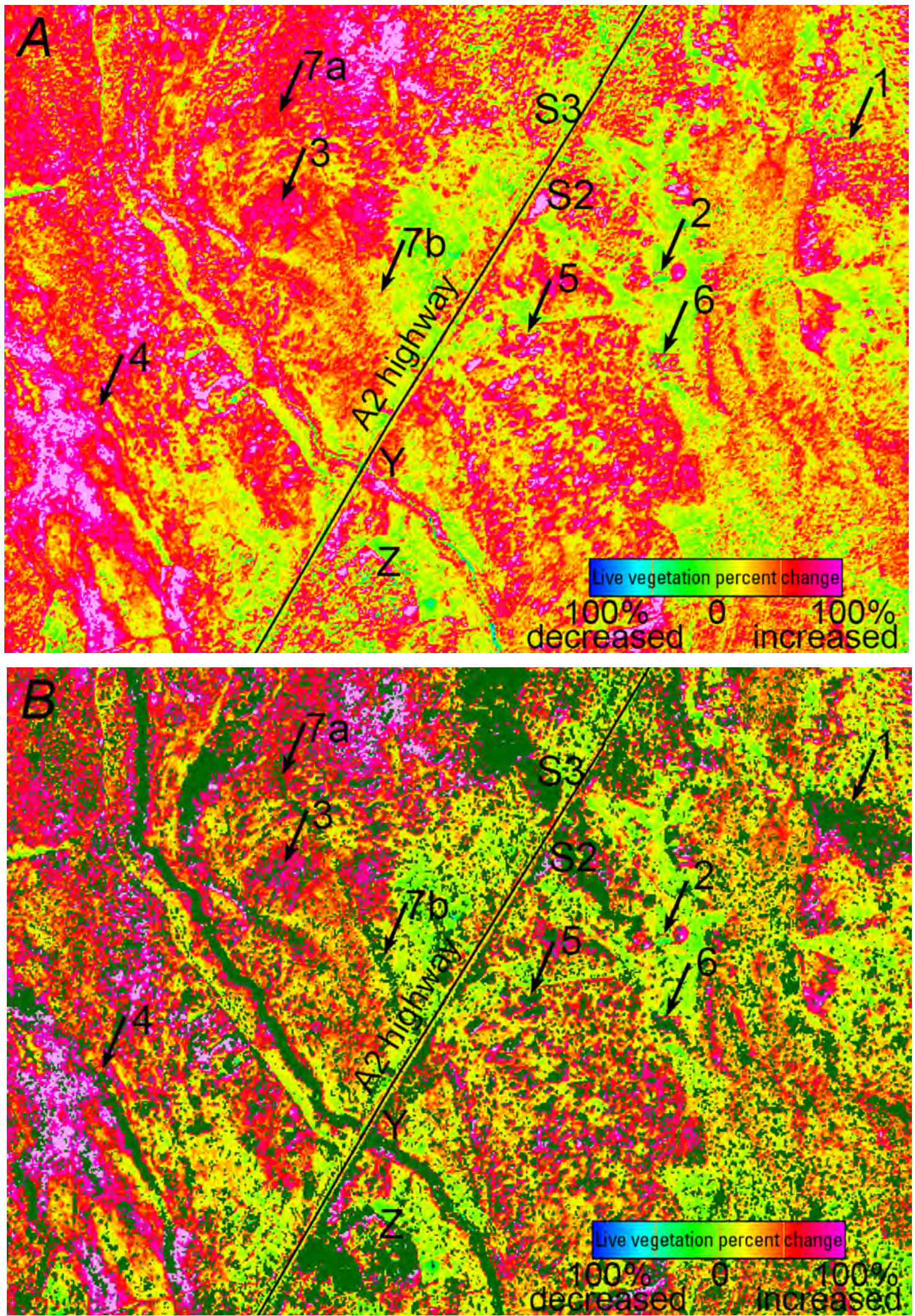

Figure 27. Nakuprat-Gotu Conservancy and Buffalo Springs National Reserve. $(A)$ Change in live vegetation cover proportion between June 2017 and June 2018. (B) June 2017 and June 2018 with September 2017 tree mask overlay [approximate frame center $37 \mathrm{~d} 39^{\prime} 12.1388^{\prime \prime} \mathrm{E}, 0 \mathrm{~d} 31^{\prime} 13.3858^{\prime \prime} \mathrm{N}$, approximately $4 \mathrm{~km} \mathrm{~N}-\mathrm{S}$ and $5.8 \mathrm{~km} \mathrm{E}-\mathrm{W}$. The annotated features are noted in figure 22. 


\section{Meibae Conservancy}

The Meibae Conservancy site-specific example area (figs. $28 A-28 F$ ) has a live vegetation cover proportion history somewhat like that of the Nakuprat-Gotu Conservancy and Buffalo Springs National Reserve. The foremost difference in this area is that the June 2018 live cover magnitude was lower than that of the June 2017 live cover magnitude. Another difference is the inclusion of small topographic peaks associated with increased live vegetation. The last difference is not related to the live cover mapping but to the independently created tree map. The notable feature of the tree mask depiction is its extremely fine detail. Not only riparian features but also very small fenced settlements are mapped throughout the area (fig. 28D). These were verified with GE.

Live vegetation cover proportion change maps depict little change from June 2017 to September 2017 and more change from September 2017 to June 2018 and likewise from June 2017 to June 2018 (figs. 29A to 29F). In this example though, change is a bit higher from June 2017 to June 2018 than from September 2017 to June 2018. Furthermore, outside the topographic highs, the region to the east of the major north-south river shows a higher magnitude of live cover change in September 2017 and June 2017 in comparison to June 2018. Some additional image or geographic information system (GIS) processing could be used to distinguish whether the differences from the west to the east side of the river are due to a June 2018 difference or to September and June 2017 differences.

\section{Nasuulu Conservancy-Southwest}

Figures $30 \mathrm{~A}$ to $30 \mathrm{~F}$ show a region in the southwest part of the Nasuulu Conservancy. The pattern of live vegetation cover proportion fits that of the Nakuprat-Gotu Conservancy and Buffalo Springs National Reserve-high proportions of live cover in June 2018 and much lower proportions in September and June 2017, but with proportions in June slightly higher than those in September. Compared to the change in live cover in the Meibae Conservancy (figs. 29E and 29F), the difference in live cover between June and September 2017 is higher in this region of the Nasuulu Conservancy.

Two arrows ( 1 and 2) labeled on figure 30 point to areas depicted on GE images as moderate to high density trees or shrubs that are not captured by the tree mapping. The live cover proportions fall below the threshold for dense tree stands and are not captured along drainage features within reference areas 1 and 2. The reason for this implied inconsistency is not apparent from the information available.
In addition, graphic reference 3 points to a seemingly black-topped airport runway. Although the runway should show zero live cover, the runway is mapped as low proportion vegetation cover. The approximate width of the runway is $12 \mathrm{~m}$, about the same as the $10-\mathrm{m}$ mapping spatial resolution. That narrowness and nonalignment of the runway with the mapping orientation means pixels covering the runway will contain some portion of runway and live vegetation. This scenario is the same for all features near the 10-m mapping spatial resolution.

Also, the changes of live cover proportion at dense tree or shrub stands located at arrows 1 and 2 differ (figs. $31 \mathrm{~A}$ and $31 E$ ). Forest 1 (reference arrow 1 ) displays only moderate change in both June and September 2017 as related to June 2018, whereas forest 2 shows high change. The reason for the difference is not provided by the mapping; however, the ability to detect these differences illustrates the added discrimination capability of change mapping applied to status maps at two or more time periods.

\section{Kalama Conservancy-Field Site 1}

Figures $32 A$ to $F$ depict a small region surrounding Kalama Conservancy site 1 . As in other example sites, the trend of the live vegetation maps is high in June 2018 and substantially lower in September and June 2017. At this site, however, the proportions of live vegetation are slightly higher than at other sites in September and June 2017.

Graphic reference arrow 1 on figure 32 points to an area of hummocky ground cover that does not look like trees or shrubs on GE. Graphic reference arrow 2 points out an area of scattered trees that is shown on a somewhat older GE image with a substantially higher tree density.

Although change in proportion of live cover remains high when compared to previous examples, changes are substantially lower between the September 2017 and June 2018 live vegetation levels (figs. $33 A$ and $B$ ). Although the area containing Kalama Conservancy site 1 shows moderate change, the live cover change is higher extending from the September 2017 tree mask covering a topographic feature to the west. The June to September 2017 change is higher than seen for all previous sites, with high proportions of change scattered throughout a fairly neutral background of little change. The June 2017 to June 2018 change throughout this area is substantially lower than seen in previous examples. The expansion of live vegetation cover surrounding the September 2017 tree map is also apparent on the June to September 2017 change map. 

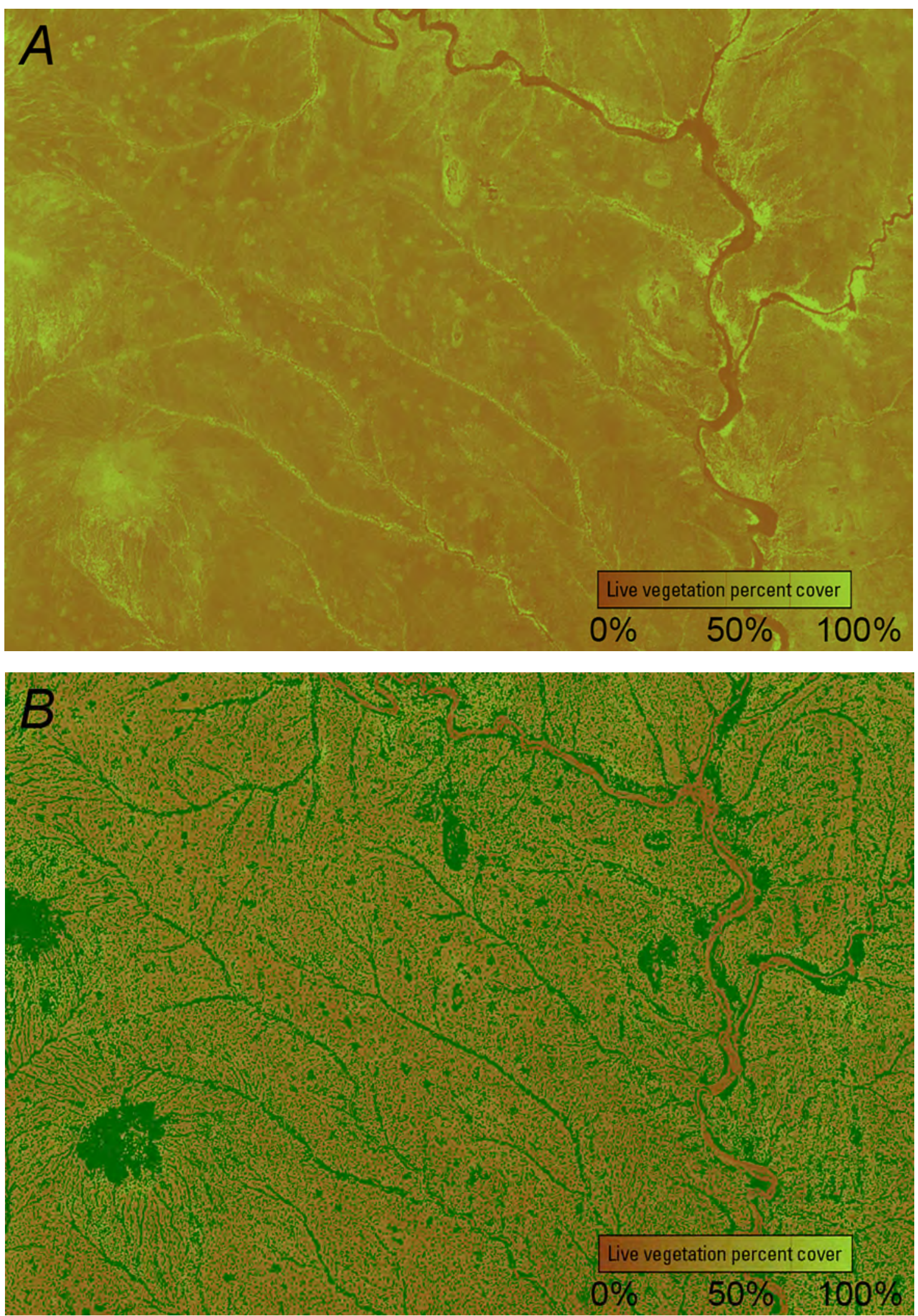

Figure 28. Meibae Conservancy. Live vegetation cover proportion classification and September 2017 tree mask overlay [approximate frame center $37 \mathrm{~d} 14^{\prime} 16.8178^{\prime \prime} \mathrm{E}, 0 \mathrm{~d} 50^{\prime} 15.0359^{\prime \prime} \mathrm{N}$, approximately $6.7 \mathrm{~km} \mathrm{~N}-\mathrm{S}$ and $9.6 \mathrm{~km} \mathrm{E-W]}$. $A$ and $B$, June 2018; $C$ and $D$, September 2017; and $E$ and $F$, June 2017. Arrows on $D$ point to small fenced settlements as identified on May 2011 Google Earth image. 

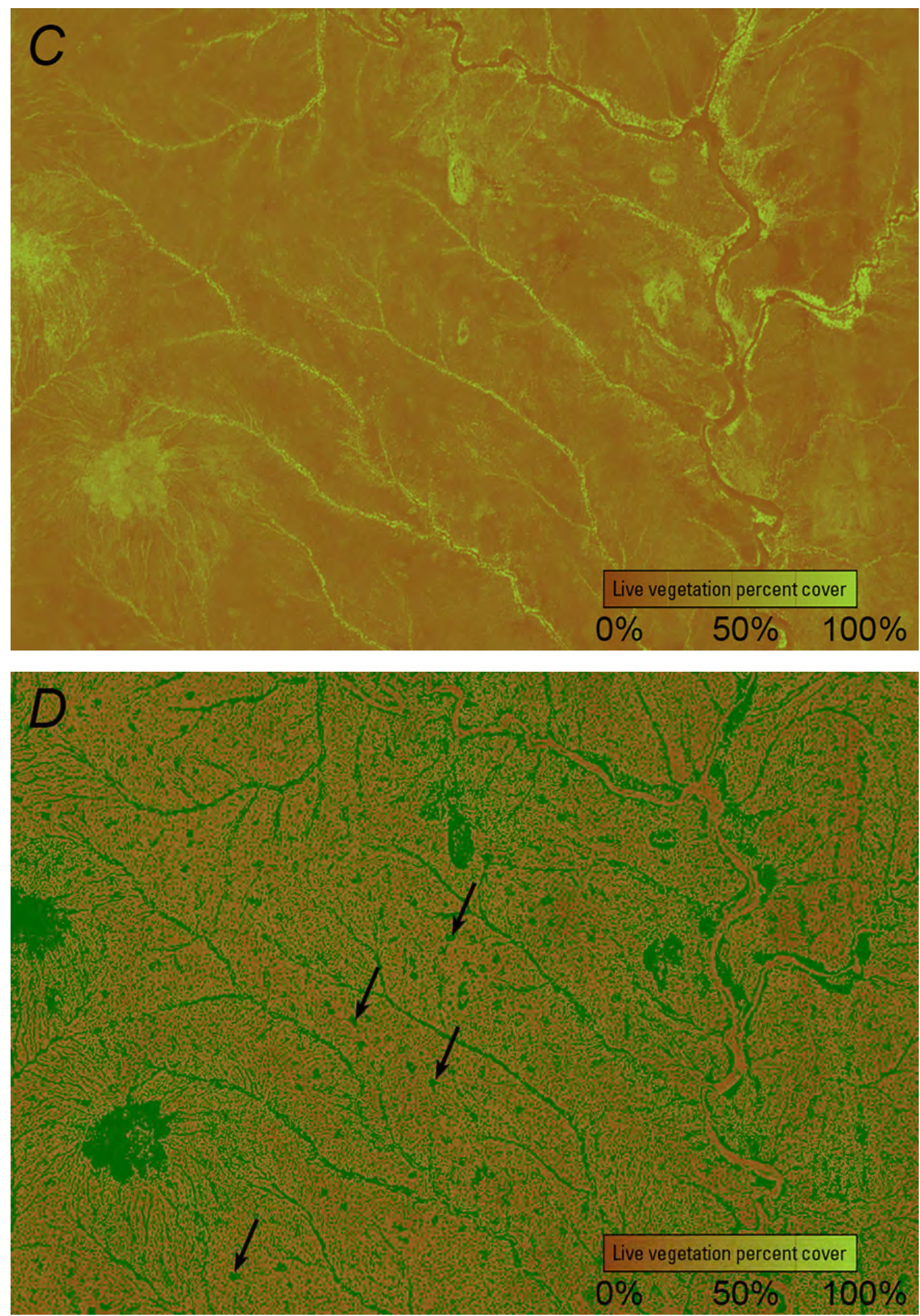

Figure 28. Meibae Conservancy. Live vegetation cover proportion classification and September 2017 tree mask overlay [approximate frame center $37 \mathrm{~d} 14^{\prime} 16.8178$ "E, $0 \mathrm{~d} 50^{\prime} 15.0359^{\prime \prime} \mathrm{N}$, approximately $6.7 \mathrm{~km} \mathrm{~N}-\mathrm{S}$ and $9.6 \mathrm{~km} \mathrm{E-W].} A$ and $B$, June 2018; $C$ and $D$, September 2017; and $E$ and $F$, June 2017. Arrows on $D$ point to small fenced settlements as identified on May 2011 Google Earth image._-Continued 

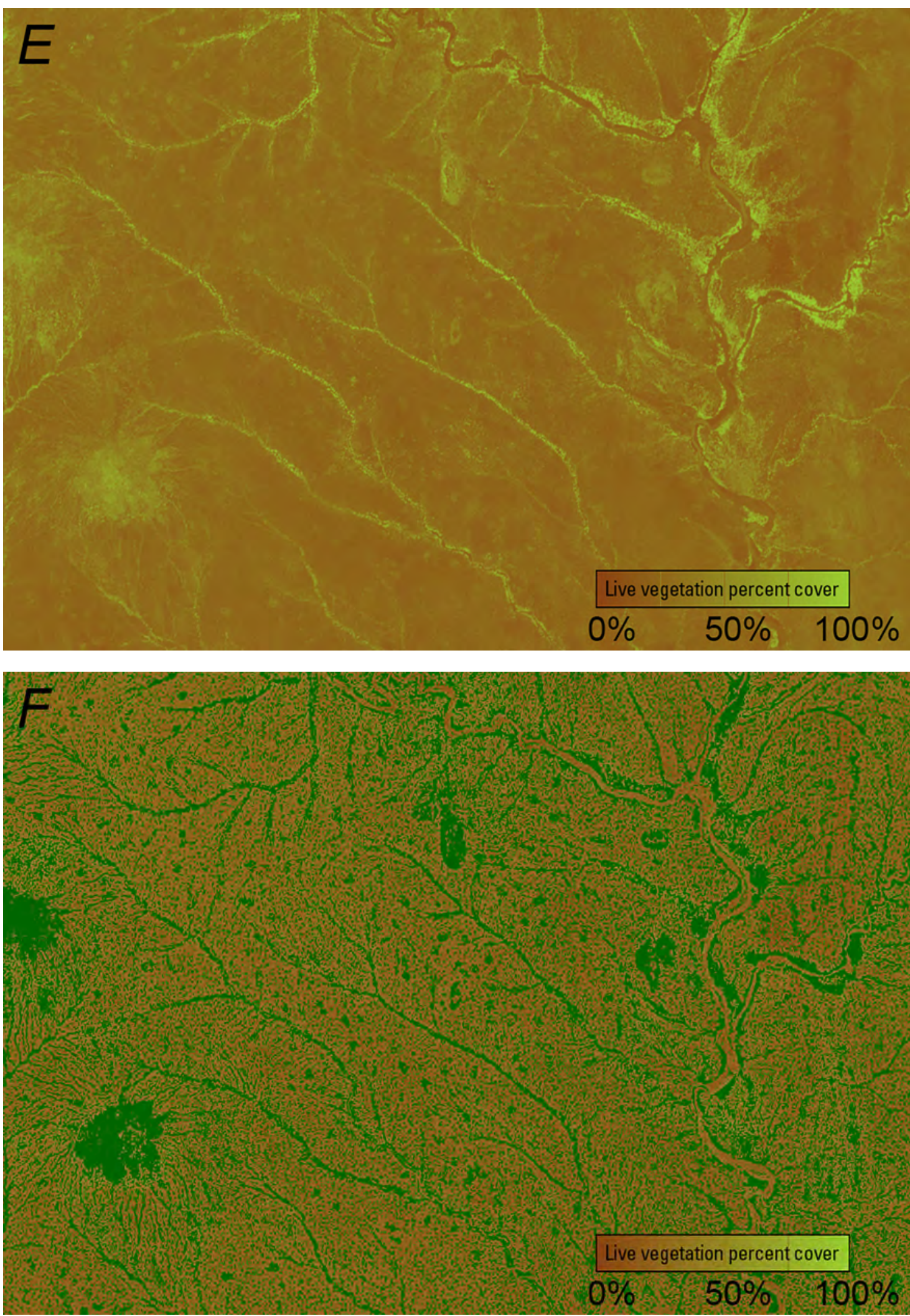

Figure 28. Meibae Conservancy. Live vegetation cover proportion classification and September 2017 tree mask overlay [approximate frame center $37 \mathrm{~d} 14^{\prime} 16.8178^{\prime \prime} \mathrm{E}, 0 \mathrm{~d} 50^{\prime} 15.0359^{\prime \prime} \mathrm{N}$, approximately $6.7 \mathrm{~km} \mathrm{~N}-\mathrm{S}$ and $9.6 \mathrm{~km} \mathrm{E-W].} A$ and $B$, June 2018; $C$ and $D$, September 2017; and $E$ and $F$, June 2017. Arrows on $D$ point to small fenced settlements as identified on May 2011 Google Earth image.-Continued 

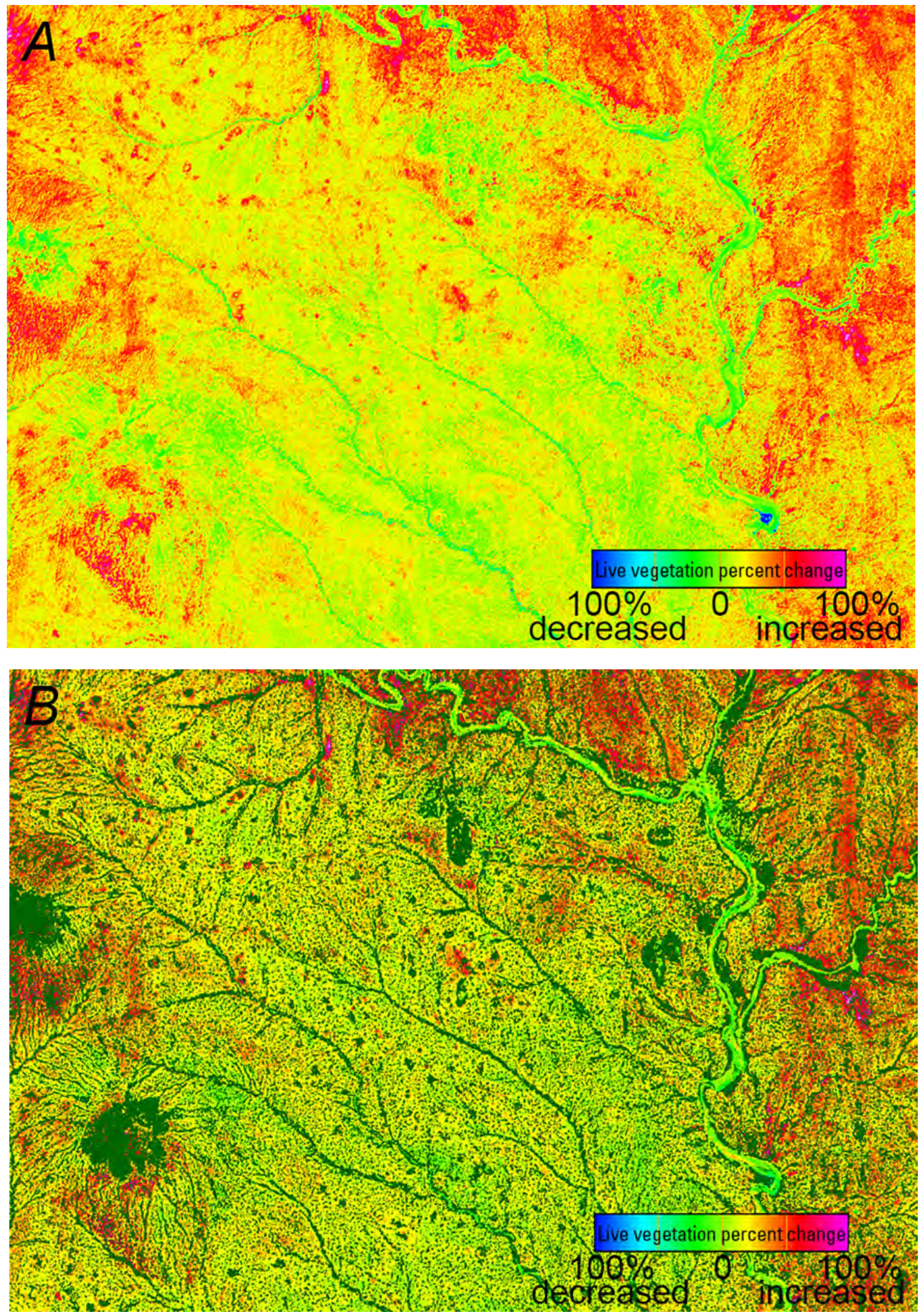

Figure 29. Meibae Conservancy. Live vegetation cover proportion change and September 2017 tree mask overlay [approximate frame center $37 \mathrm{~d} 14^{\prime} 16.8178^{\prime \prime} \mathrm{E}, 0 \mathrm{~d} 50^{\prime} 15.0359^{\prime \prime} \mathrm{N}$, approximately $6.7 \mathrm{~km} \mathrm{~N}-\mathrm{S}$ and $9.6 \mathrm{~km}$ $\mathrm{E}-\mathrm{W}$ ]. Change in live cover between $A$ and $B$, September 2017 and June 2018; $C$ and $D$, June 2017 and September 2017; and $E$ and $F$, June 2017 and June 2018. Arrows on $D$ point to small fenced settlements as identified on May 2011 Google Earth photography. 

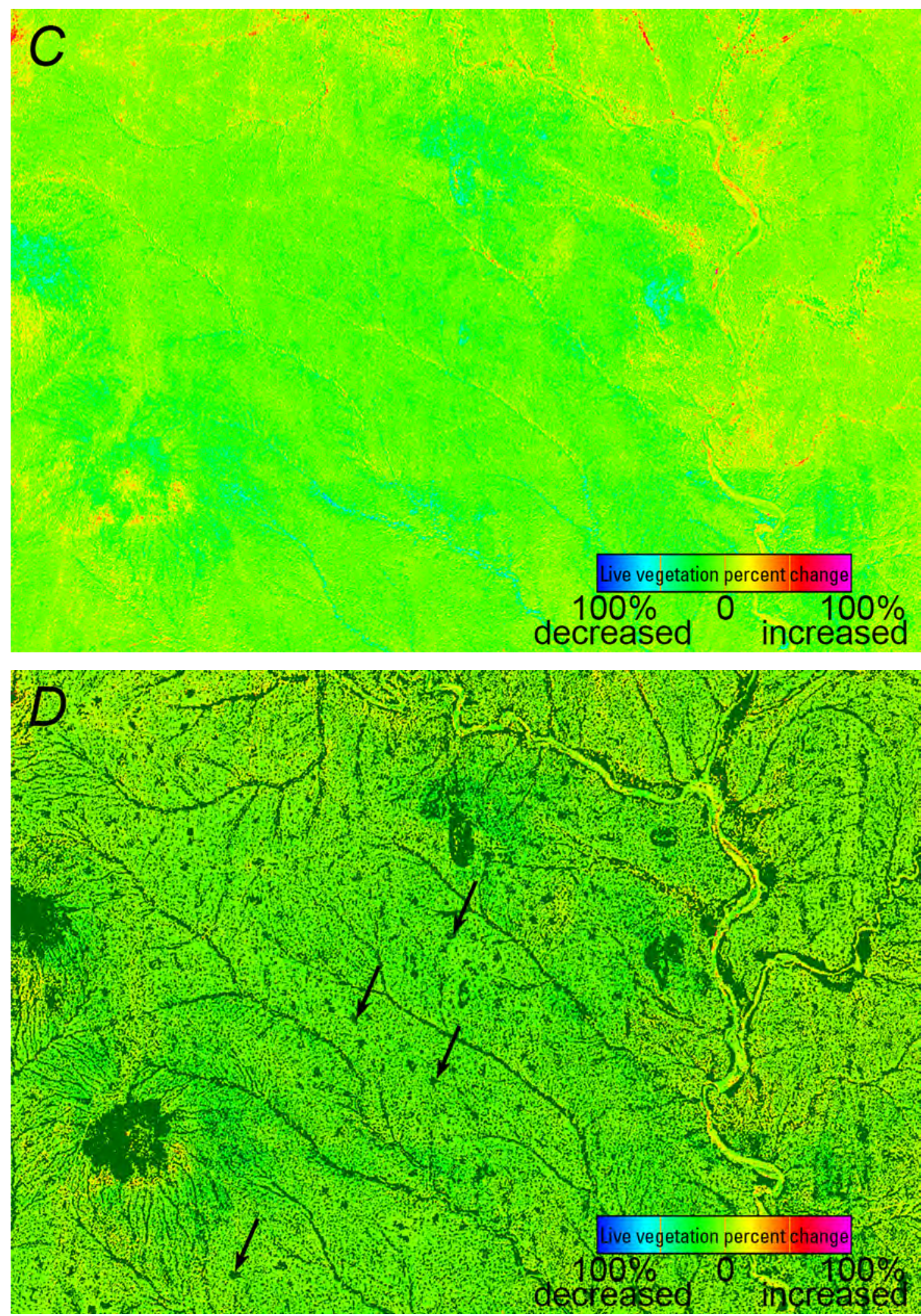

Figure 29. Meibae Conservancy. Live vegetation cover proportion change and September 2017 tree mask overlay [approximate frame center $37 \mathrm{~d} 14^{\prime} 16.8178^{\prime \prime} \mathrm{E}, 0 \mathrm{~d} 50^{\prime} 15.0359^{\prime \prime} \mathrm{N}$, approximately $6.7 \mathrm{~km} \mathrm{~N}-\mathrm{S}$ and $9.6 \mathrm{~km}$ E-W]. Change in live cover between $A$ and $B$, September 2017 and June 2018; $C$ and $D$, June 2017 and September 2017; and $E$ and $F$, June 2017 and June 2018. Arrows on $D$ point to small fenced settlements as identified on May 2011 Google Earth photography.-Continued 

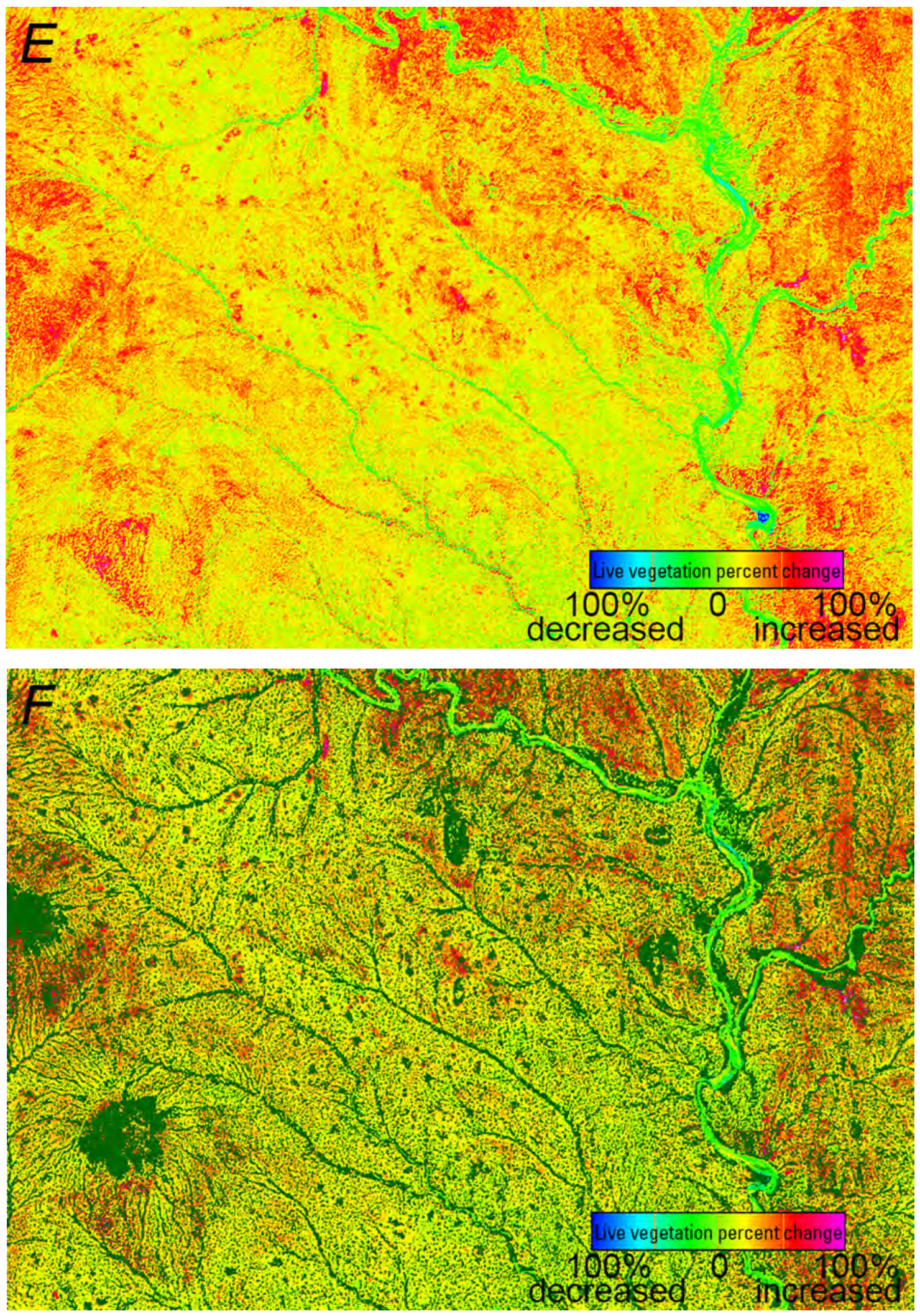

Figure 29. Meibae Conservancy. Live vegetation cover proportion change and September 2017 tree mask overlay [approximate frame center $37 \mathrm{~d} 14^{\prime} 16.8178^{\prime \prime} \mathrm{E}, 0 \mathrm{~d} 50^{\prime} 15.0359{ }^{\prime \prime} \mathrm{N}$, approximately $6.7 \mathrm{~km} \mathrm{~N}-\mathrm{S}$ and $9.6 \mathrm{~km}$ E-W]. Change in live cover between $A$ and $B$, September 2017 and June 2018; $C$ and $D$, June 2017 and September 2017; and $E$ and $F$, June 2017 and June 2018. Arrows on $D$ point to small fenced settlements as identified on May 2011 Google Earth photography.-Continued 

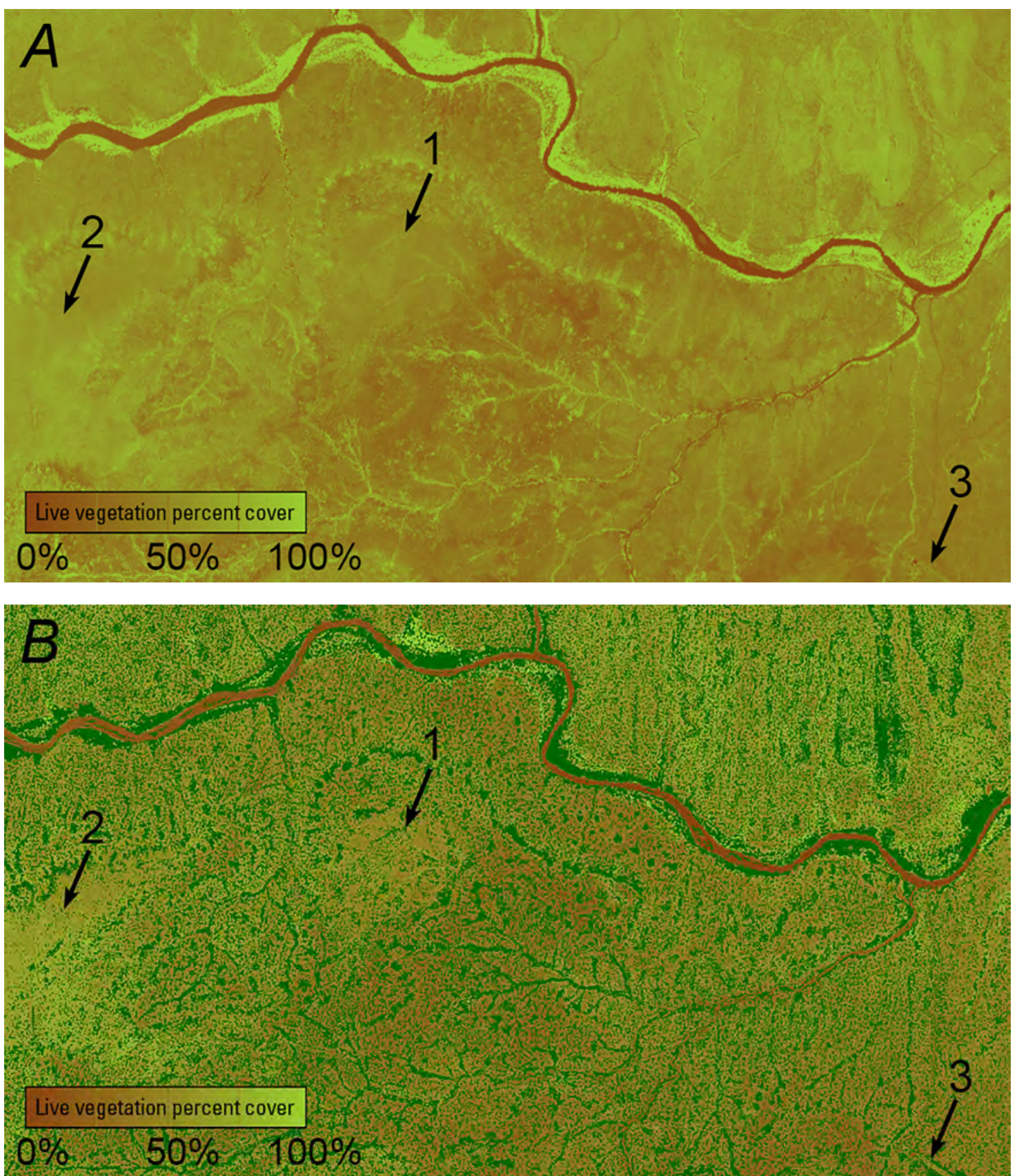

Figure 30. Nasuulu Conservancy. Live vegetation cover proportion and September 2017 tree mask overlay [approximate frame center $37 \mathrm{~d} 29^{\prime} 02.4303^{\prime \prime} \mathrm{E}, 0 \mathrm{~d} 33^{\prime} 36.6237^{\prime \prime} \mathrm{N}$, approximately $6.8 \mathrm{~km} \mathrm{~N}-\mathrm{S}$ and $12.1 \mathrm{~km} \mathrm{E-W]}$. $A$ and $B$, June 2018; $C$ and $D$, September 2017; and $E$ and $F$, June 2017. Reference arrows 1 and 2 point to dense trees or shrubs not represented well by tree classification, and reference arrow 3 points to a paved airport runway. 

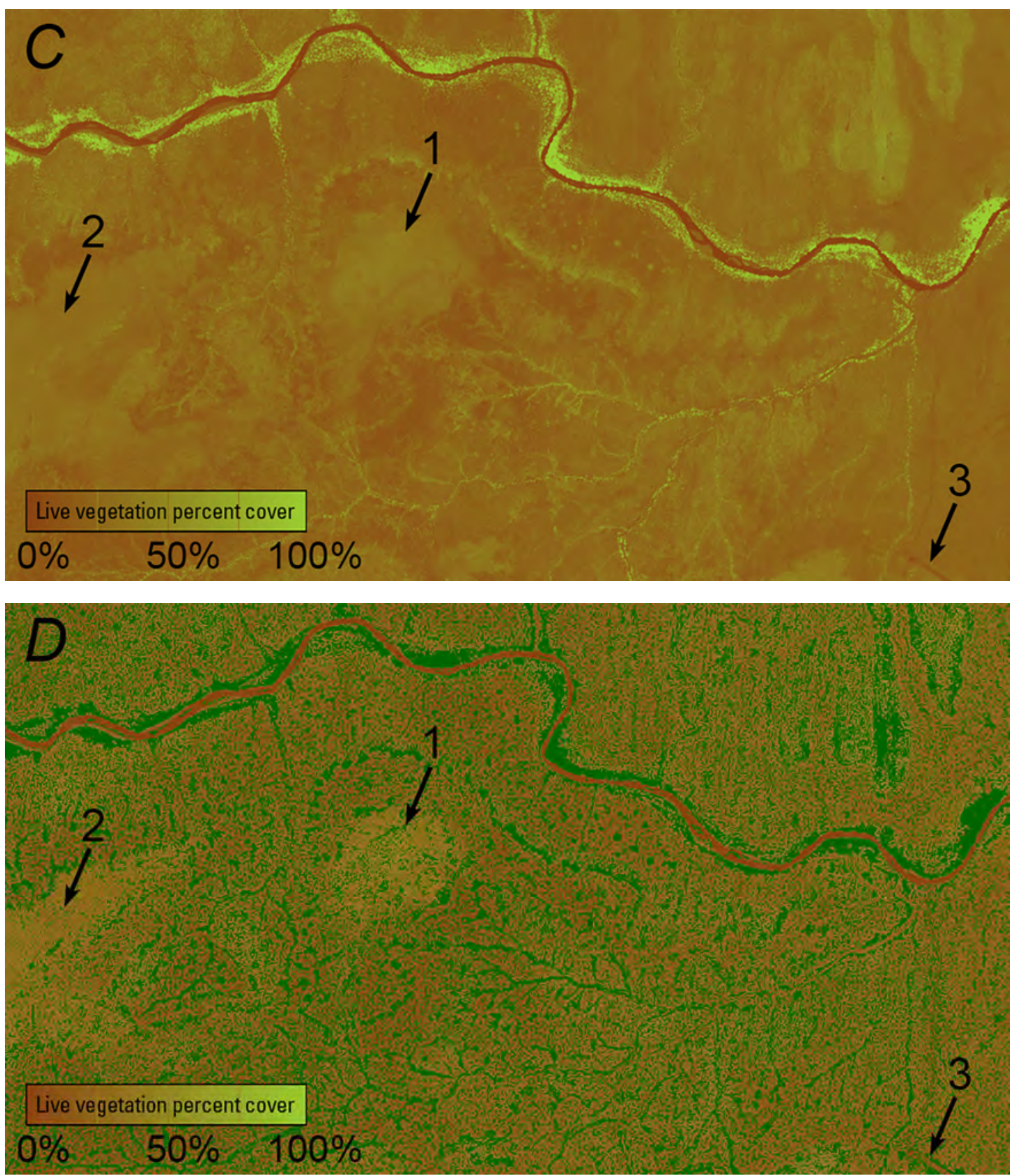

Figure 30. Nasuulu Conservancy. Live vegetation cover proportion and September 2017 tree mask overlay [approximate frame center $37 \mathrm{~d} 29^{\prime} 02.4303^{\prime \prime} \mathrm{E}, 0 \mathrm{~d} 33^{\prime} 36.6237^{\prime \prime} \mathrm{N}$, approximately $6.8 \mathrm{~km} \mathrm{~N}-\mathrm{S}$ and $12.1 \mathrm{~km} \mathrm{E-W]}$. $A$ and $B$, June 2018; $C$ and $D$, September 2017; and $E$ and $F$, June 2017. Reference arrows 1 and 2 point to dense trees or shrubs not represented well by tree classification, and reference arrow 3 points to a paved airport runway.-Continued 

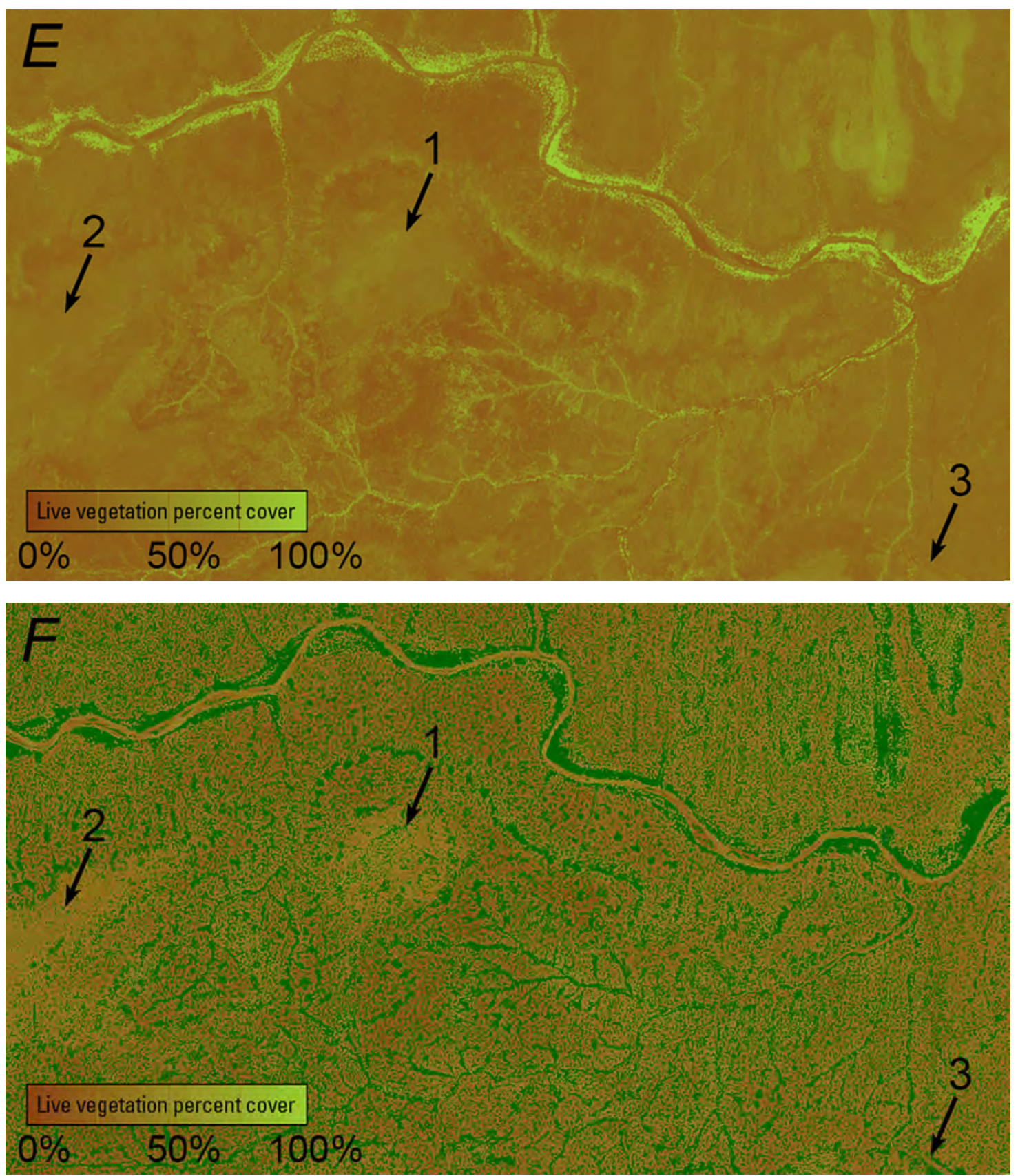

Figure 30. Nasuulu Conservancy. Live vegetation cover proportion and September 2017 tree mask overlay [approximate frame center $37 \mathrm{~d} 29^{\prime} 02.4303^{\prime \prime} \mathrm{E}, 0 \mathrm{~d} 33^{\prime} 36.6237^{\prime \prime} \mathrm{N}$, approximately $6.8 \mathrm{~km} \mathrm{~N}-\mathrm{S}$ and $12.1 \mathrm{~km} \mathrm{E}-\mathrm{W}$ ]. $A$ and $B$, June 2018; $C$ and $D$, September 2017; and $E$ and $F$, June 2017. Reference arrows 1 and 2 point to dense trees or shrubs not represented well by tree classification, and reference arrow 3 points to a paved airport runway.-Continued 

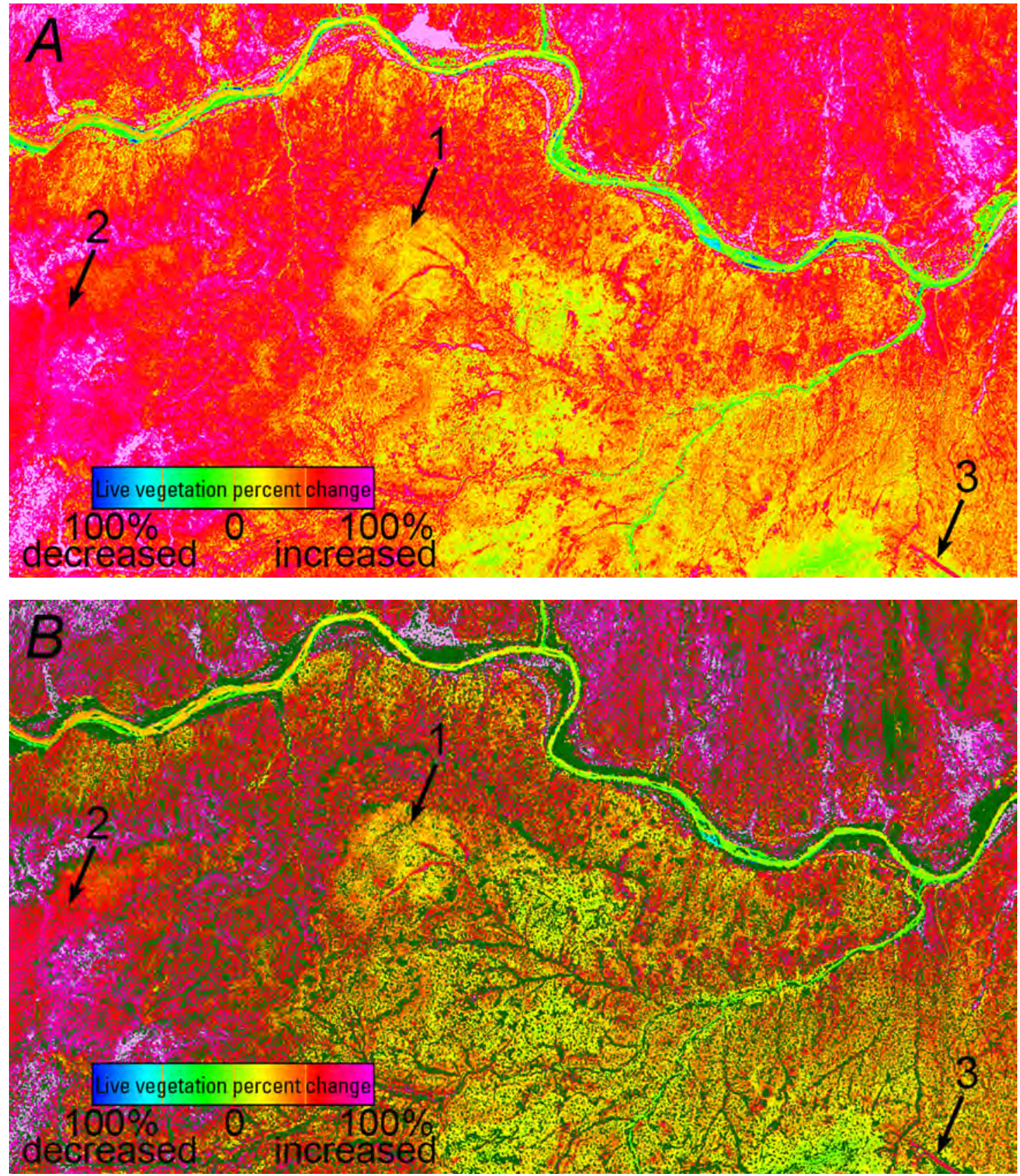

Figure 31. Nasuulu Conservancy. Live vegetation cover proportion change and September 2017 tree mask overlay [approximate frame center $37 \mathrm{~d} 29^{\prime} 02.4303^{\prime \prime} \mathrm{E}, 0 \mathrm{~d} 33^{\prime} 36.6237^{\prime \prime} \mathrm{N}$, approximately $6.8 \mathrm{~km} \mathrm{~N}-\mathrm{S}$ and $12.1 \mathrm{~km} \mathrm{E}-\mathrm{W}$ ]. Change in live cover between $A$ and $B$, September 2017 and June 2018; $C$ and D, June 2017 and September 2017; and $E$ and $F$, June 2017 and June 2018. Reference arrows explained in figure 30. 

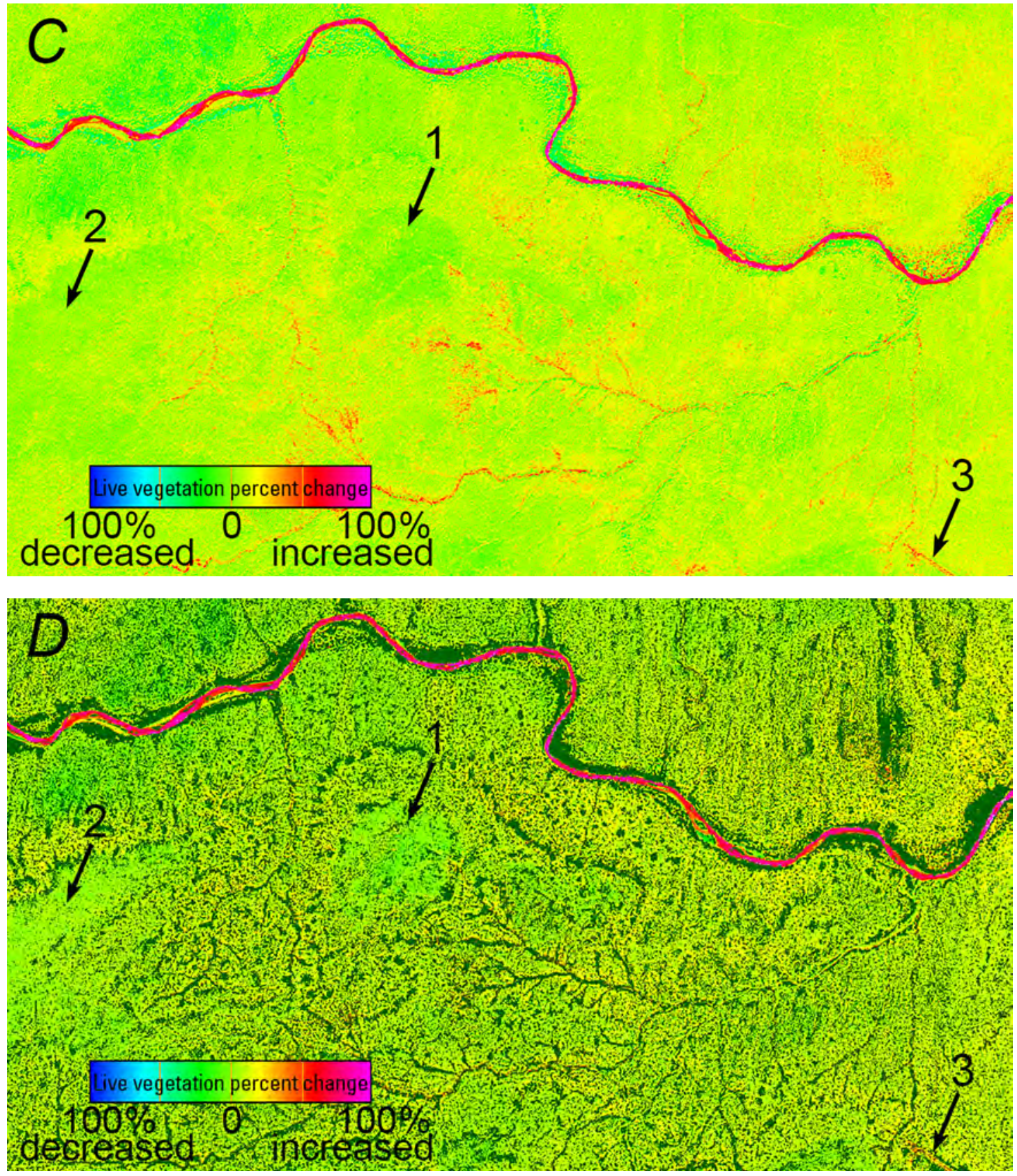

Figure 31. Nasuulu Conservancy. Live vegetation cover proportion change and September 2017 tree mask overlay [approximate frame center $37 \mathrm{~d} 29^{\prime} 02.4303$ " $\mathrm{E}, 0 \mathrm{~d} 33^{\prime} 36.6237^{\prime \prime} \mathrm{N}$, approximately $6.8 \mathrm{~km} \mathrm{~N}-\mathrm{S}$ and $12.1 \mathrm{~km} \mathrm{E-W]}$. Change in live cover between $A$ and $B$, September 2017 and June 2018; $C$ and $D$, June 2017 and September 2017; and $E$ and $F$, June 2017 and June 2018. Reference arrows explained in figure 30.-Continued 

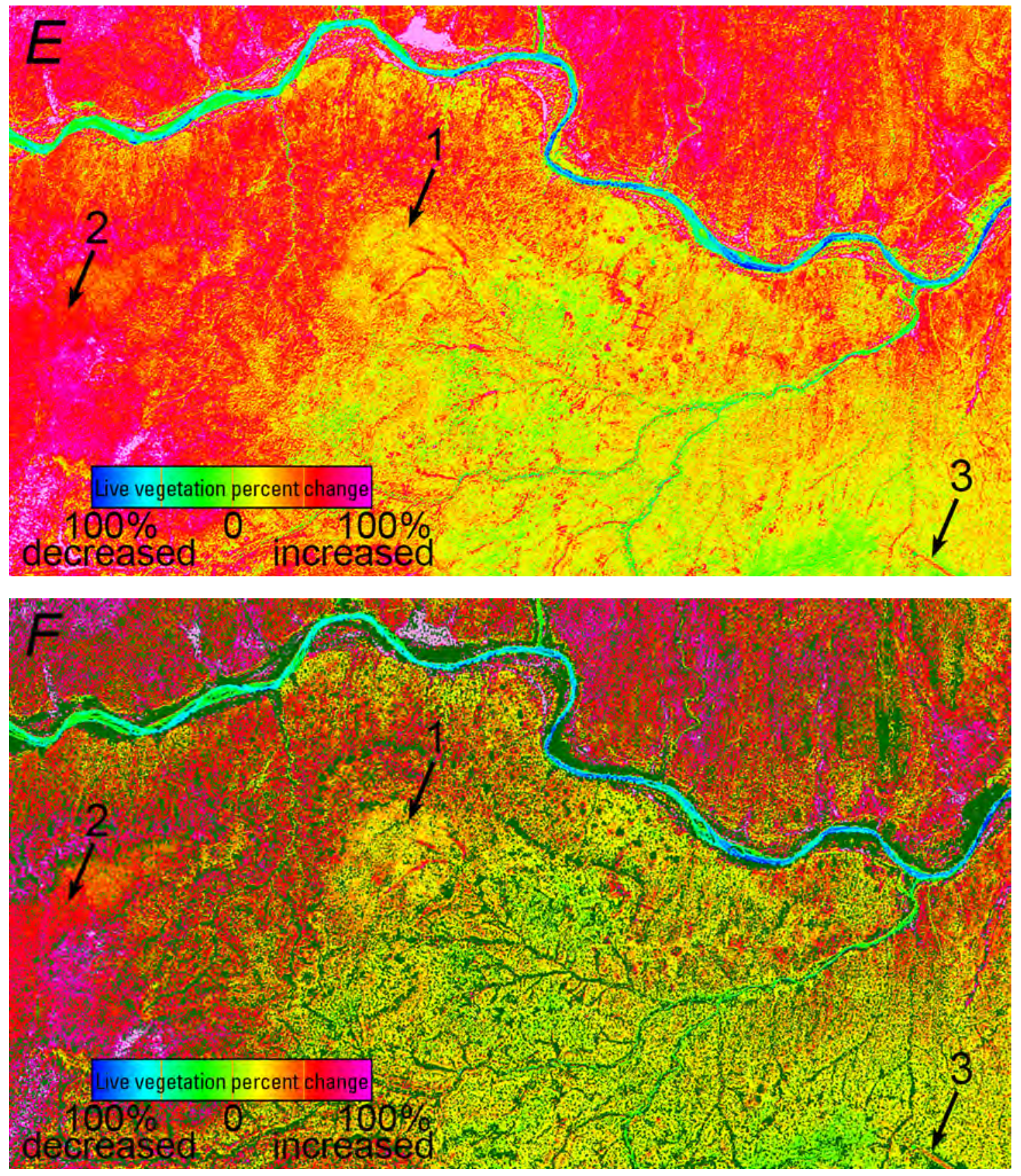

Figure 31. Nasuulu Conservancy. Live vegetation cover proportion change and September 2017 tree mask overlay [approximate frame center $37 \mathrm{~d} 29^{\prime} 02.4303^{\prime \prime} \mathrm{E}, 0 \mathrm{~d} 33^{\prime} 36.6237^{\prime \prime} \mathrm{N}$, approximately $6.8 \mathrm{~km} \mathrm{~N}-\mathrm{S}$ and $12.1 \mathrm{~km} \mathrm{E-W].}$ Change in live cover between $A$ and $B$, September 2017 and June 2018; $C$ and D, June 2017 and September 2017; and $E$ and $F$, June 2017 and June 2018. Reference arrows explained in figure 30.-Continued 

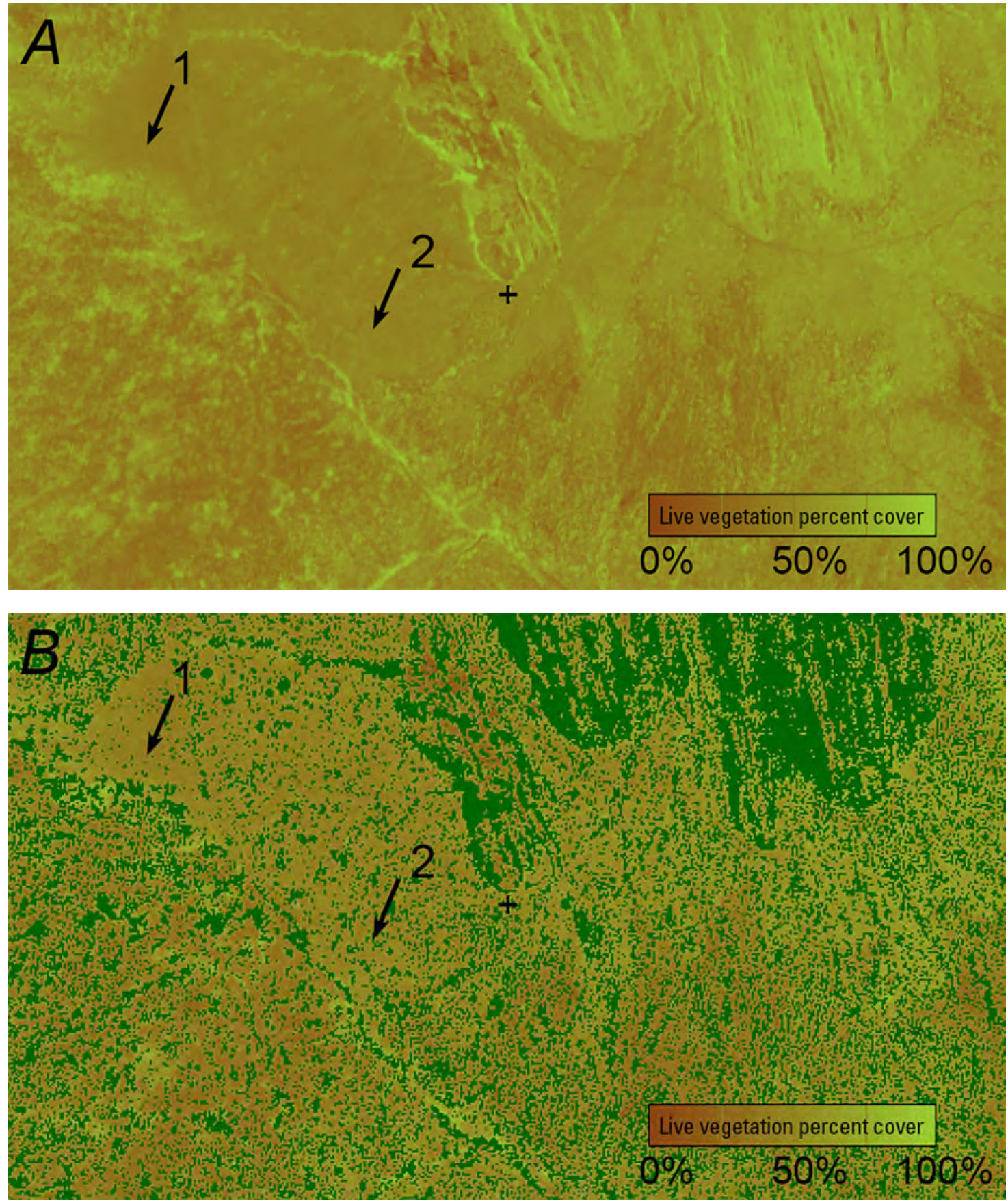

Figure 32. Kalama Conservancy site $1(+)$. Live vegetation cover proportion and September 2017 tree mask overlay [approximate frame center $37 \mathrm{~d} 31^{\prime} 48.9657 " \mathrm{E}, 0 \mathrm{~d} 41^{\prime} 56.6427 " \mathrm{~N}$, approximately $2.8 \mathrm{~km} \mathrm{~N}-\mathrm{S}$ and $4.8 \mathrm{~km} \mathrm{E-W]}$. $A$ and $B$, June 2018; $C$ and $D$, September 2017; and $E$ and $F$, June 2017. Reference arrow 1 points to an unknown hummocky feature, and arrow 2 points to an area of lower tree density than expected. 

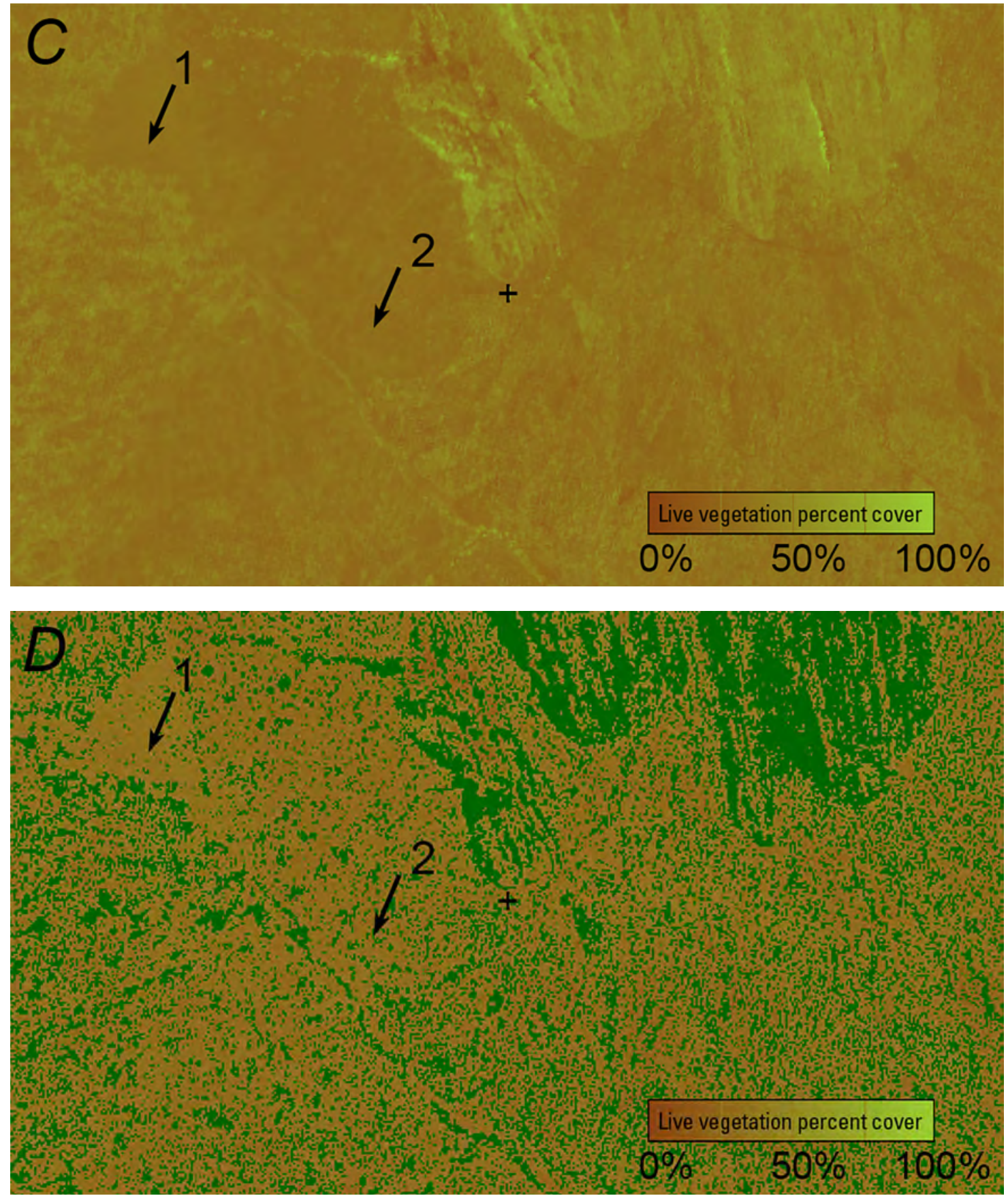

Figure 32. Kalama Conservancy site $1(+)$. Live vegetation cover proportion and September 2017 tree mask overlay [approximate frame center 37d31'48.9657"E, 0d41'56.6427"N, approximately $2.8 \mathrm{~km} \mathrm{~N}-\mathrm{S}$ and $4.8 \mathrm{~km} \mathrm{E-W].}$ $A$ and $B$, June 2018; $C$ and $D$, September 2017; and $E$ and $F$, June 2017. Reference arrow 1 points to an unknown hummocky feature, and arrow 2 points to an area of lower tree density than expected. - Continued 

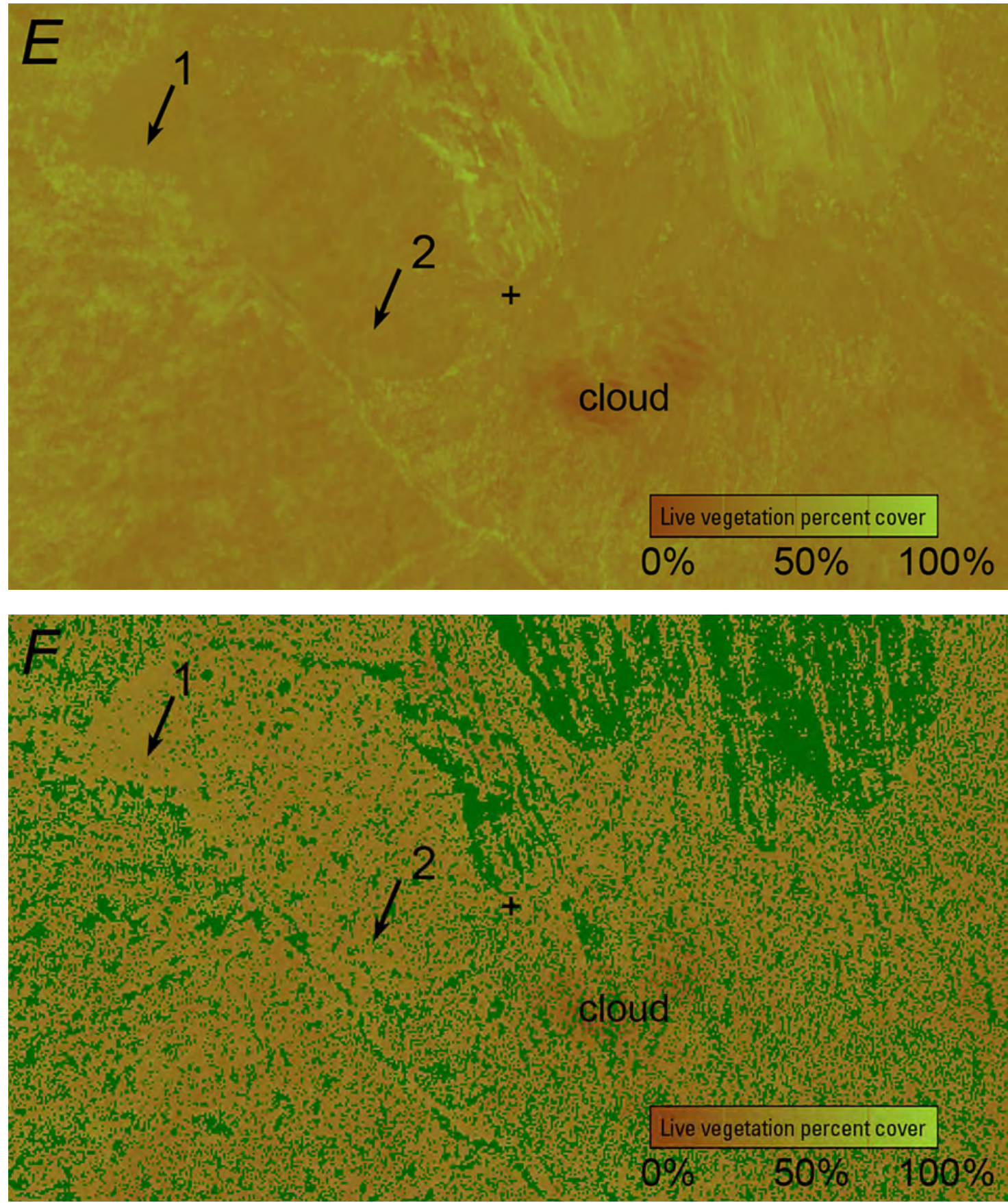

Figure 32. Kalama Conservancy site $1(+)$. Live vegetation cover proportion and September 2017 tree mask overlay [approximate frame center $37 \mathrm{~d} 31^{\prime} 48.9657 " \mathrm{E}, 0 \mathrm{~d} 41^{\prime} 56.6427 " \mathrm{~N}$, approximately $2.8 \mathrm{~km} \mathrm{~N}-\mathrm{S}$ and $4.8 \mathrm{~km} \mathrm{E-W]}$. $A$ and $B$, June 2018; $C$ and $D$, September 2017; and $E$ and $F$, June 2017. Reference arrow 1 points to an unknown hummocky feature, and arrow 2 points to an area of lower tree density than expected.-Continued 

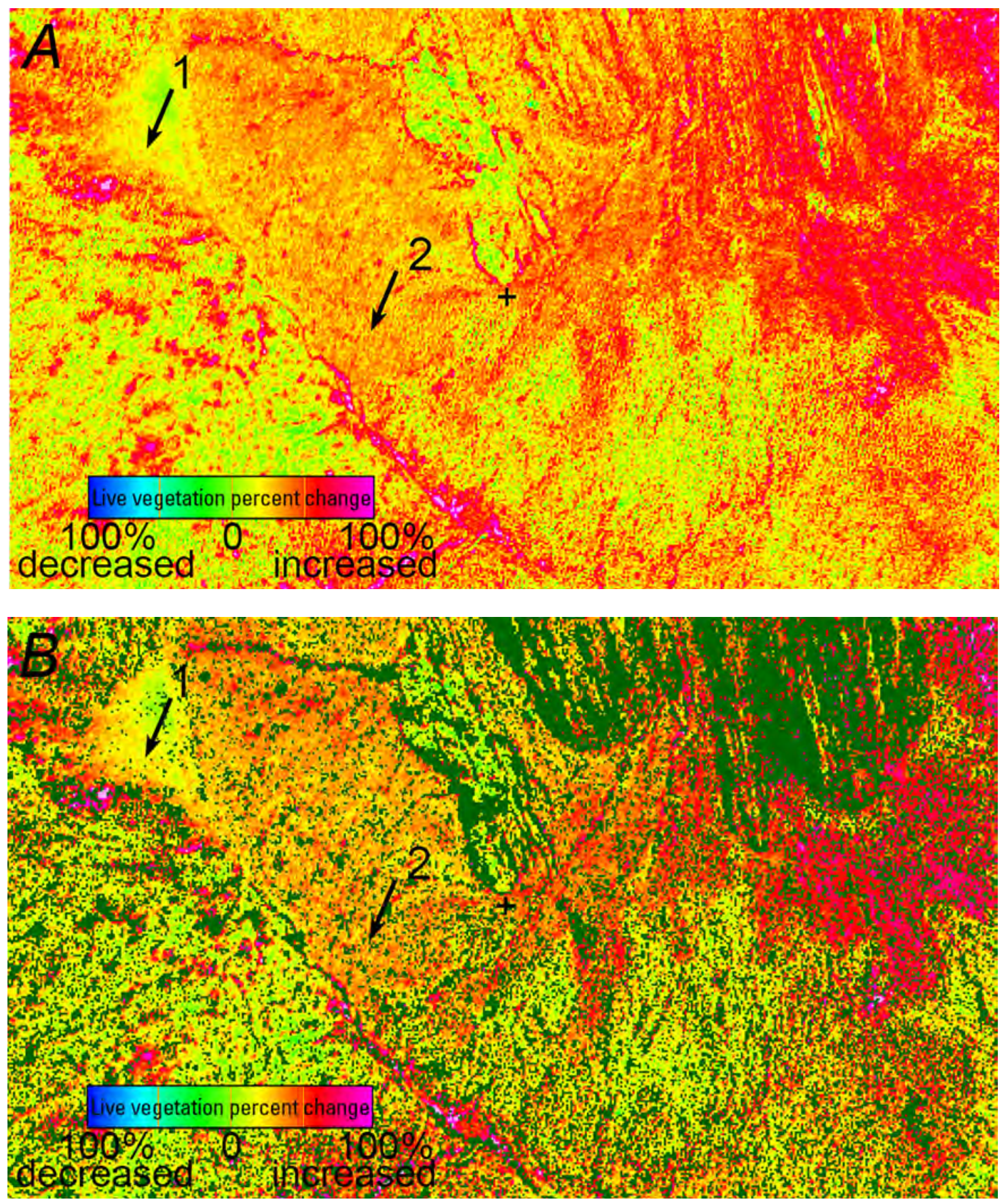

Figure 33. Kalama Conservancy site $1(+)$. Live vegetation cover proportion change and September 2017 tree mask overlay [approximate frame center $37 \mathrm{~d} 31^{\prime} 48.9657 " \mathrm{E}, 0 \mathrm{~d} 41^{\prime} 56.6427 " \mathrm{~N}$, approximately $2.8 \mathrm{~km} \mathrm{~N}-\mathrm{S}$ and $4.8 \mathrm{~km} \mathrm{E}-\mathrm{W}]$. Change in live cover between $A$ and $B$, September 2017 and June 2018; $C$ and $D$, June 2017 and September 2017; and $E$ and $F$, June 2017 and June 2018. Reference arrow 1 points to an unknown hummocky feature, and arrow 2 points to an area of lower tree density than expected. 

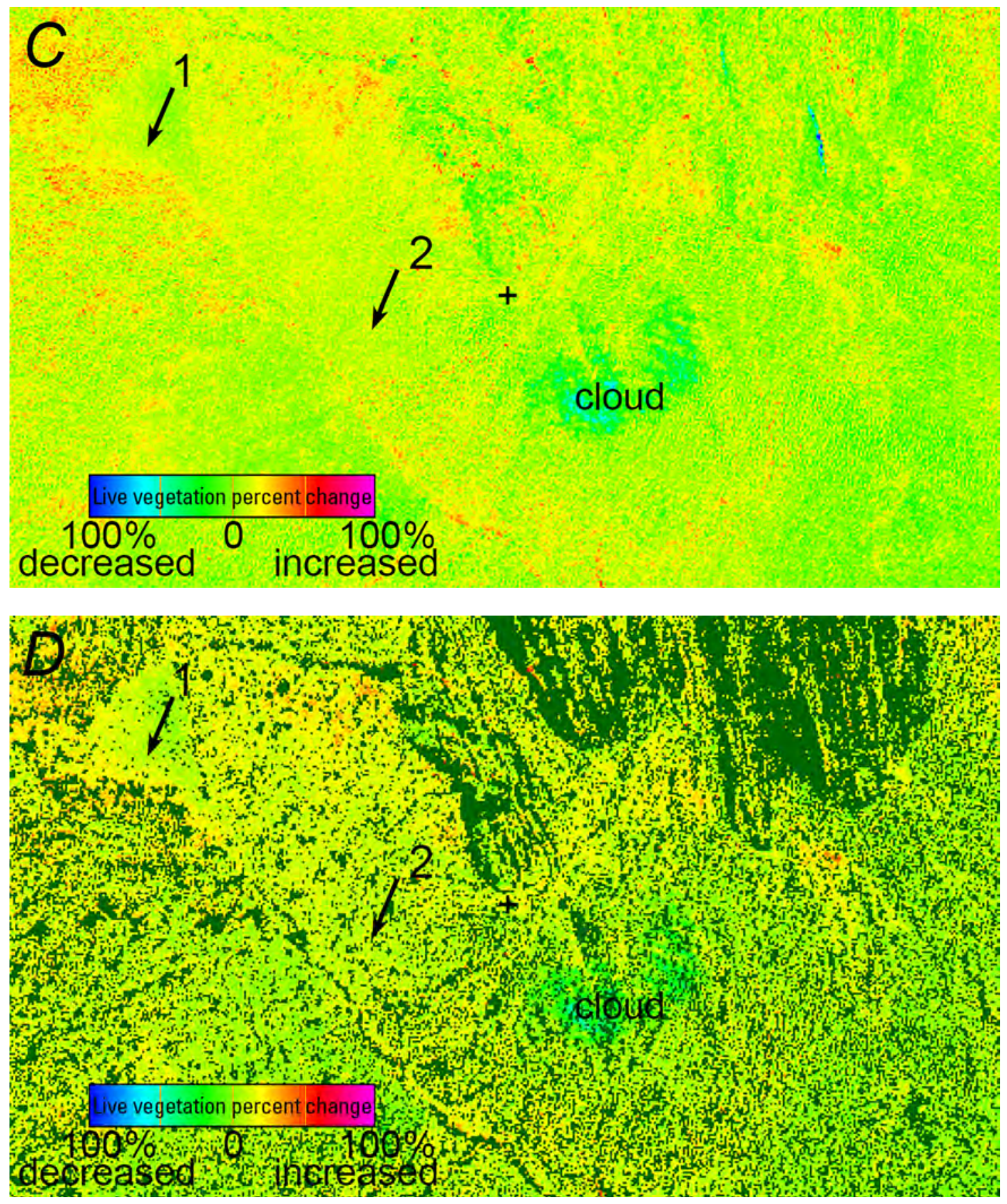

Figure 33. Kalama Conservancy site $1(+)$. Live vegetation cover proportion change and September 2017 tree mask overlay [approximate frame center $37 \mathrm{~d} 31^{\prime} 48.9657 " \mathrm{E}, 0 \mathrm{~d} 41^{\prime} 56.64277^{\prime \prime} \mathrm{N}$, approximately $2.8 \mathrm{~km} \mathrm{~N}-\mathrm{S}$ and $4.8 \mathrm{~km} \mathrm{E}-\mathrm{W}]$. Change in live cover between $A$ and $B$, September 2017 and June 2018; $C$ and $D$, June 2017 and September 2017; and $E$ and $F$, June 2017 and June 2018. Reference arrow 1 points to an unknown hummocky feature, and arrow 2 points to an area of lower tree density than expected.-Continued 

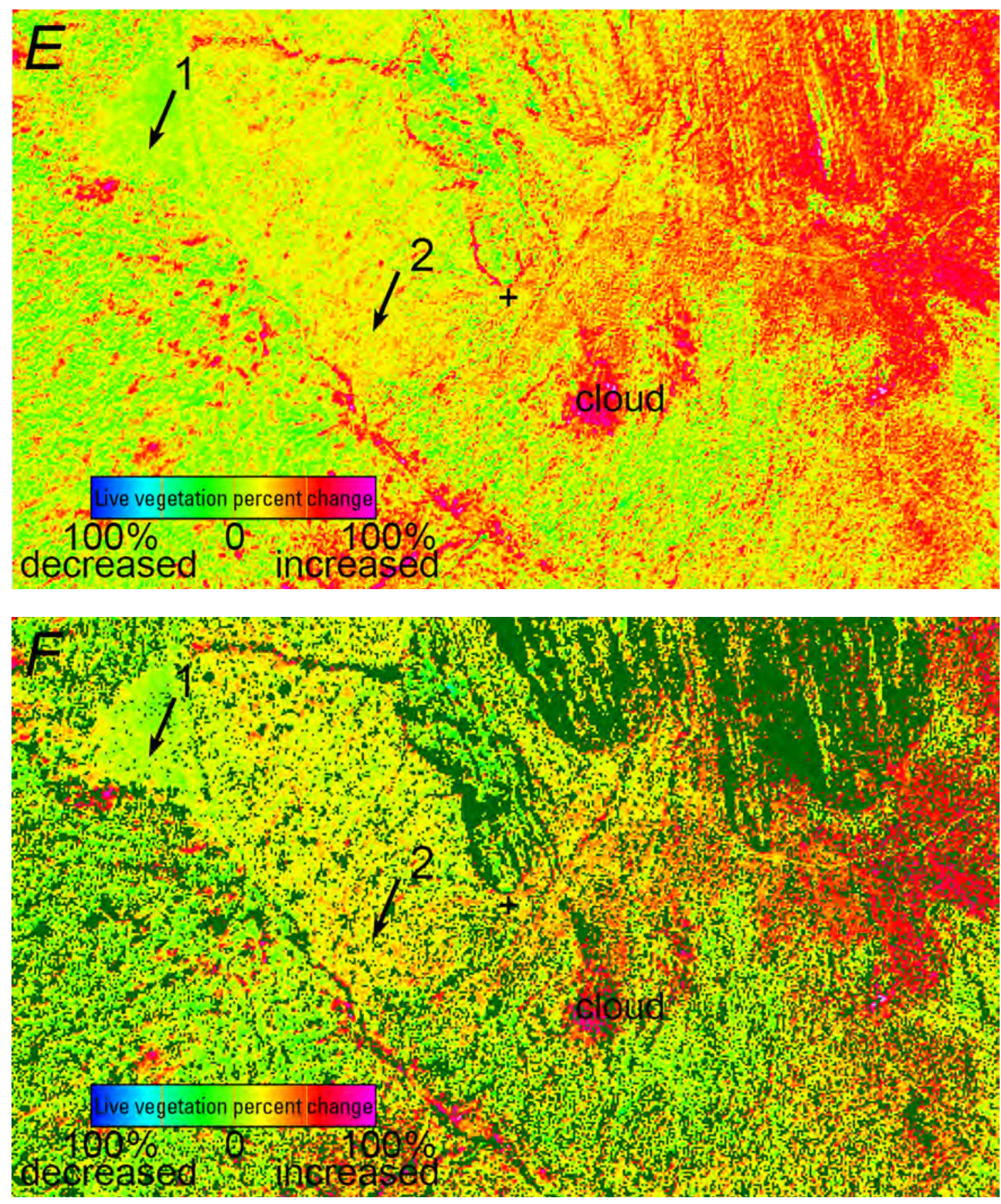

Figure 33. Kalama Conservancy site $1(+)$. Live vegetation cover proportion change and September 2017 tree mask overlay [approximate frame center $37 \mathrm{~d} 31^{\prime} 48.9657$ "E, $0 \mathrm{~d} 41^{\prime} 56.6427$ "N, approximately $2.8 \mathrm{~km} \mathrm{~N}-\mathrm{S}$ and $4.8 \mathrm{~km} \mathrm{E}-\mathrm{W}$ ]. Change in live cover between $A$ and $B$, September 2017 and June 2018; $C$ and $D$, June 2017 and September 2017; and $E$ and $F$, June 2017 and June 2018. Reference arrow 1 points to an unknown hummocky feature, and arrow 2 points to an area of lower tree density than expected.-Continued 


\section{Nasuulu Conservancy-Field Sites 1, 2, 3, and 12}

Figures $34 A$ to $F$ depict a small area within the eastern part of the Nasuulu Conservancy. The area contains field data collection sites 1 and 2 that had the highest live vegetation cover proportions outside of the Lewa Conservancy, site 3 with a more average live cover level, and site 12 representing several closely spaced sites with low ( $<25$ percent) live forb vegetation. This site has higher proportions of live cover than the area surrounding Kalama Conservancy site 1. As in the Kalama Conservancy, the highest live cover proportions are in June 2018 followed by June and September 2017.

In contrast with the Kalama Conservancy, the Nasuulu Conservancy live vegetation cover proportion change maps depict somewhat higher changes in the proportions of live cover between June 2018 and September 2017, slightly lower changes between June and September 2017, and higher overall changes between June 2018 and June 2017 (figs. 35A to $F$ ). Within the three Nasuulu Conservancy sites, site 12 with the lowest live cover exhibited the least change over time.

\section{Namunyak Conservancy}

A large area in the Namunyak Conservancy has observation sites along the A2 highway (fig. 36). Proportions of live vegetation cover are similar in June 2017 and in June 2018; proportions of live cover are lower in September 2017. This area has a high density of ephemeral drainage features and more permanent drainage features in the northwest.

During field reconnaissance, patches of ground vegetation were noted between the numerous gaps in the short (approximately 3 to $4 \mathrm{~m}$ ) tree canopy characterizing this area. The ground vegetation cover was also observed to primarily include smaller shrubs (approximately $<1 \mathrm{~m}$ ) within the gaps. Visually, the gap spacing appeared most often to be less than $10 \mathrm{~m}$. The short shrubs are included in the live vegetation cover proportion mapping; however, the narrow spacing increases the possibility that when green leafed, trees surrounding the gaps will add to the reflectance, thus heightening the live vegetation cover proportion base level.

The change maps for this area depict a different scenario than seen at the previous example areas (fig. 37). First, even though spatial patterns of change differ between the two change periods, there is an overall similarity of the June 2017 and June 2018 to September 2017 change maps. Furthermore, other than some prominent linear features in the southwest part of the area, the June 2017 to June 2018 change map depicts an overall low difference of live vegetation.

\section{Melako Conservancy}

A large region in the northern part of the Melako Conservancy features prominent ephemeral drainage (fig. 38). Live vegetation cover proportions in June 2018 were substantially higher than 2017 levels throughout the region. In addition, the tree mask also shows high spatial variability in density, varying from areas of near absence to smaller scatter pockets of high density. Other than trees, the proportions of live cover were lower in June 2017 and September 2017 than in June 2018.

Live vegetation cover proportion change was substantially higher throughout the entire area in September 2017 to June 2018 as compared to June 2017 to September 2017 (figs. 39A and $B$ ). The change between June 2017 and September 2017 is higher than expected, based on the live cover status maps. This is best shown within the extensive drainage system where some live vegetation was produced during June 2017. 

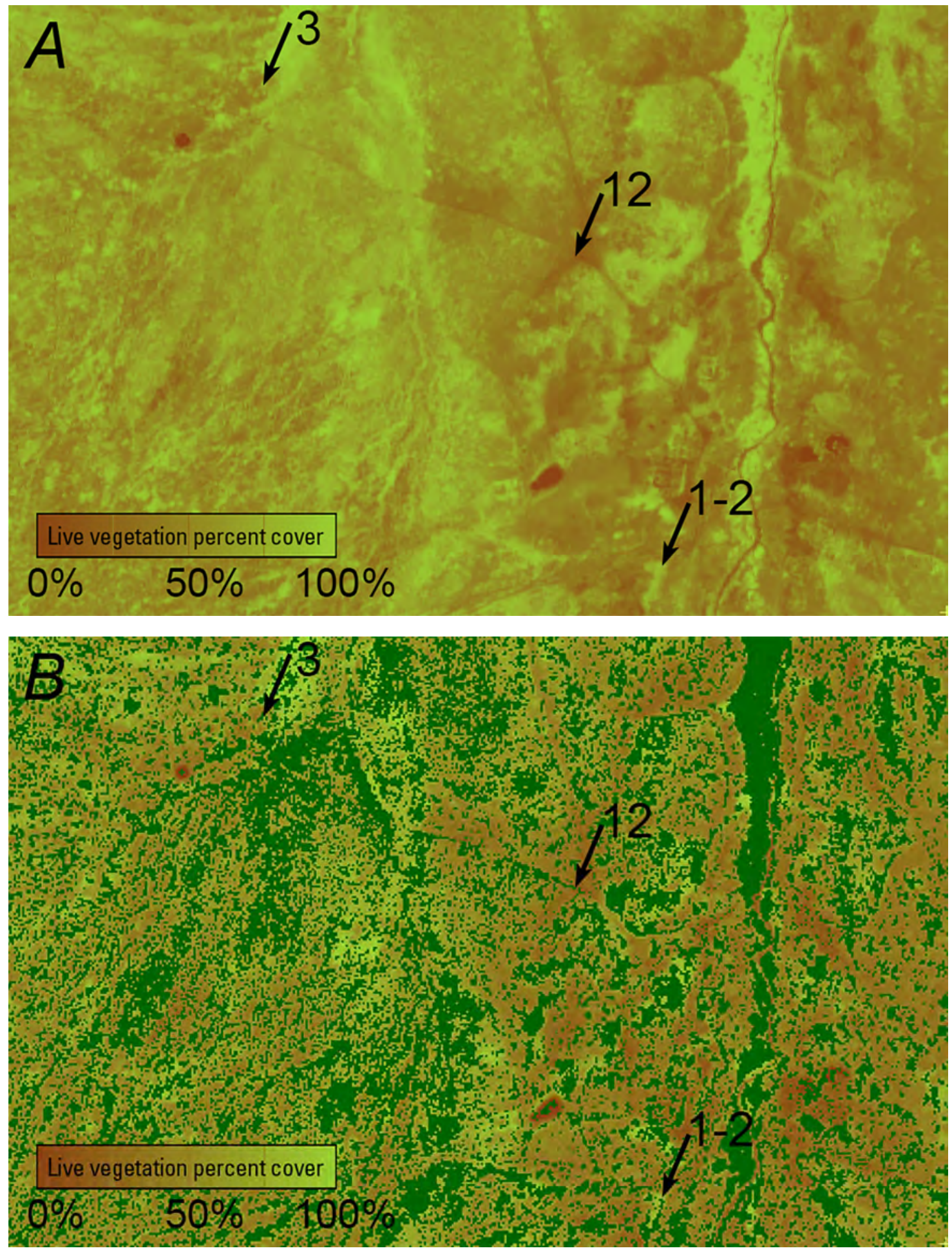

Figure 34. Nasuulu Conservancy. Live vegetation cover proportion and September 2017 tree mask overlay [approximate frame center 37d34'07.6910"E, $0 \mathrm{~d} 26^{\prime} 55.7317 " \mathrm{~N}$, approximately $2.9 \mathrm{~km} \mathrm{~N}-\mathrm{S}$ and $4.5 \mathrm{~km}$ E-W]. $A$ and $B$, June 2018; $C$ and $D$, September 2017; and $E$ and $F$, June 2017. Reference arrows point to Nasuulu sites 1, 2, 3, and 12 . 

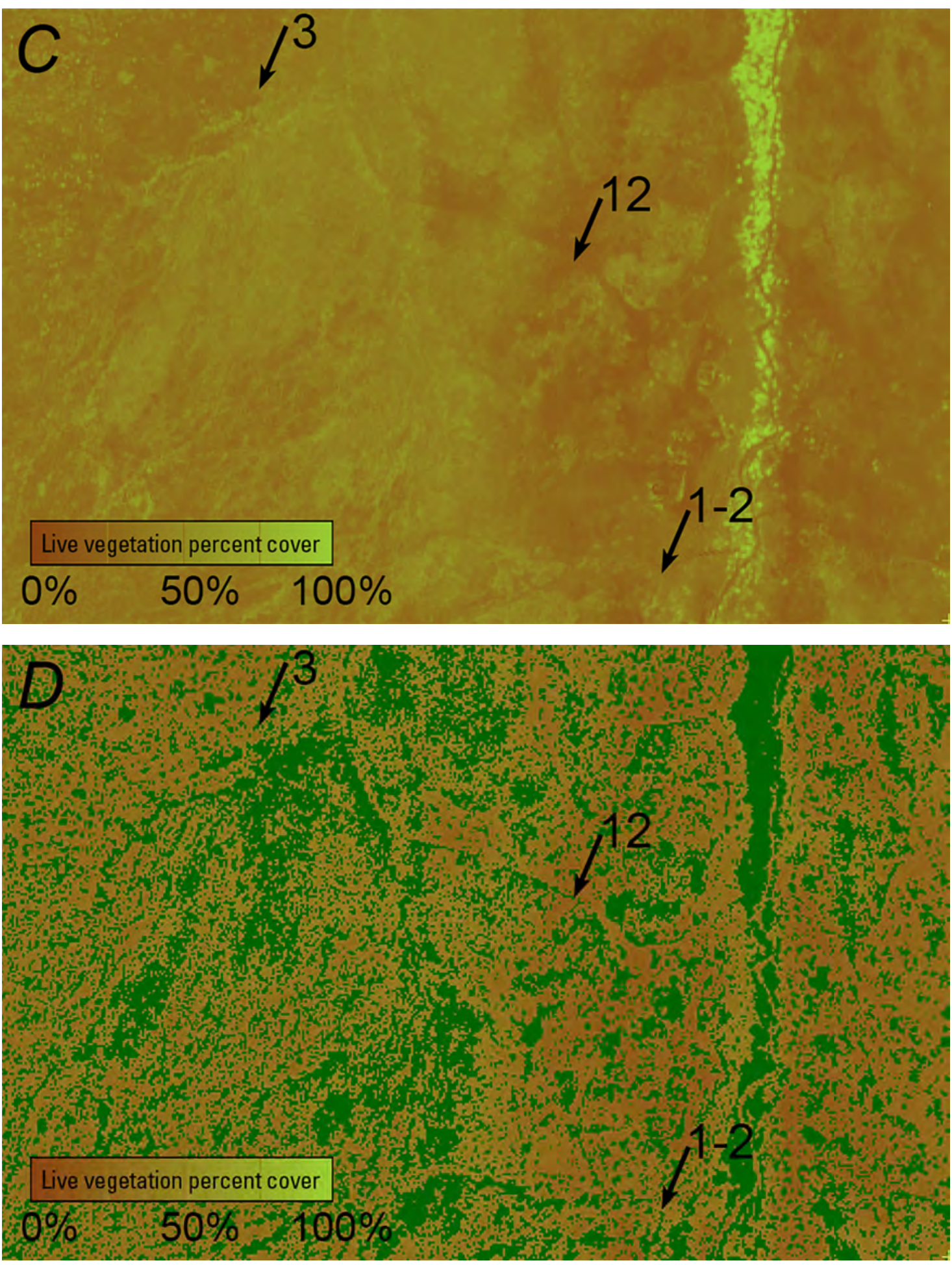

Figure 34. Nasuulu Conservancy. Live vegetation cover proportion and September 2017 tree mask overlay [approximate frame center $37 \mathrm{~d} 34^{\prime} 07.6910^{\prime \prime} \mathrm{E}, 0 \mathrm{~d} 26^{\prime} 55.7317^{\prime \prime} \mathrm{N}$, approximately $2.9 \mathrm{~km} \mathrm{~N}-\mathrm{S}$ and $4.5 \mathrm{~km}$ E-W]. $A$ and $B$, June 2018; $C$ and $D$, September 2017; and $E$ and $F$, June 2017. Reference arrows point to Nasuulu sites 1, 2, 3, and 12.-Continued 

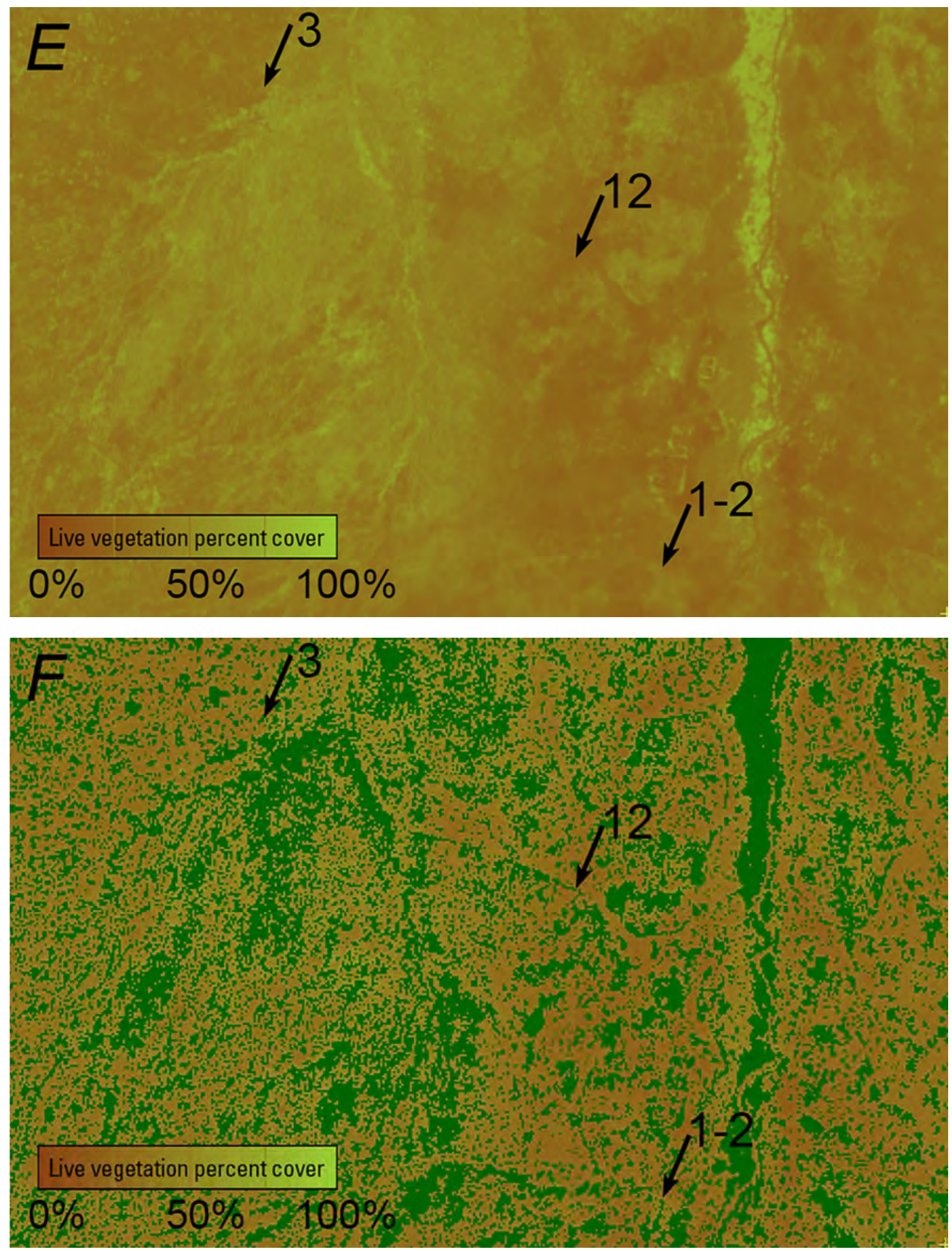

Figure 34. Nasuulu Conservancy. Live vegetation cover proportion and September 2017 tree mask overlay [approximate frame center 37d34'07.6910"E, $0 \mathrm{~d} 26^{\prime} 55.7317^{\prime \prime} \mathrm{N}$, approximately $2.9 \mathrm{~km} \mathrm{~N}-\mathrm{S}$ and $4.5 \mathrm{~km}$ E-W]. $A$ and $B$, June 2018; $C$ and $D$, September 2017; and $E$ and $F$, June 2017. Reference arrows point to Nasuulu sites 1, 2, 3, and 12.-Continued 

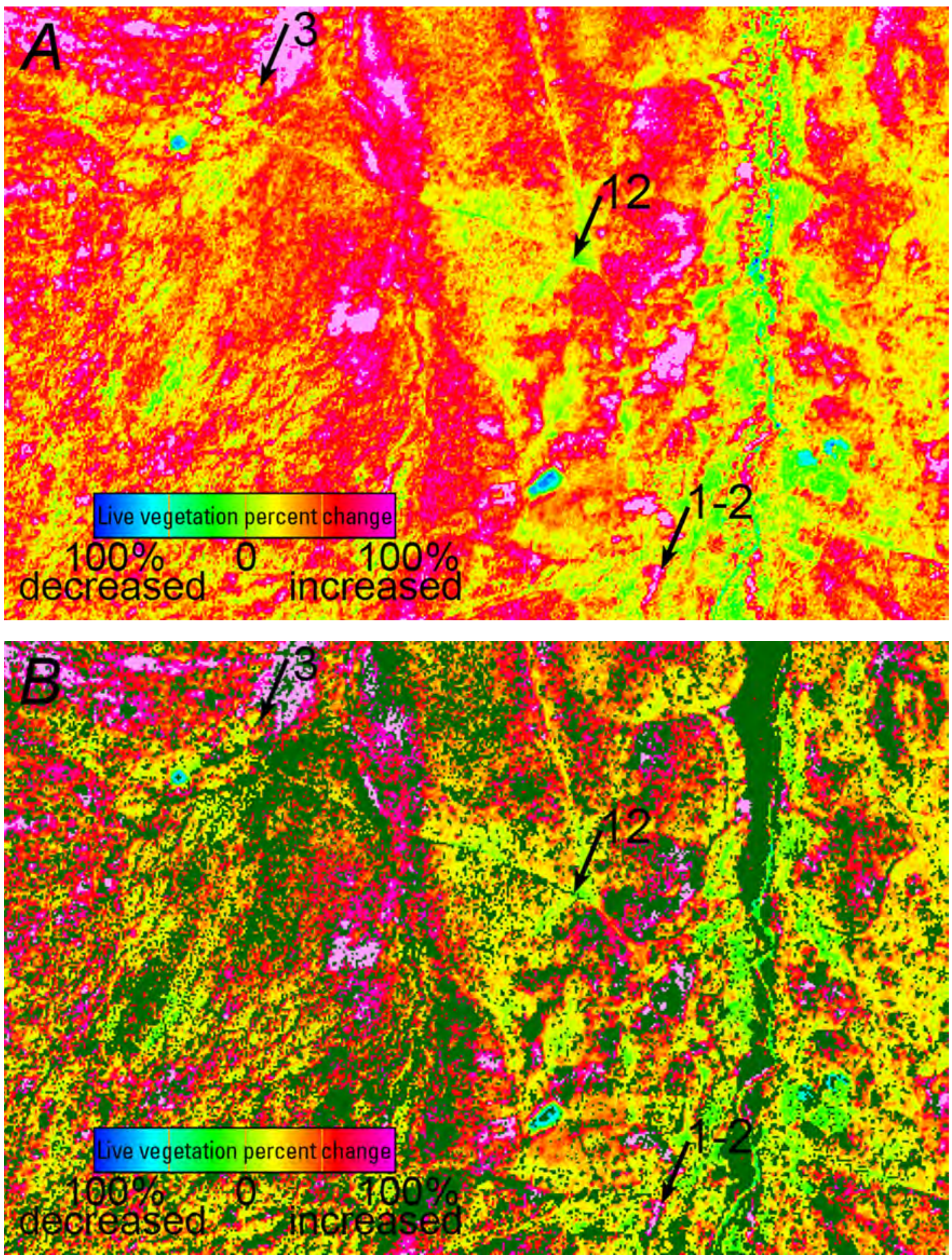

Figure 35. Nasuulu Conservancy. Live vegetation cover proportion change and September 2017 tree mask overlay [approximate frame center 37d34'07.6910"E, $0 \mathrm{~d} 26^{\prime} 55.7317^{\prime \prime} \mathrm{N}$, approximately $2.9 \mathrm{~km} \mathrm{~N}-\mathrm{S}$ and $4.5 \mathrm{~km} \mathrm{E-W]}$. Change in live cover between $A$ and $B$, September 2017 and June 2018; $C$ and $D$, June 2017 and September 2017; and $E$ and $F$, June 2017 and June 2018. Reference arrows point to Nasuulu sites 1, 2 , 3 , and 12 . 

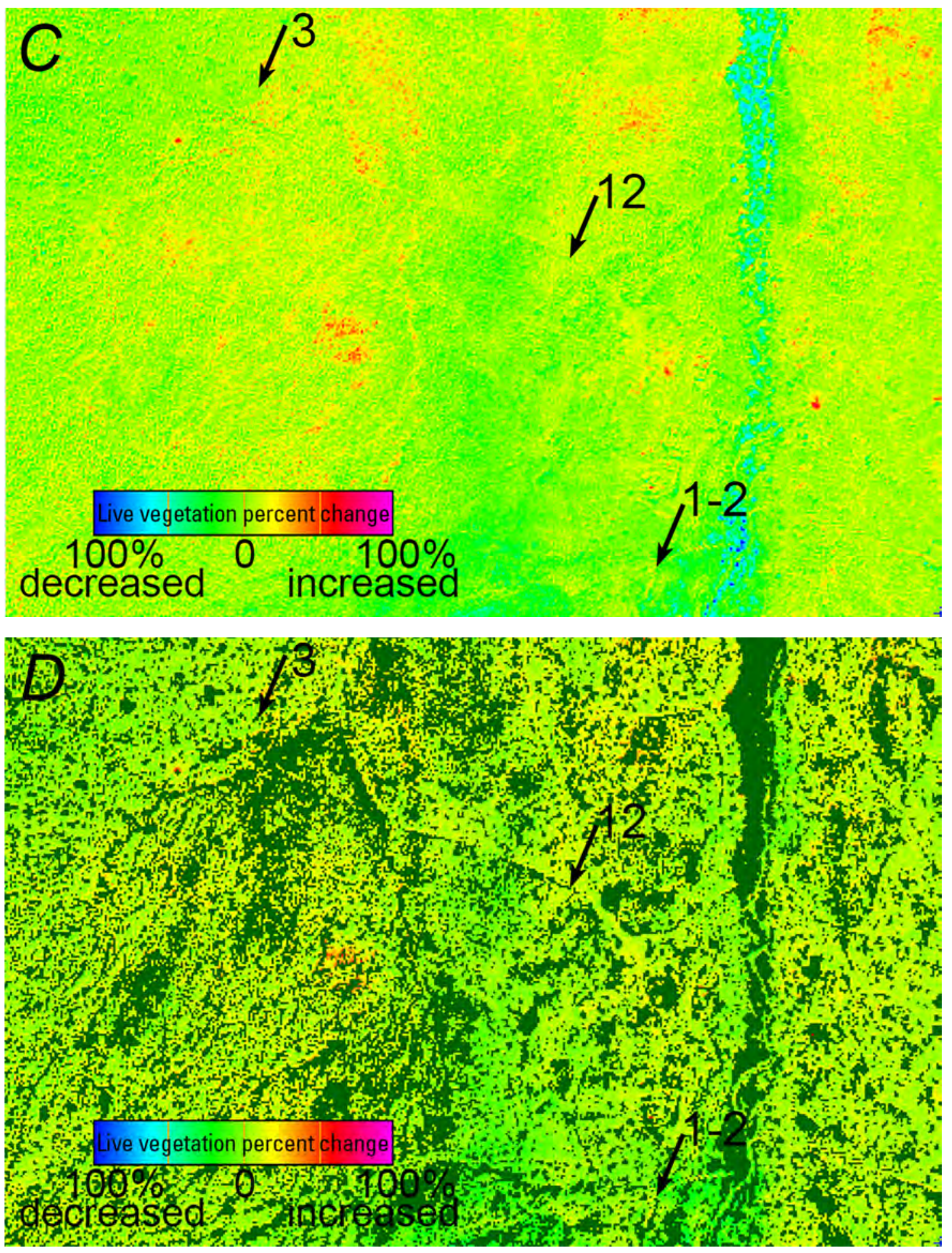

Figure 35. Nasuulu Conservancy. Live vegetation cover proportion change and September 2017 tree mask overlay [approximate frame center $37 \mathrm{~d} 34^{\prime} 07.6910^{\prime \prime} \mathrm{E}, 0 \mathrm{~d} 26^{\prime} 55.7317^{\prime \prime} \mathrm{N}$, approximately $2.9 \mathrm{~km} \mathrm{~N}-\mathrm{S}$ and $4.5 \mathrm{~km} \mathrm{E-W]}$. Change in live cover between $A$ and $B$, September 2017 and June 2018; $C$ and $D$, June 2017 and September 2017; and $E$ and $F$, June 2017 and June 2018. Reference arrows point to Nasuulu sites 1, 2, 3 , and 12.-Continued 

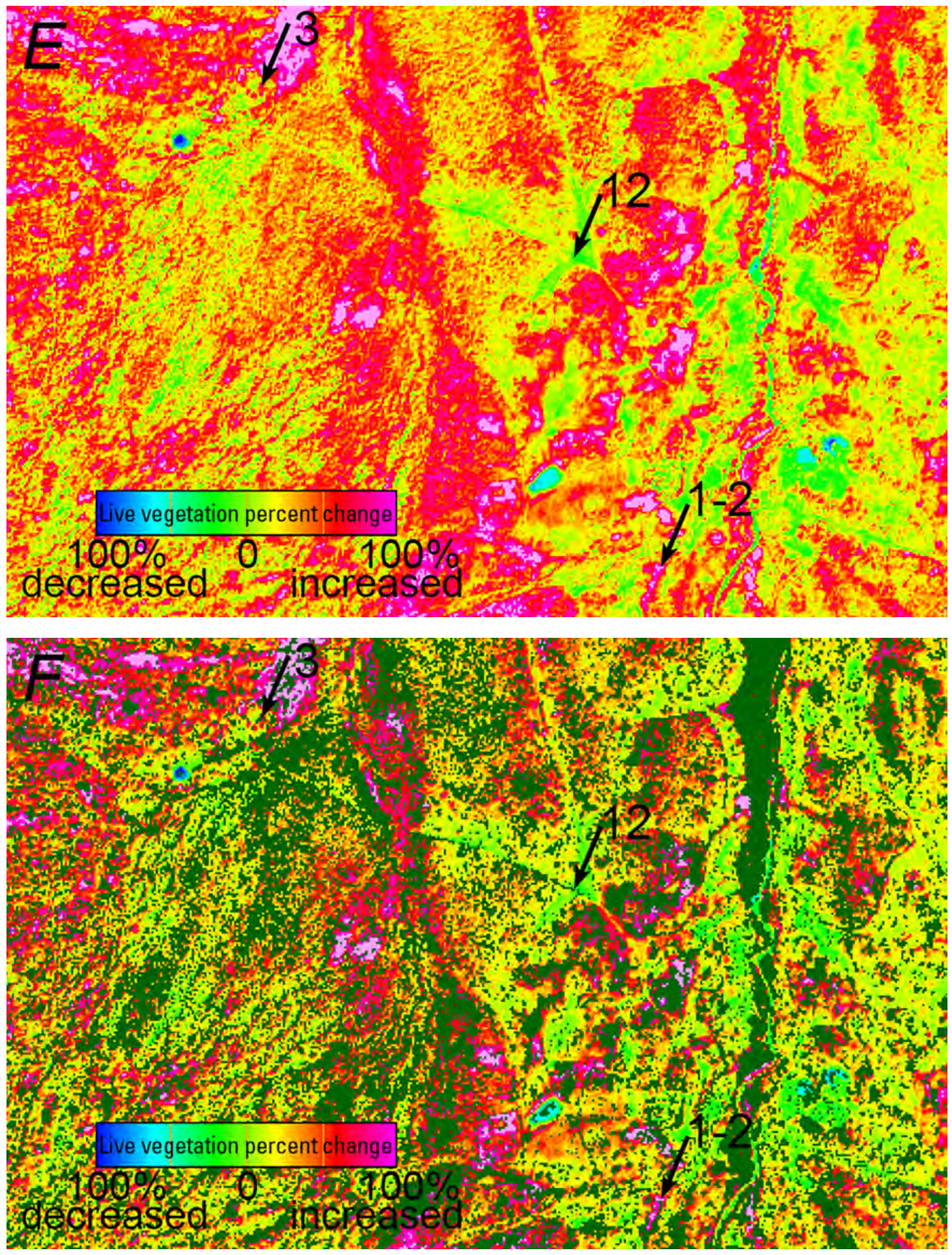

Figure 35. Nasuulu Conservancy. Live vegetation cover proportion change and September 2017 tree mask overlay [approximate frame center $37 \mathrm{~d} 34^{\prime} 07.6910^{\prime \prime} \mathrm{E}, 0 \mathrm{~d} 26^{\prime} 55.7317^{\prime \prime} \mathrm{N}$, approximately $2.9 \mathrm{~km} \mathrm{~N}-\mathrm{S}$ and $4.5 \mathrm{~km} \mathrm{E-W]}$. Change in live cover between $A$ and $B$, September 2017 and June 2018; $C$ and $D$, June 2017 and September 2017; and $E$ and $F$, June 2017 and June 2018. Reference arrows point to Nasuulu sites 1, 2, 3 , and 12.-Continued 

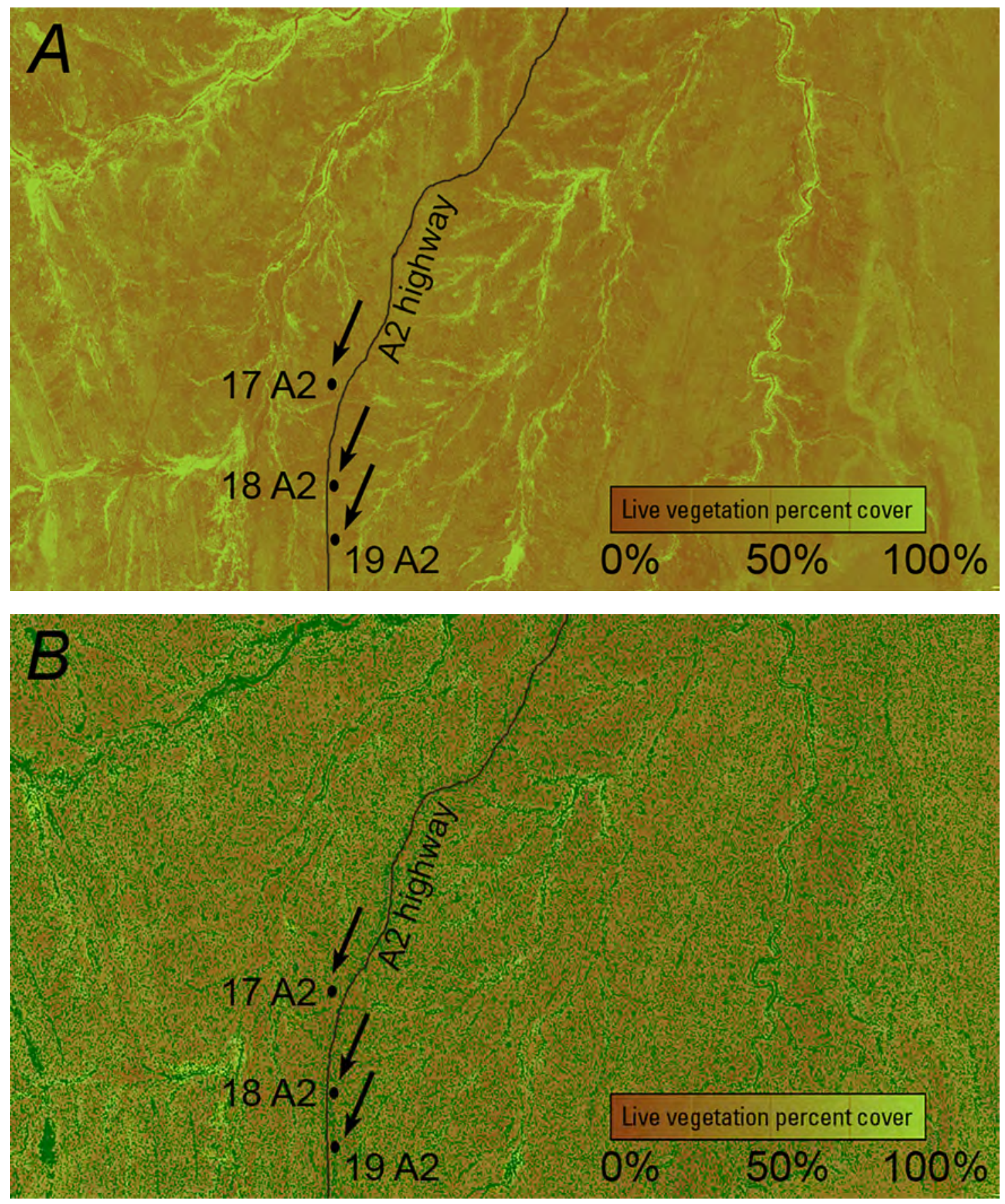

Figure 36. Namunyak Conservancy. Live vegetation cover proportion and September 2017 tree mask overlay [approximate frame center $37 \mathrm{~d} 35^{\prime} 23.8878 " \mathrm{E}, 1 \mathrm{~d} 04^{\prime} 45.3749^{\prime \prime} \mathrm{N}$, approximately $10.3 \mathrm{~km} \mathrm{~N}-\mathrm{S}$ and $17.9 \mathrm{~km} \mathrm{E-W]}$. $A$ and $B$, June 2018; $C$ and $D$, September 2017; and $E$ and $F$, June 2017. Reference arrows point to observation sites 17-19 located along the A2 highway. 

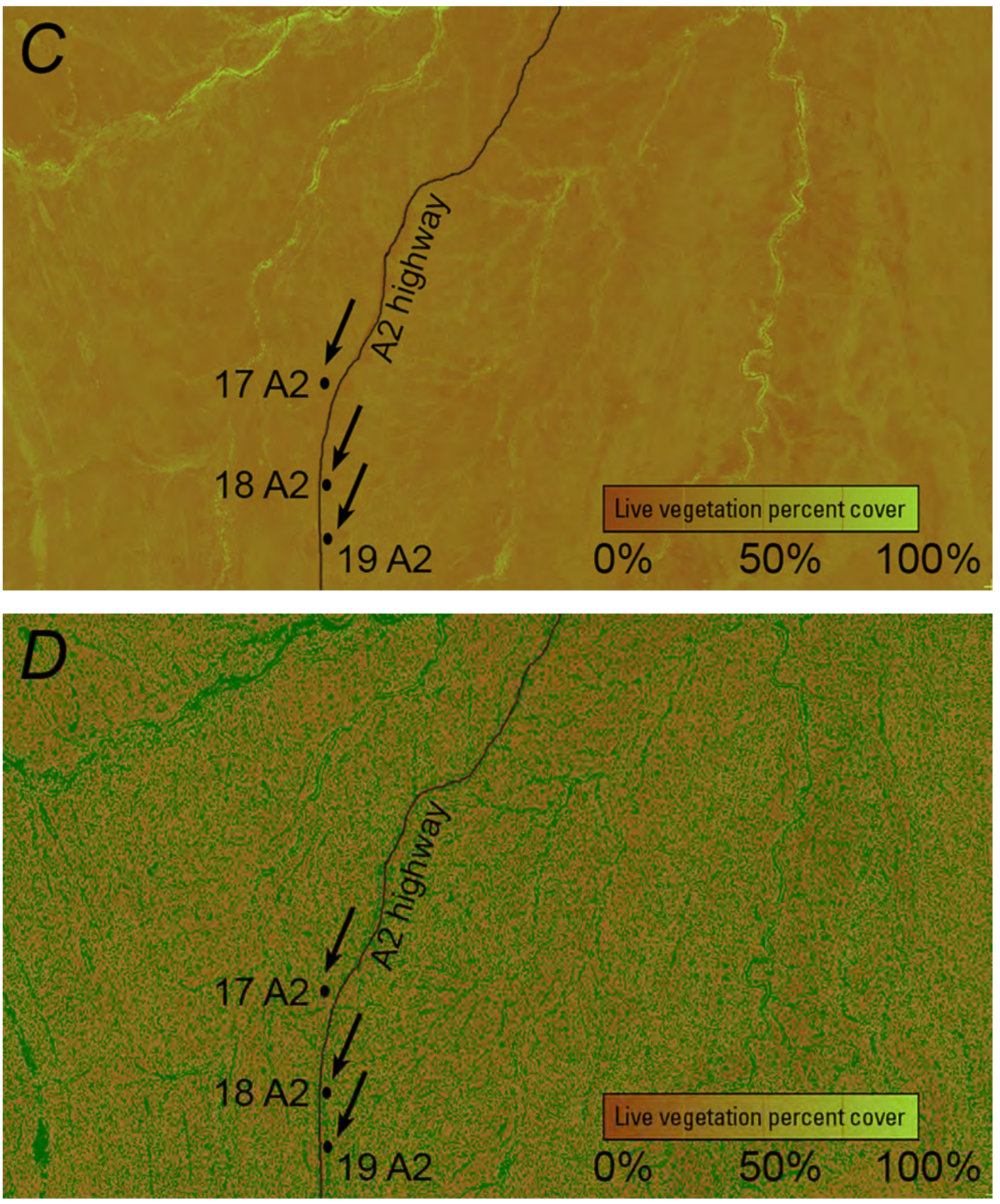

Figure 36. Namunyak Conservancy. Live vegetation cover proportion and September 2017 tree mask overlay [approximate frame center $37 \mathrm{~d} 35^{\prime} 23.8878{ }^{\prime \prime} \mathrm{E}, 1 \mathrm{~d} 04^{\prime} 45.3749^{\prime \prime} \mathrm{N}$, approximately $10.3 \mathrm{~km} \mathrm{~N}-\mathrm{S}$ and $17.9 \mathrm{~km} \mathrm{E-W].} A$ and $B$, June 2018; $C$ and $D$, September 2017; and $E$ and $F$, June 2017. Reference arrows point to observation sites 17-19 located along the A2 highway.-Continued 

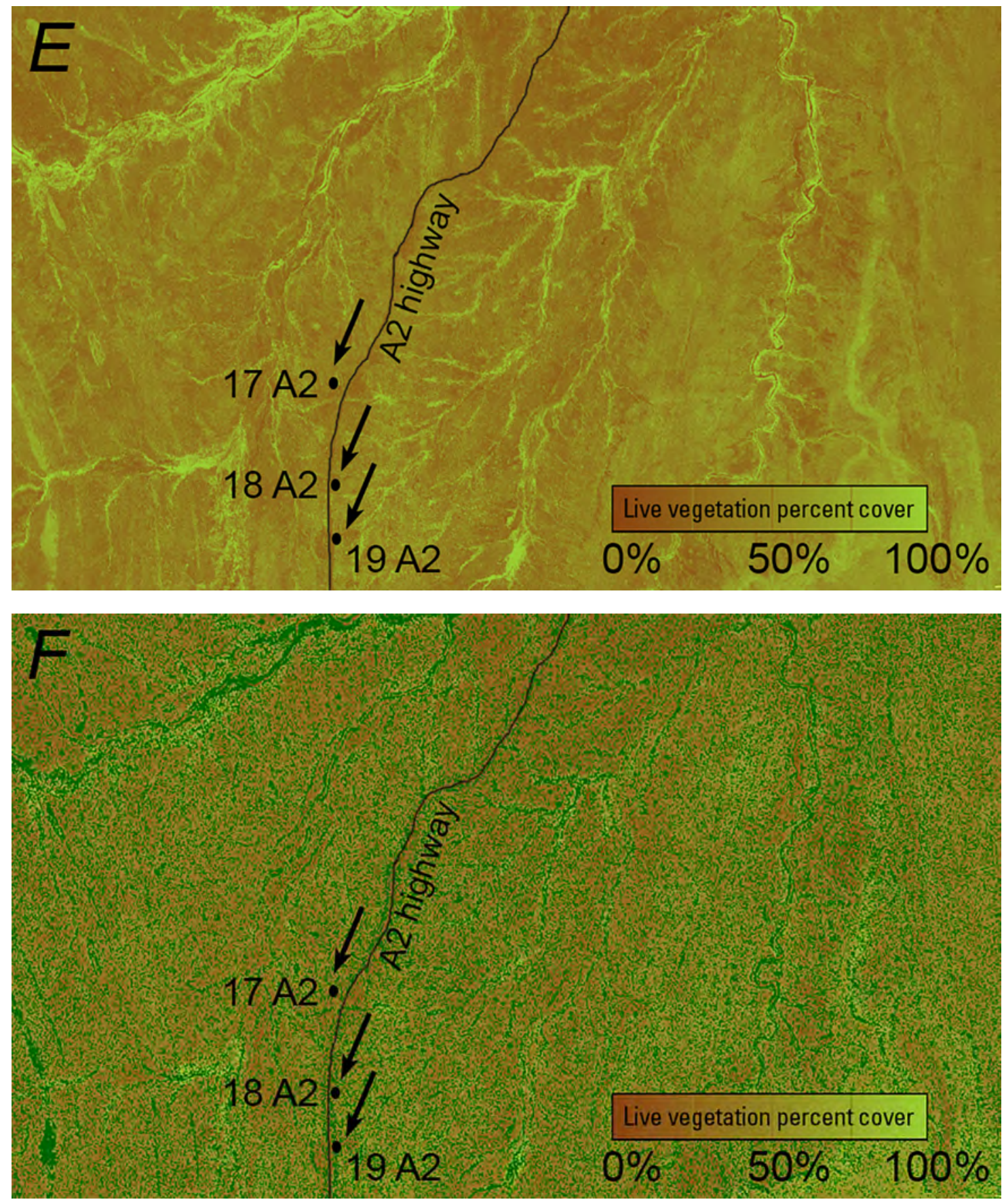

Figure 36. Namunyak Conservancy. Live vegetation cover proportion and September 2017 tree mask overlay [approximate frame center 37d35'23.8878"E, 1d04'45.3749"N, approximately $10.3 \mathrm{~km} \mathrm{~N}-\mathrm{S}$ and $17.9 \mathrm{~km} \mathrm{E-W].} A$ and $B$, June 2018; $C$ and $D$, September 2017; and $E$ and $F$, June 2017. Reference arrows point to observation sites 17-19 located along the A2 highway.-Continued 

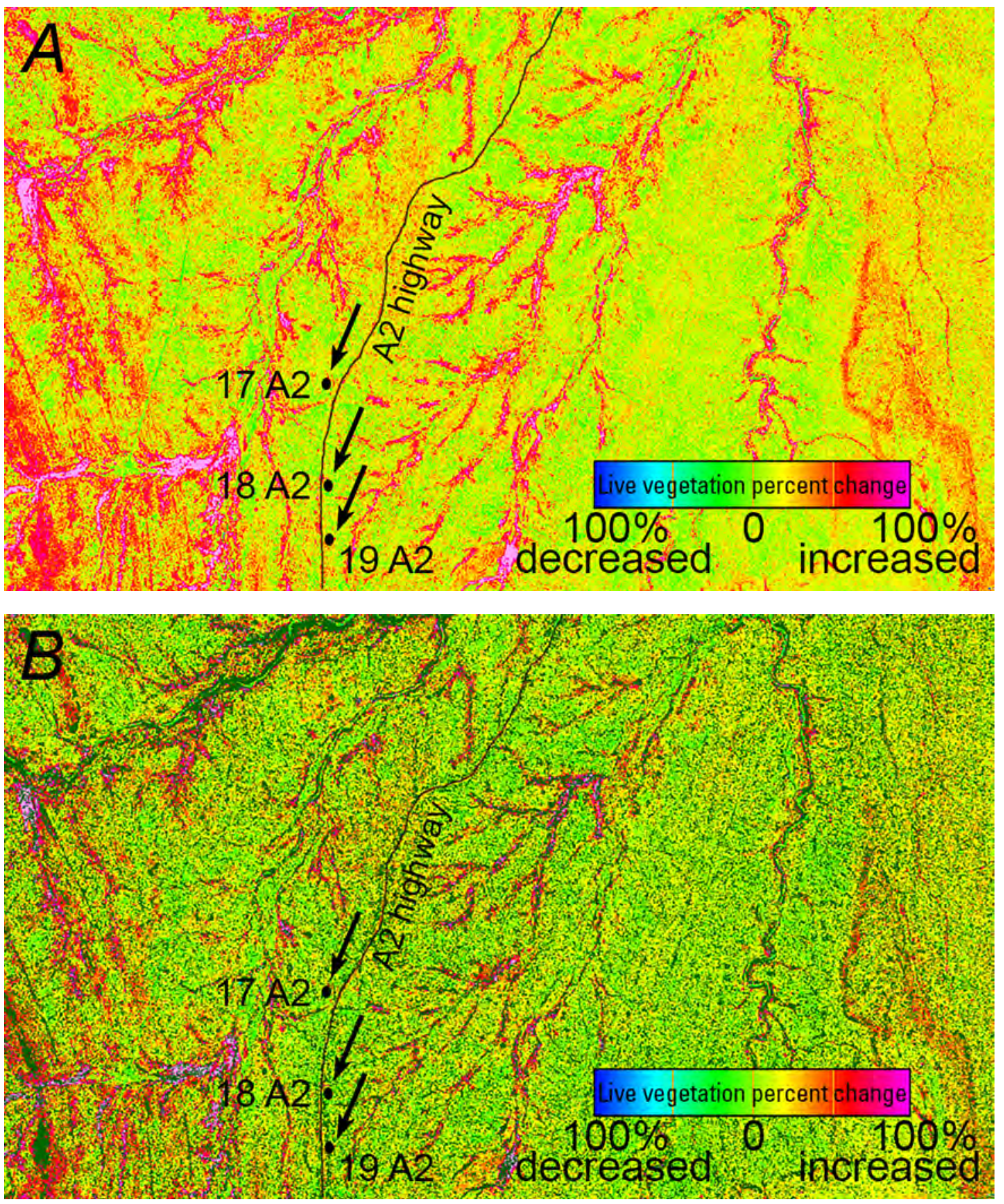

Figure 37. Namunyak Conservancy. Live vegetation cover proportion change and September 2017 tree mask overlay [approximate frame center $37 \mathrm{~d} 35^{\prime} 23.8878^{\prime \prime} \mathrm{E}, 1 \mathrm{~d} 04^{\prime} 45.3749^{\prime \prime} \mathrm{N}$, approximately $10.3 \mathrm{~km} \mathrm{~N}-\mathrm{S}$ and $17.9 \mathrm{~km} \mathrm{E-W]}$. Change in live cover between $A$ and $B$, September 2017 and June 2018; $C$ and $D$, June 2017 and September 2017; and $E$ and $F$, June 2017 and June 2018. Reference arrows point to observation sites 17-19 located along the A2 highway. 

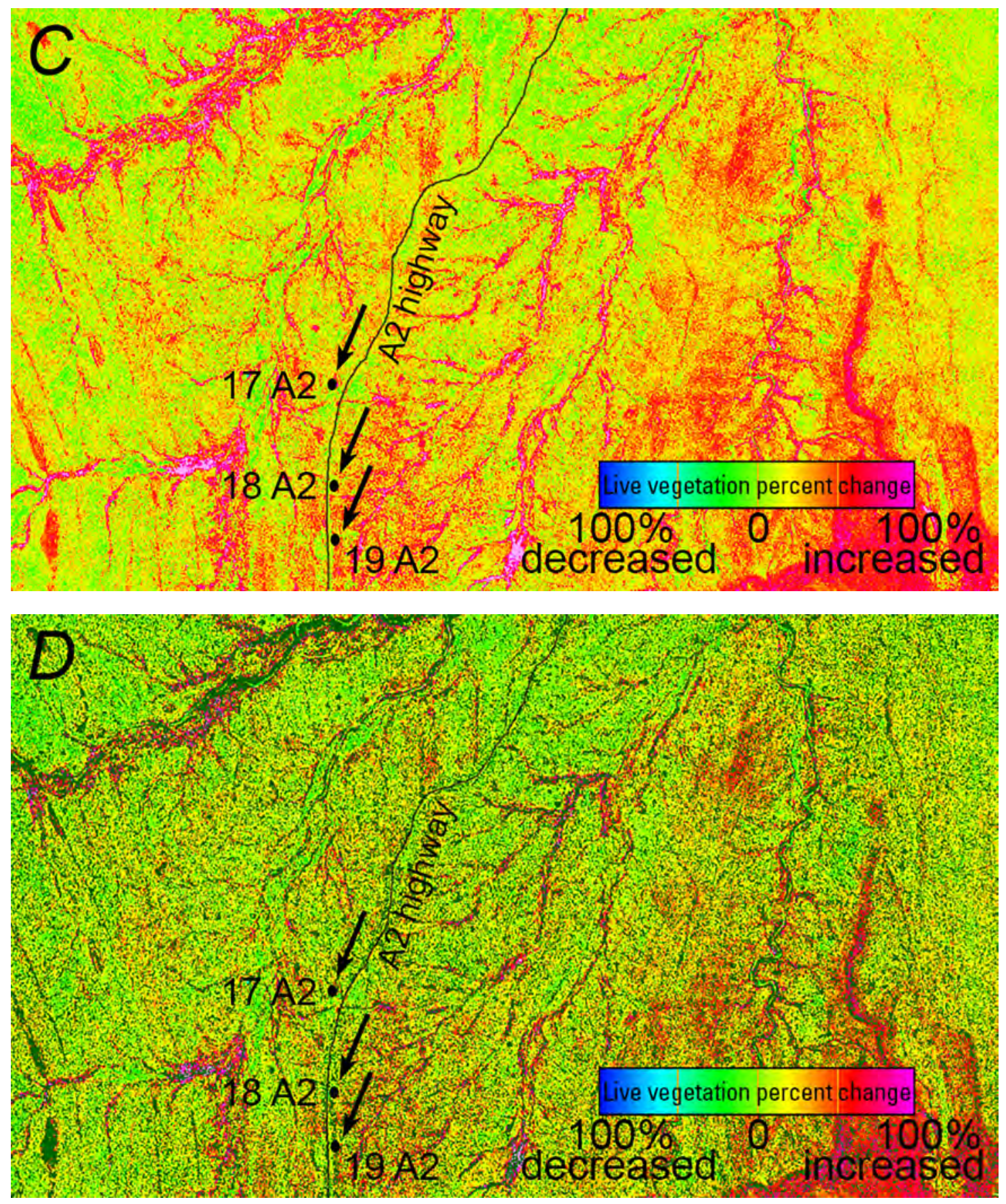

Figure 37. Namunyak Conservancy. Live vegetation cover proportion change and September 2017 tree mask overlay [approximate frame center $37 \mathrm{~d} 35^{\prime} 23.8878^{\prime \prime} \mathrm{E}, 1 \mathrm{~d} 04^{\prime} 45.3749^{\prime \prime} \mathrm{N}$, approximately $10.3 \mathrm{~km} \mathrm{~N}-\mathrm{S}$ and $17.9 \mathrm{~km} \mathrm{E-W].} \mathrm{Change} \mathrm{in} \mathrm{live} \mathrm{cover} \mathrm{between} A$ and $B$, September 2017 and June 2018; $C$ and $D$, June 2017 and September 2017; and $E$ and $F$, June 2017 and June 2018. Reference arrows point to observation sites 17-19 located along the A2 highway.-Continued 

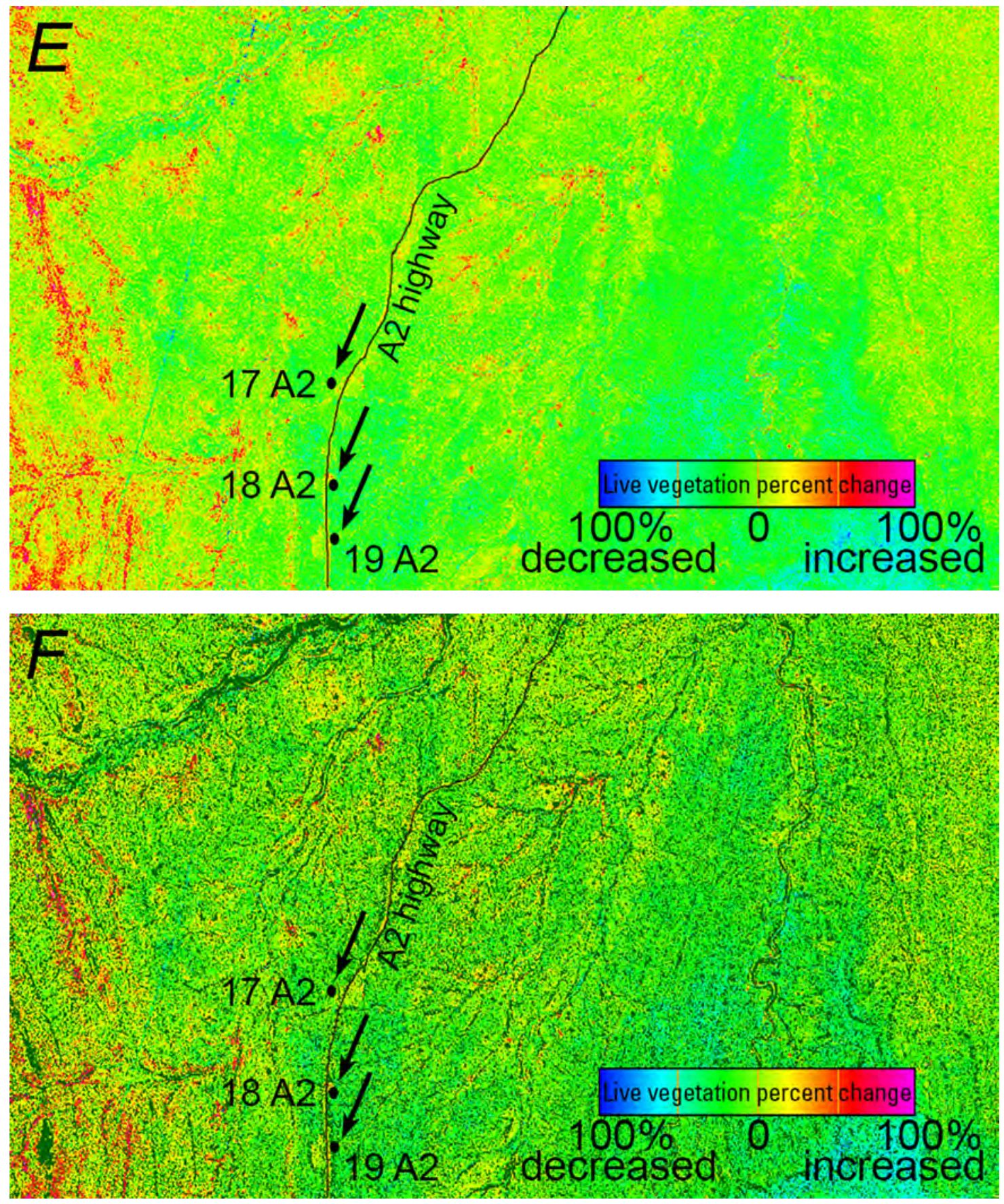

Figure 37. Namunyak Conservancy. Live vegetation cover proportion change and September 2017 tree mask overlay [approximate frame center $37 \mathrm{~d} 35^{\prime} 23.8878^{\prime \prime} \mathrm{E}, 1 \mathrm{~d} 04^{\prime} 45.3749^{\prime \prime} \mathrm{N}$, approximately $10.3 \mathrm{~km} \mathrm{~N}-\mathrm{S}$ and $17.9 \mathrm{~km} \mathrm{E-W]}$. Change in live cover between $A$ and $B$, September 2017 and June 2018; $C$ and $D$, June 2017 and September 2017; and $E$ and $F$, June 2017 and June 2018. Reference arrows point to observation sites 17-19 located along the A2 highway.-Continued 

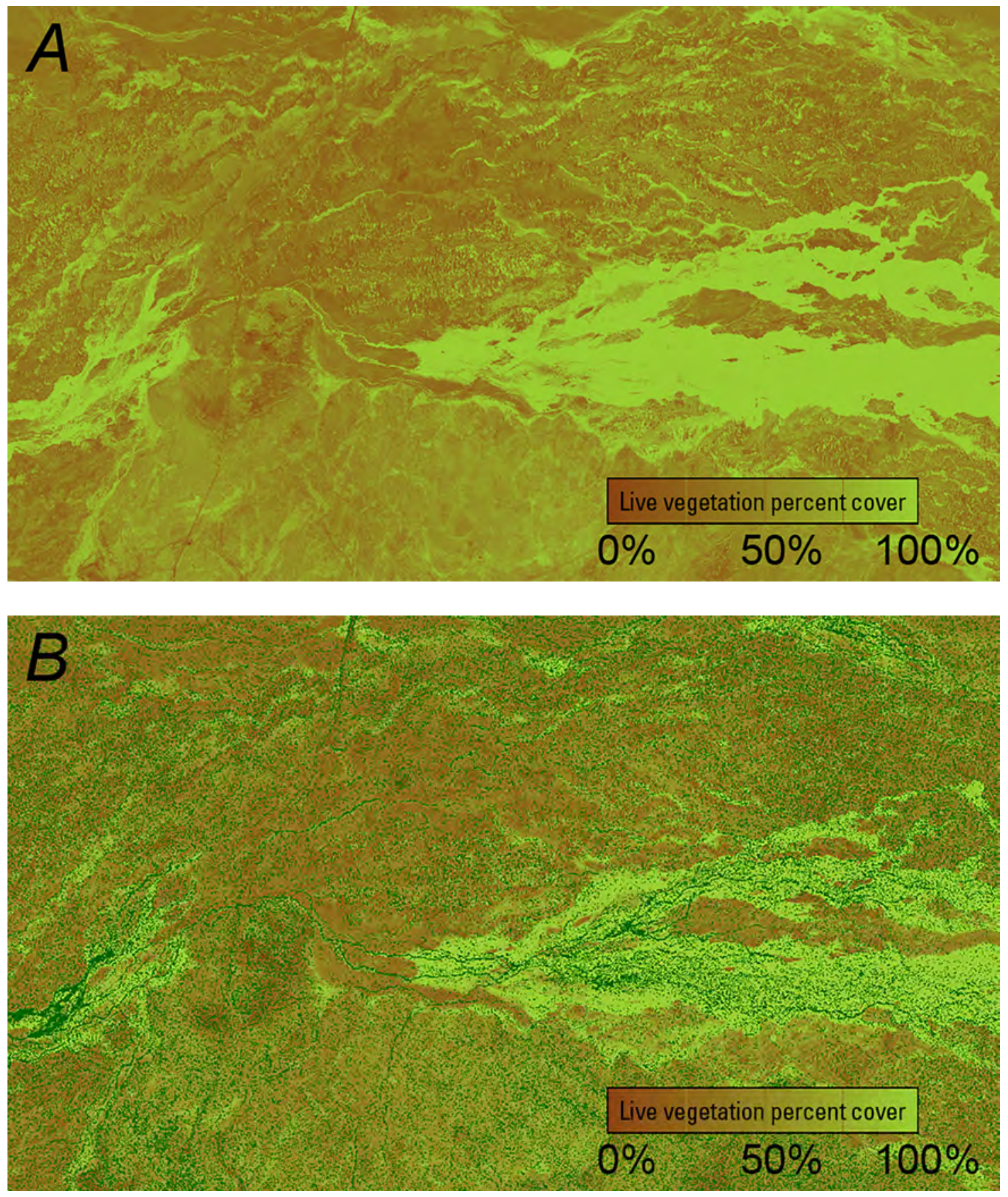

Figure 38. Melako Conservancy. Live vegetation cover proportion and September 2017 tree mask overlay [approximate frame center 37d56'56.8786"E, 1d50'23.2893"N, approximately $23.7 \mathrm{~km} \mathrm{~N}-\mathrm{S}$ and $41.2 \mathrm{~km} \mathrm{E-W].}$ $A$ and $B$, June 2018; $C$ and $D$, September 2017; and $E$ and $F$, June 2017. 

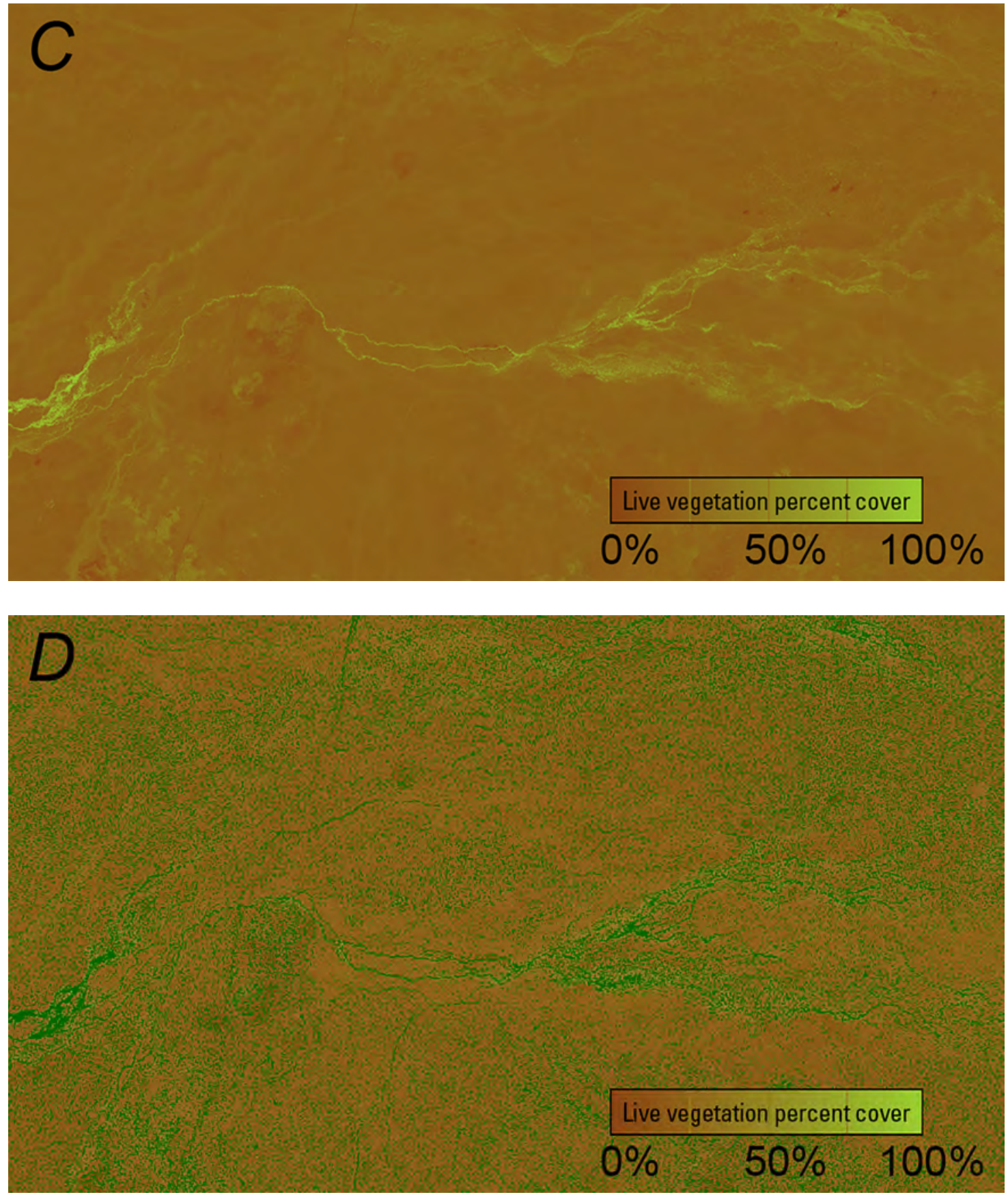

Figure 38. Melako Conservancy. Live vegetation cover proportion and September 2017 tree mask overlay [approximate frame center $37 \mathrm{~d} 56^{\prime} 56.8786^{\prime \prime} \mathrm{E}, 1 \mathrm{~d} 50^{\prime} 23.2893^{\prime \prime} \mathrm{N}$, approximately $23.7 \mathrm{~km} \mathrm{~N}-\mathrm{S}$ and $41.2 \mathrm{~km} \mathrm{E-W]}$. $A$ and $B$, June 2018; $C$ and $D$, September 2017; and $E$ and $F$, June 2017.-Continued 

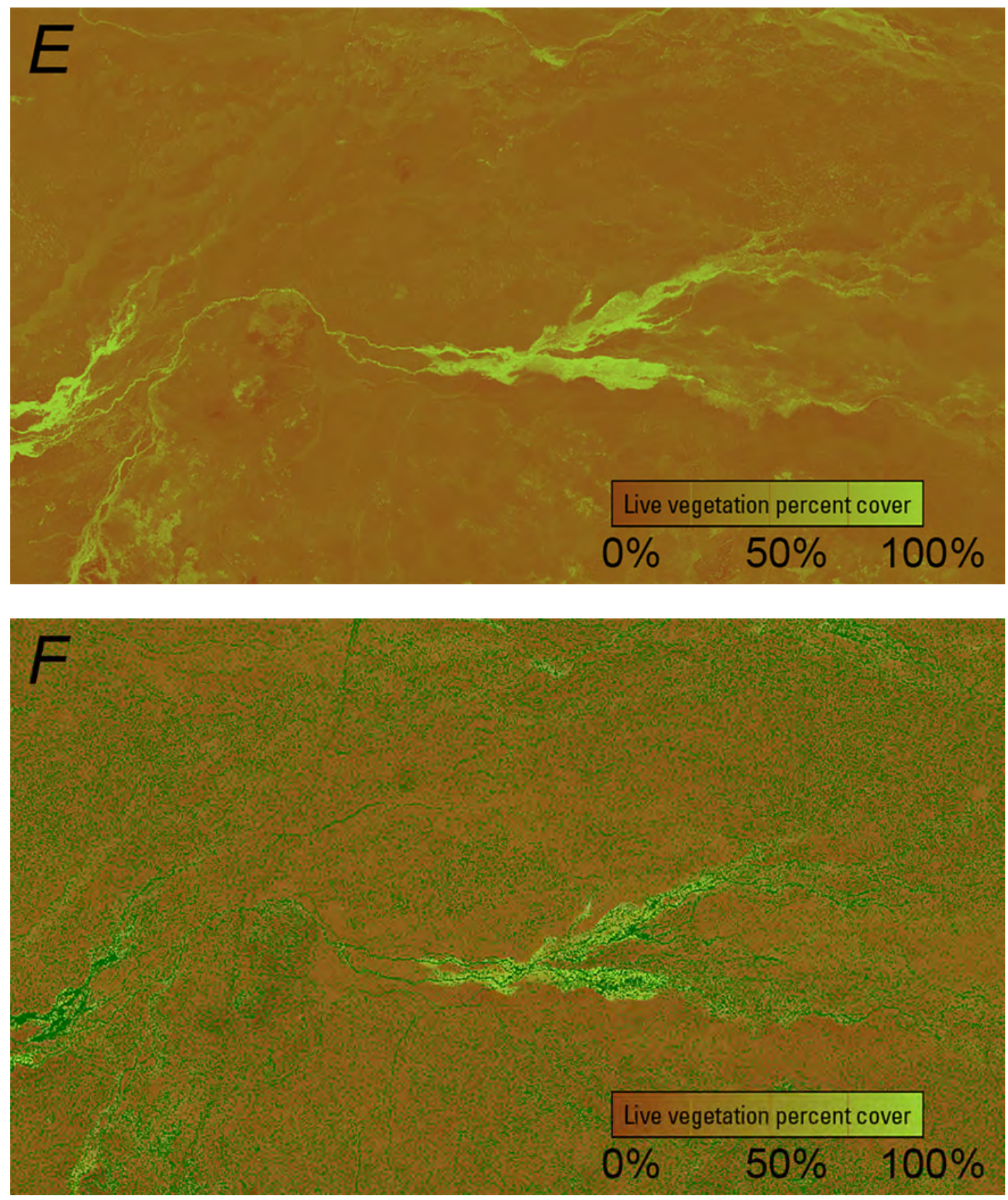

Figure 38. Melako Conservancy. Live vegetation cover proportion and September 2017 tree mask overlay [approximate frame center 37d56'56.8786"E, $1 \mathrm{~d} 50^{\prime} 23.2893^{\prime \prime} \mathrm{N}$, approximately $23.7 \mathrm{~km} \mathrm{~N}-\mathrm{S}$ and $41.2 \mathrm{~km} \mathrm{E-W]}$. $A$ and $B$, June 2018; $C$ and $D$, September 2017; and $E$ and $F$, June 2017.-Continued 

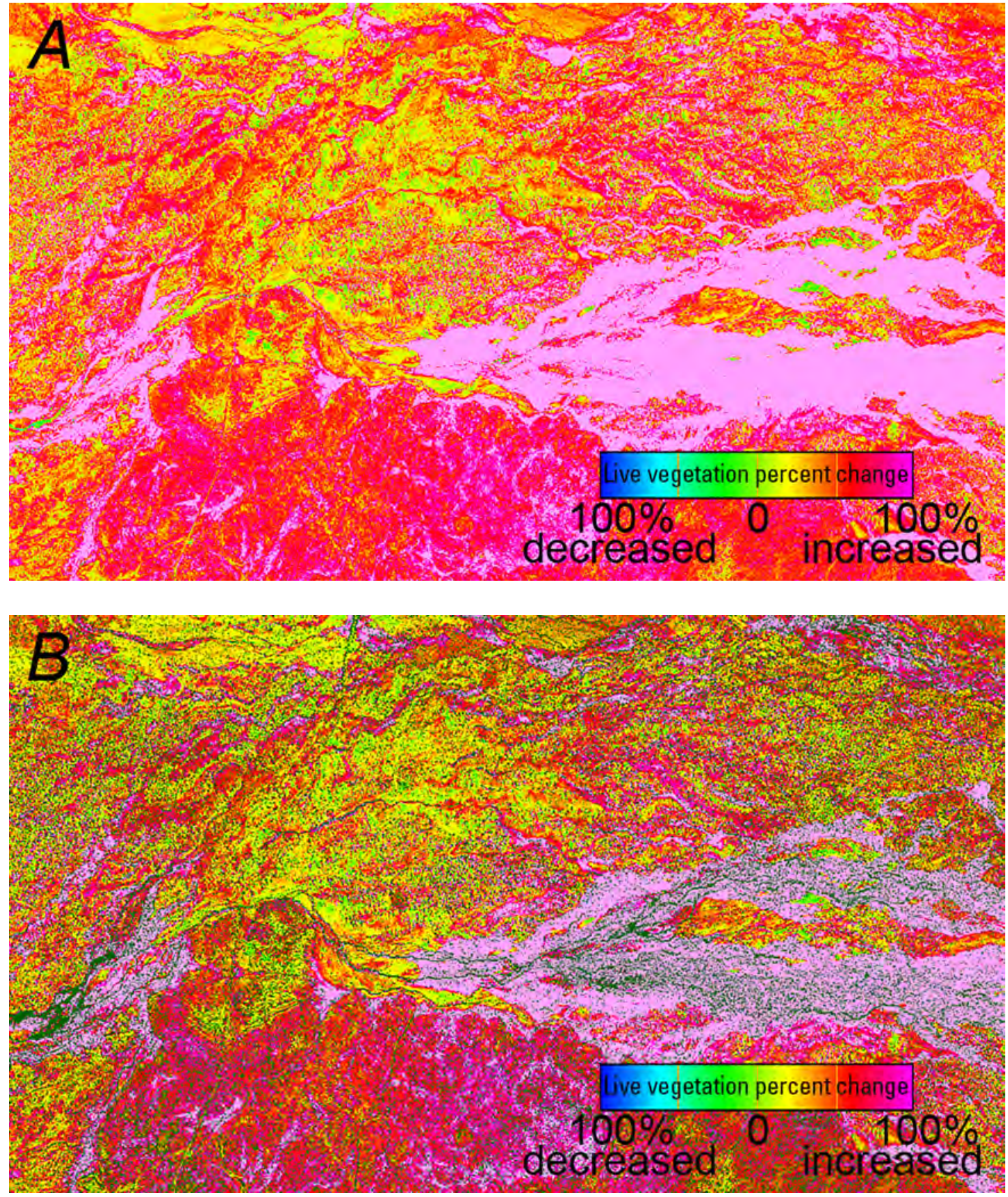

Figure 39. Melako Conservancy. Live vegetation cover proportion change and September 2017 tree overlay [approximate frame center $37 \mathrm{~d} 56^{\prime} 56.8786^{\prime \prime} \mathrm{E}, 1 \mathrm{~d} 50^{\prime} 23.2893^{\prime \prime} \mathrm{N}$, approximately $41.2 \mathrm{~km} \mathrm{~N}-\mathrm{S}$ and $23.7 \mathrm{~km} \mathrm{E-W]}$. Change in live cover between $A$ and $B$, September 2017 and June 2018; $C$ and $D$, June 2017 and September 2017; and $E$ and $F$, June 2017 and June 2018. 

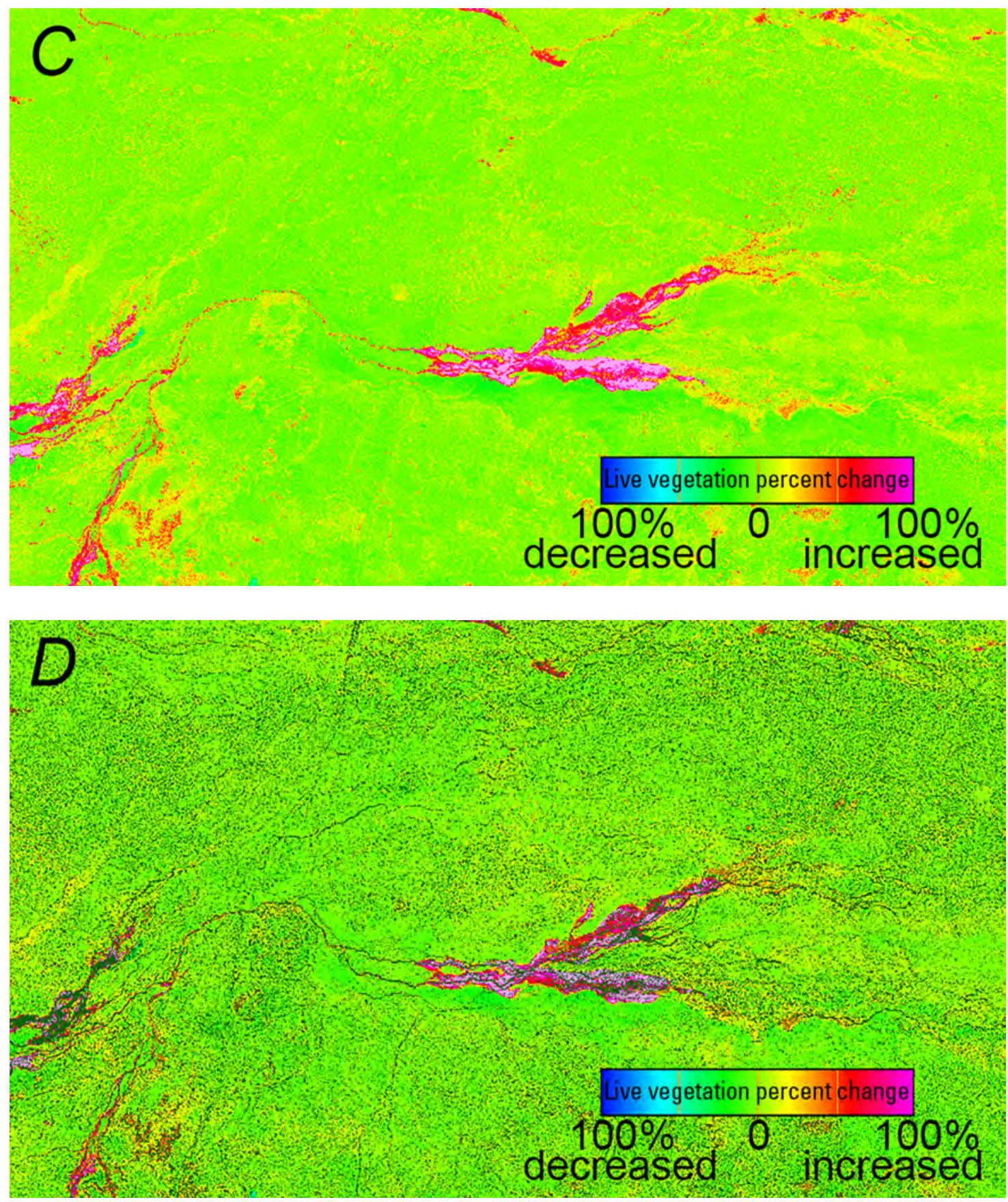

Figure 39. Melako Conservancy. Live vegetation cover proportion change and September 2017 tree overlay [approximate frame center $37 \mathrm{~d} 56^{\prime} 56.87866^{\prime \prime} \mathrm{E}, 1 \mathrm{~d} 50^{\prime} 23.2893^{\prime \prime} \mathrm{N}$, approximately $41.2 \mathrm{~km} \mathrm{~N}-\mathrm{S}$ and $23.7 \mathrm{~km} \mathrm{E-W]}$. Change in live cover between $A$ and $B$, September 2017 and June 2018; $C$ and $D$, June 2017 and September 2017; and $E$ and $F$, June 2017 and June 2018.-Continued 

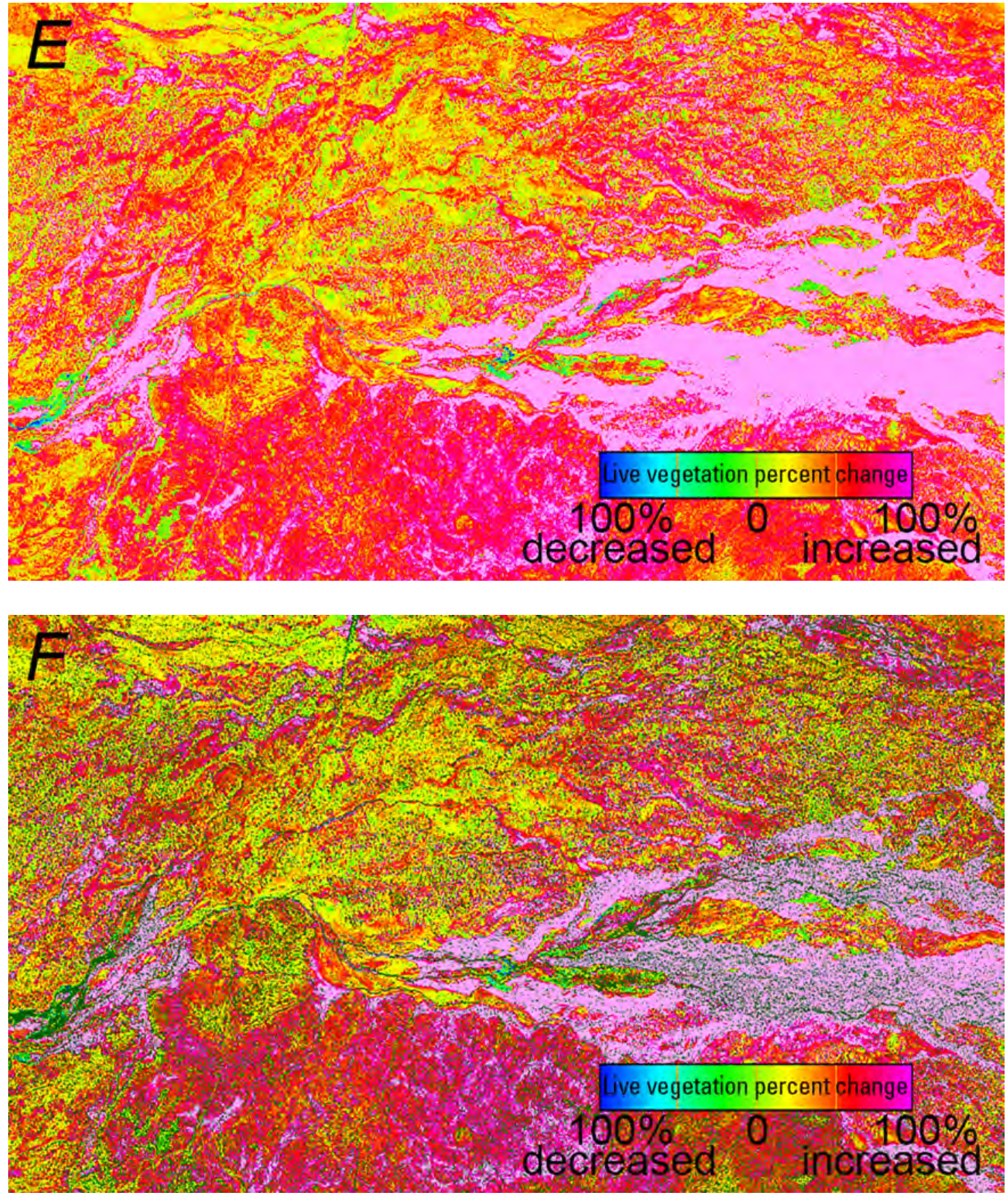

Figure 39. Melako Conservancy. Live vegetation cover proportion change and September 2017 tree overlay [approximate frame center $37 \mathrm{~d} 56^{\prime} 56.87866^{\prime \prime} \mathrm{E}, 1 \mathrm{~d} 50^{\prime} 23.2893^{\prime \prime} \mathrm{N}$, approximately $41.2 \mathrm{~km} \mathrm{~N}-\mathrm{S}$ and $23.7 \mathrm{~km} \mathrm{E}-\mathrm{W}$ ]. Change in live cover between $A$ and $B$, September 2017 and June 2018; $C$ and $D$, June 2017 and September 2017; and $E$ and $F$, June 2017 and June 2018.-Continued 


\section{Extending Live Vegetation Mapping into the Past SAR Vegetation Density Mapping}

Extension of the Sentinel-2 live vegetation cover proportion mapping into the past relies on the historical record of optical image data collected by the Landsat satellite system. To demonstrate the historical mapping capability, Landsat-8 images collected on 15 and 22 June 2018 were atmospherically corrected and mosaiced to create a single reflectance image covering the core-NRT. For direct comparability, the 15 and 22 June 2018 Landsat- 8 dates were chosen to be as close as possible to the field-calibrated Sentinel-2 June 2018 image mapping. For additional evidence, Landsat- 8 images collected on 19 and 28 June 2017 were also processed. The June 2017 Landsat images were chosen to be directly comparable to the June 2017 Sentinel-2 live vegetation classification.

The same calibration equations used for creating the Sentinel-2 live vegetation cover proportion maps were used to create the Landsat-8 live cover maps of the core-NRT. The same color scheme used to represent the Sentinel-2 live cover proportion was applied to the Landsat live cover maps. Although a critical component of the Sentinel-2 mapping, the tree mask based on the Sentinel-2 September 2017 image could not be overlain on the spatially coarser $30-\mathrm{m}$ resolution Landsat map. In addition, because of the 30-m spatial resolution, the tree mask was not derivable from the Landsat image data. The capability to extend the calibrated Sentinel mapping into the past with Landsat data is based on visual comparison of the June 2017 (fig. 40A) and June 2018 (fig. 40B) live cover maps produced with Landsat image data.

The Landsat live vegetation cover proportion mapping is less detailed, and changes are more subdued in comparison to the Sentinel-2 maps (figs. 15 and 17). The inability to recreate finer features and include a tree mask restricts the use of Landsat for timely and effective proactive management. However, the 2017 and 2018 Landsat mapping visually recreated the high to low ranges as well as the pattern of change exhibited in the 2017 and 2018 Sentinel-2 maps. The Landsat and Sentinel-2 live cover maps exhibited good overall visual correlation. That level of reproduction supports the use of Landsat to provide NRT the historical recreation of prominent live cover changes. However, Sentinel-2 and Landsat-8 mapping performance should be quantitatively compared before undertaking a historical recreation of live vegetation changes throughout the core-NRT.
Sentinel-1 SAR scenes covering the core-NRT were collected between 21 and 26 June 2018 close to the time of the June 2018 field data collections. Each downloaded SAR scene contained two images: one with a vertical send and vertical receive $(\mathrm{VV})$ polarization and another with a vertical send and horizontal receive $(\mathrm{VH})$ polarization. Each SAR image was processed to produce a sigma-naught calibrated and ground projected georeferenced image. The four calibrated and georeferenced images were then mosaiced to provide a continuous SAR cover of the core-NRT. The SAR-mosaiced coverage comprised the VV image coverage and the VH image coverage. The $\mathrm{VH}$ polarization image is relatively more sensitive to vegetation, and the $\mathrm{VV}$ polarization image is more sensitive to the surface roughness and changes in relief (fig. 41).

Site LAIs were obtained from light recordings as described in the Sentinel-1 SAR Image Data Calibration section of this report (Ramsey and others, 2015) (see fig. 6). With the LAI, a measure of vegetation density is added to the Sentinel-2 (and Landsat) live vegetation cover proportion mapping. SAR calibration to LAI mapping was done by using the same methods used in the Sentinel-2 optical data calibration (see the Sentinel-2 Optical Image Data Calibration section of this report). VV and VH data were extracted from the coreNRT mosaics by using the central GPS coordinates obtained at each field site. Regression analysis determined the strength of the relations between the VV and VH SAR data and the field LAI data.

The best calibration equation found by the regression analysis is shown in figure 42. Thirteen of the 18 field and SAR image data points had a very high correlation as expressed by the $0.93 \mathrm{R}^{2}$ regression confidence; however, 5 points plotted far outside the regression line (fig. 42). The reason for the five outliers is not apparent from examination of the field and image data. The excellent alignment of the majority of site values provides assurance that a workable SAR-LAI calibration equation can be developed with additional collections of field and SAR data. 

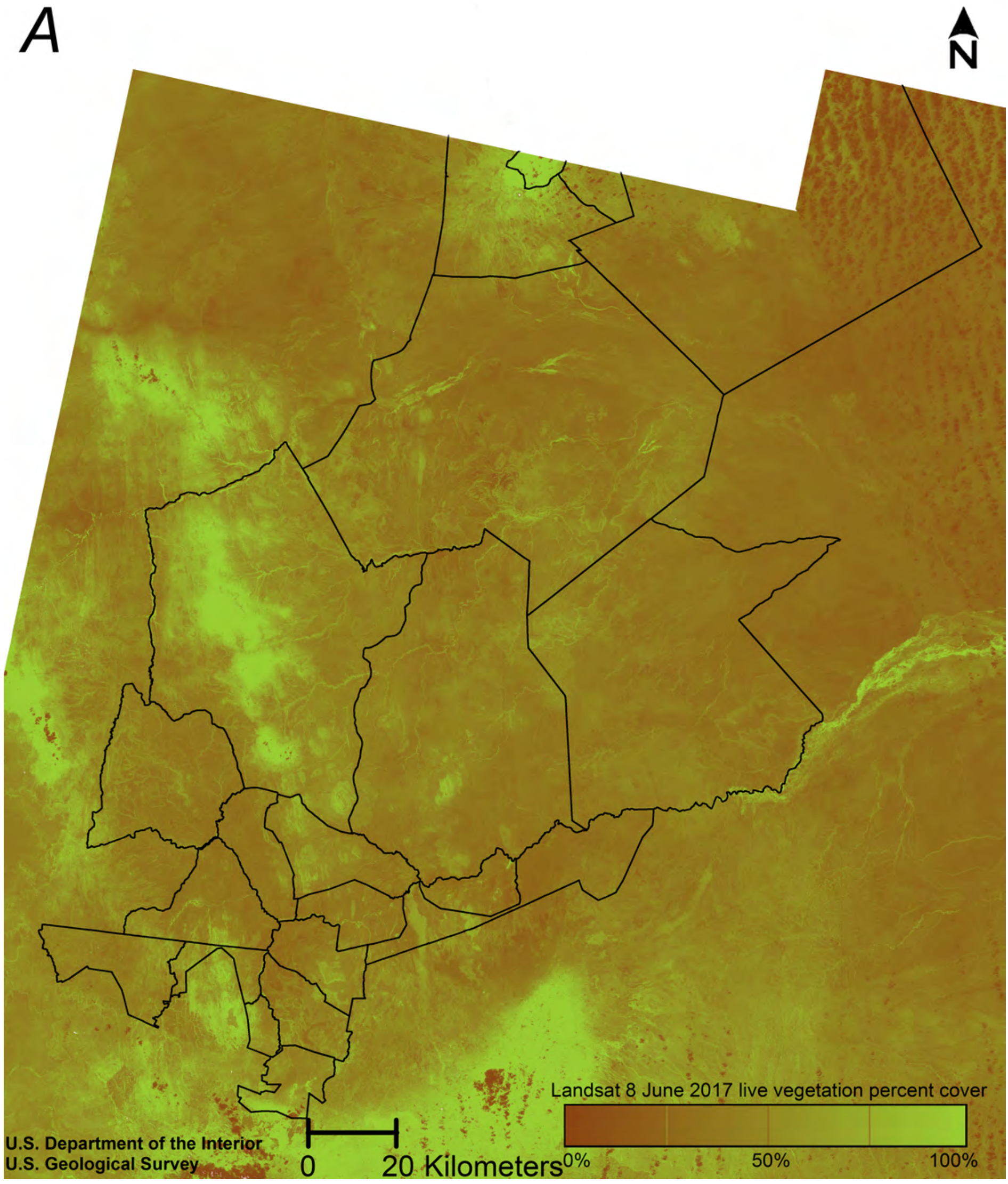

Figure 40. Live vegetation cover proportion for the core-Kenyan Northern Rangelands Trust conservancies in $(A)$ June 2017 and $(B)$ June 2018. The Landsat-8 live cover maps can be compared with the Sentinel-2 live cover maps shown in figures 15 and 17. Cloud contamination apparent in the NE. High resolution files available from https://doi.org/10.3133/ofr20191037. 


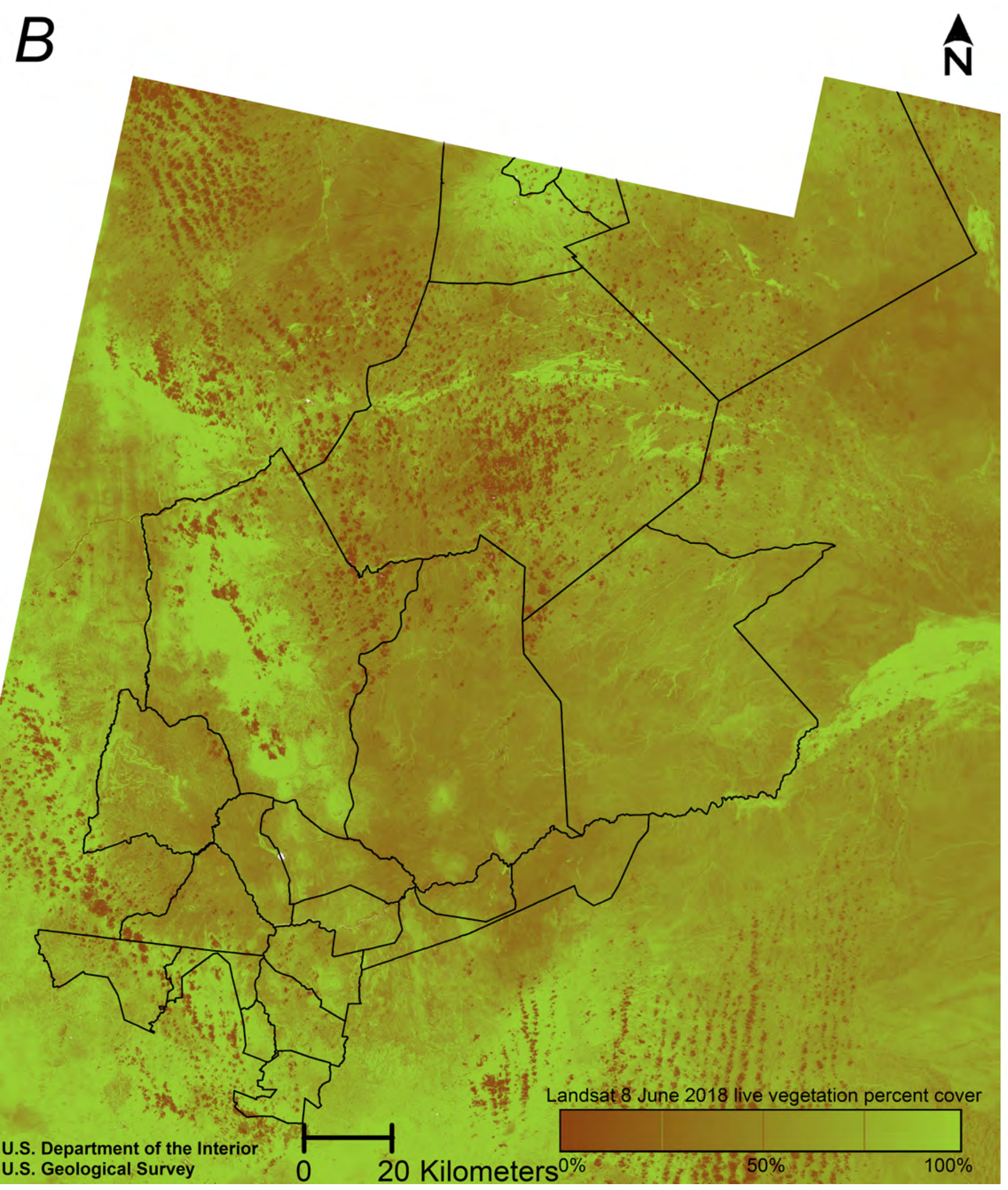

Figure 40. Live vegetation cover proportion for the core-Kenyan Northern Rangelands Trust conservancies in $(A)$ June 2017 and $(B)$ June 2018. The Landsat-8 live cover maps can be compared with the Sentinel-2 live cover maps shown in figures 15 and 17 . Cloud contamination apparent in the NE. High resolution files available from https://doi.org/10.3133/ofr20191037._Continued 


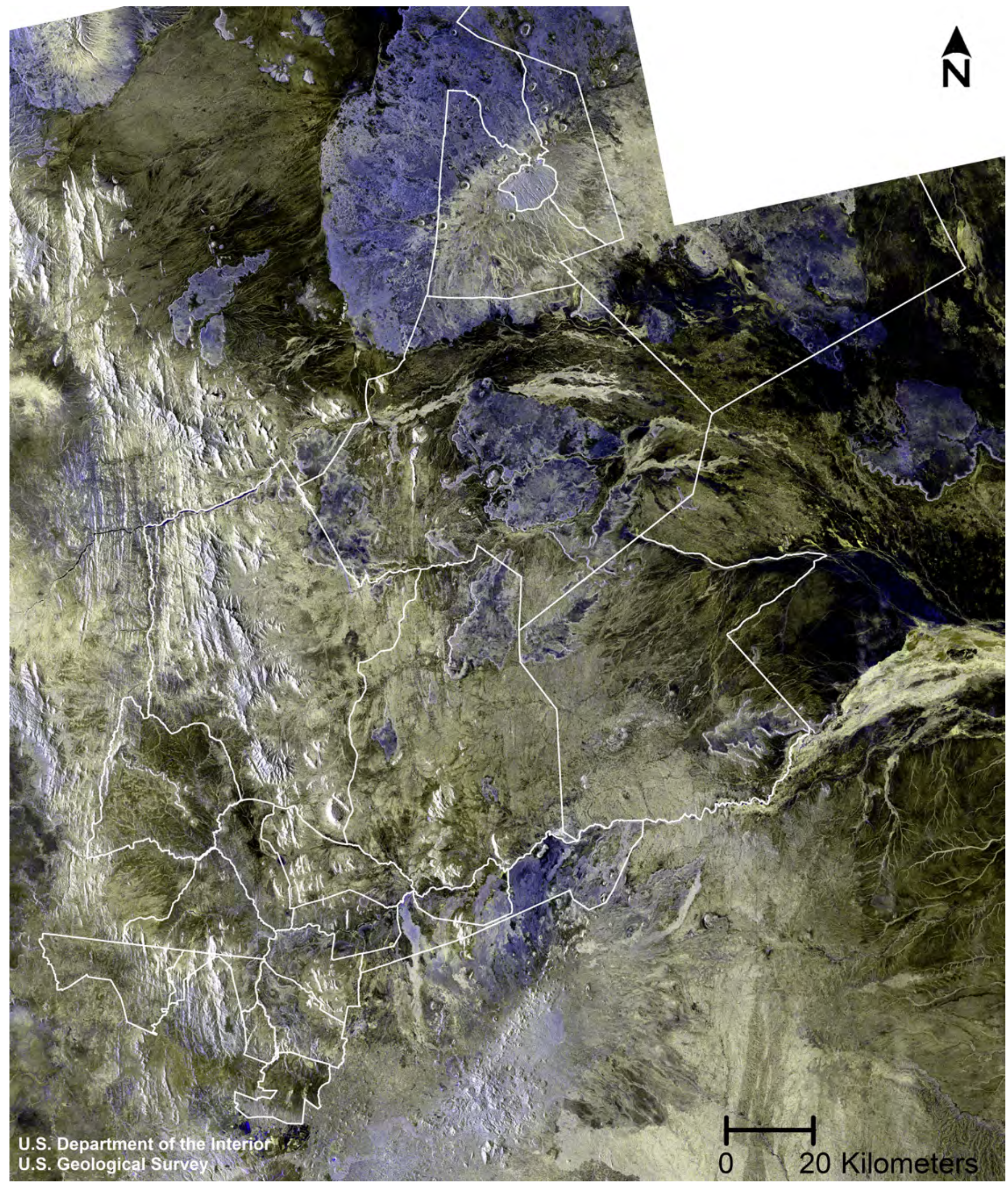

Figure 41. June 2018 synthetic aperture radar (SAR) vertical send and vertical receive (VV) and vertical send and horizontal receive (VH) images. The SAR VH is shown in the red and green color bands and the SAR VV in the blue color band. In general, the green-yellow tint emphasizes areas with vegetation while the blue tends to emphasize areas with little to no vegetation. Changes in the green-yellow from lighter to darker tones suggest changes in vegetation type and density. High resolution files available from https://doi.org/10.3133/ofr20191037. 


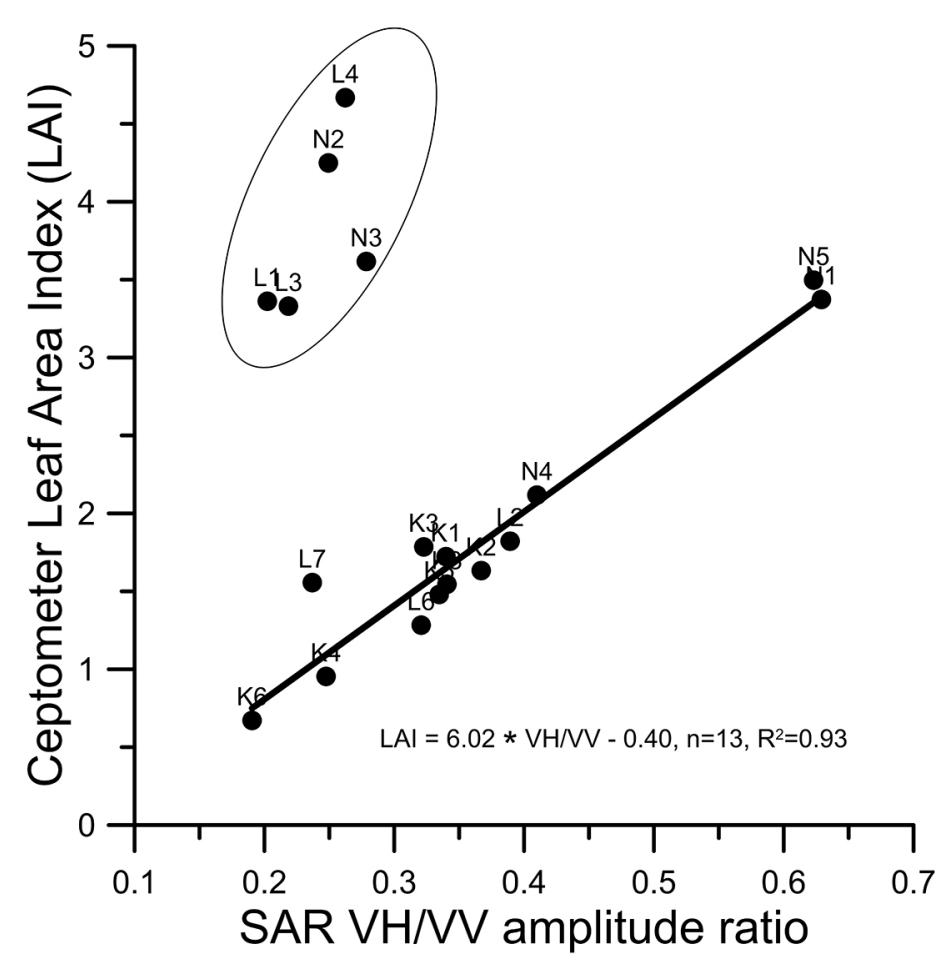

Figure 42. Field leaf area index (LAI) data and Sentinel-1 synthetic aperture radar (SAR) image data. Thirteen of the 18 points are closely aligned. Although the presence of five outliers (within the oval outline) prevents the calibration of the SAR image to the LAI density representation, the close alignment of most site values indicates that a workable calibration equation could be determined with the collection of additional field and SAR image data.

\section{Summary}

The U.S. Geological Survey, in collaboration with the U.S. Department of the Interior Technical Assistance Program and the U.S. Agency for International Development, successfully created a satellite-based live vegetation monitoring system for the Kenyan Northern Rangelands Trust (NRT) covering the core-NRT and surrounding areas. Driving the success of the mapping was the field data collection strategy that included new instrument technologies and remote sensing vegetation mapping indicators. The technologically advanced field instruments simultaneously captured a spatially coincident photographic snapshot and optical sensor measurement of the ground area. The photography was used to quantify the live vegetation cover proportion, whereas the optical sensor directly simulated the satellite optical data, albeit, of a single image pixel. The applied strategy directly converted Sentinel-2 satellite optical image data to a quantitative and highly accurate map of live vegetation cover proportion. Based on the near-coincident collection of field and satellite data in June 2018, the satellite live cover mapping has an 92-percent accuracy, a 10-meter (m) spatial resolution, and up to a 5-day repeat cycle.
The field-to-satellite live vegetation cover proportion calibration was extended to the Sentinel-2 images collected in June and September 2017. Together, the maps revealed expected differences between the live cover during the June 2017 drought and June 2018 wet periods and the September 2017 seasonally dry period. Although the overall low to high live cover levels per date were expected, there existed high spatial variability of live cover within each date and live cover differences between dates within the core-NRT. The coreNRT landscape is highly varied, and the live cover status and change maps reflected that high spatial variability with high confidence.

The sensitivity of the Sentinel-2 live vegetation cover proportion mapping allowed the creation of a September 2017 tree mask covering the core-NRT. Even though not a complete one-to-one depiction of all occurrences, patterns and densities were overall well depicted in the tree classification. Addition of tree occurrences not only reduces possible misinterpretation of live cover proportions as solely associated with the dominant grazing forage, but it also enhances the live cover information content. Improvements in the one-to-one tree mapping should be pursued over time; however, the tree mask created within this project provides a substantial improvement in the contextual distribution and discernment of patterns in the live vegetation cover spatial distributions.

In addition to the successful development of live vegetation cover proportion mapping with Sentinel-2 satellite image data, the project successfully extended the capability to map live cover into the past. The mapping extension relies on the Landsat-8 historical archive. Although the Landsat 30-m spatial resolution does not provide the same mapping quality as the Sentinel-2 10-m spatial resolution, visual comparison indicated that Landsat can provide the NRT with data to quantify the long-term and more distinct changes in live vegetation. Detailed comparisons to better quantify the correlations should be conducted before creation of the historical time series.

Another addition to the Sentinel-2 optical mapping was the Sentinel-1 synthetic aperture radar (SAR) mapping of leaf area index (LAI) as an indicator of vegetation density. Field measures of sunlight attenuation by the grass canopy were converted to LAI. Calibration of the SAR image data to LAI indicated that a majority of the field density measures aligned closely with the SAR image data; however, there were outliers from that alignment. The results indicate that a working relation can be developed with additional field calibrations.

A critical objective of this study was to provide a framework conducive for transfer of all components of the mapping to NRT. To provide that framework, we based the mapping on free satellite image data that can be processed with free software downloaded to a personal workstation. The field equipment was chosen on the basis of affordability, and the equipment proprietary software is user friendly. The maps were produced in a format directly compatible with standard geographic information system software. 


\section{References Cited}

Guo, X., Zhang, C., Wilmshurst, J.F., and Sissons, R., 2005, Monitoring grassland health with remote sensing approaches, in Noble, B.F., Martz, D.J.F., and Aitken, A.E., eds., Prairie perspectives: Geographical essays: Saskatoon, Saskatchewan, Canada, University of Saskatchewan Department of Geography, p. 11-22.

Liu, Z-Y, Huang, J-F, Wu, X-H, and Dong, Y-P, 2007, Comparison of vegetation indices and red-edge parameters for estimating grassland cover from canopy reflectance data: Journal of Integrative Plant Biology, v. 49, no. 3 , p. 299-306.

Qi, J., Chehbouni, Huete, A.R., Kerr, Y.H., and Sorooshian, S., 1994, A modified soil adjusted vegetation index: Remote Sensing of Environment, v. 48, no. 2, p. 119-126.

Ramsey, E., III, Rangoonwala, A., Jones, C.E., and Bannister, T., 2015, Marsh canopy leaf area and orientation calculated for improved marsh structure mapping: Photogrammetric Engineering and Remote Sensing, v. 81, p. 807-816.

Ramsey, E., III, Spruce, J., Rangoonwala, A., Suzuoki, Y., Smoot, J., Gasser, J., and Bannister, T., 2011, Daily MODIS trends of hurricane-induced forest impact and early recovery: Photogrammetric Engineering and Remote Sensing, v. 77 , no. 11, p. $1133-1143$.

Rundquist, D., Gitelson, A., Leavitt, B., Zygiebaum, A., Perk, R., and Keydan, G., 2014, Elements of an integrated phenotyping system for monitoring crop status at canopy level: Agronomy, v. 4, no. 1, p. 108-123, accessed October 24, 2018, at https://doi.org/10.3390/agronomy4010108.

Tucker, C.J., 1979, Red and photographic infrared linear combinations for monitoring vegetation: Remote Sensing of Environment, v. 8, p. 127-150. 
For more information about this publication, contact

Director, Wetland and Aquatic Research Center

U.S. Geological Survey

700 Cajundome Blvd.

Lafayette, Louisiana 70506

For additional information, visit

https://www.usgs.gov/centers/wetland-and-aquatic-researchcenter-warc

Publishing support provided by

Lafayette Publishing Service Center 

